A thesis submitted to Victoria University of Wellington in partial fulfilment of the requirements for the degree of Master of Management Studies

\section{VICTORIA}

MANAGEMENT SCHOOL

\title{
SHAPING MORE SUSTAINABLE COMMUNITIES: A CASE STUDY IN URBAN WATER MANAGEMENT
}

By Robyn Moore

Victoria University of Wellington

New Zealand

May 2009 


\section{ABStRACT}

The motivation for this study was to consider how communities might take a more integrated and systematic approach to meeting the challenges of water management in New Zealand, and achieve more sustainable systems. The specific challenges facing a community pursuing sustainable urban water management objectives were examined and solutions sought and tested.

Urban water systems, in particular, are under increasing pressure to meet the expectations of communities, with water managers required to articulate sensible management initiatives that secure water supplies and protect water for its intended use, now and in the future. Despite policy and regulation intended to advance outcomes and integrate efforts within the complex area of urban water management, fragmented approaches persist, while a pattern of decline in the quality of New Zealand's water resources remains a cause for concern. Nearly half of urban rates collected in New Zealand apply to water and wastewater management. Thus, this study is concerned with understanding the critical constraints to achieving healthier, more sustainable urban water systems that are affordable for New Zealand communities. The thesis demonstrates the methodology by focusing on Kapiti, a settlement north of Wellington, which has been debating and responding to water quality and security issues for more than a decade.

Subsequent to a piloted investigation, a methodological framework was proposed, based on integrating three near complementary perspectives. The Theory of Constraints (TOC) was used with a Stakeholder Typology to identify system stakeholders, capturing and representing their perspectives with Intermediate Objective (IO), Current Reality Tree (CRT) and Prerequisite Trees (PRT), while Causal Loop Diagrams (CLDs) from Systems Dynamics were constructed with some participants to explore and circumvent potential negative outcomes. The combined framework provided a source of deep insights into the challenges, dilemmas, potential solutions and side effects facing resource managers and other stakeholders in an urban water system under pressure from population growth and climatic/topographical conditions. It is possible that the combined theoretical framework can be applied to other resource management cases.

The use of the Stakeholder Typology to complement TOC provided a tactical element not routinely evident in systems studies, valuing the experiential and historical perspectives of those who might otherwise be treated as being outside the system, their perspectives marginalised or ignored. The TOC framework offered a logic-based means to identify and invalidate a critical assumption that peak demand would reduce to a level predicted by system managers. Further, the TOC tools were used to focus on and agree the set of conditions necessary to deal with the demand constraint and meet the system goal agreed by the stakeholder participants.

KEY WORDS: Sustainable urban water systems, Theory of constraints, Urban water management, Stakeholder typology, Decision making, Case study 


\section{ACKNOWLEDGEMENTS}

Without the insights and wisdom of twenty special people, my participants, this thesis would be nothing. To everyone who has participated in this study, each one of you has been generous beyond expectation, in offering your time, knowledge, contacts and welcome advice. Thanks especially to Doug Avery; I am forever grateful for the time you and Kevin Loe gave to this project. I also would like to pay tribute to those KCDC Councillors who reviewed my analysis and initial findings - the feedback and advice you provided are greatly appreciated. Thanks to you all.

To my wonderfully supportive family and friends, I owe all of you more than I can repay - for listening patiently to my emerging ideas, and for just checking in, reminding me there is life during and after a thesis. Mum and Dad: extra special thanks for your life-long support and for your thoughtful and honest feedback on the various incarnations of my research proposal and abstract. Tessa and Samuel, my children, who appear unwaveringly proud of their student mother - and Julian, patient to a fault through these last few months of interrupted sleep and thrown together dinners: thank you, you guys are awesome!

Thanks are due to Dr Arun Elias and Associate Professor Bob Cavana, for a compelling introduction to stakeholder theory and feedback loops. Thanks also to Garoon Pongsart, fellow Masters (and now PhD) student, for your invaluable advice, particularly when I was piloting the questions. And Stan Abbott, Director of Roof Water Research at Massey University: I simply cannot find the words to express how grateful I am for your guidance...this thesis journey would not be the same without you.

And last, but of course not least, my two supervisors, Associate Dean Vicky Mabin and Associate Professor Lawrie Corbett; your feedback has been absolutely justified, every time. You steered me back to the right path more than once, helping me make sense of a massive topic, guiding me to disentangle logic and reason from a confusion of data.

To all of you affectionately, THANK YOU, I hope you enjoy the pages to follow. 


\section{TABle OF CONTENTS}

Abstract

Acknowledgements.

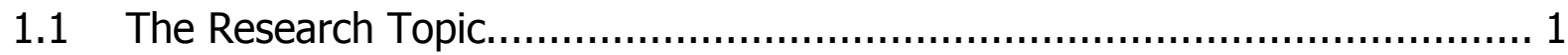

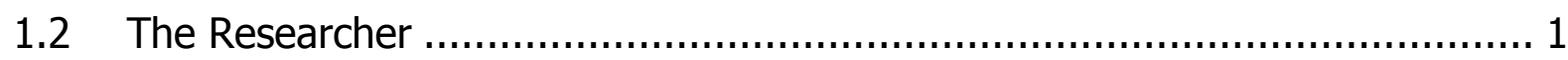

1.3 Definitions and Assumption.................................................................... 3

1.4 Thesis Purpose Statement ..................................................................... 4

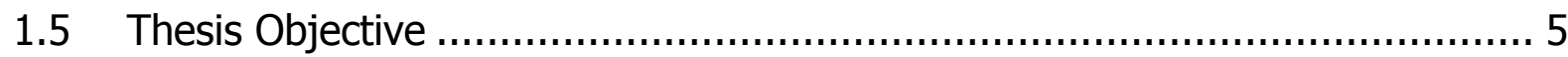

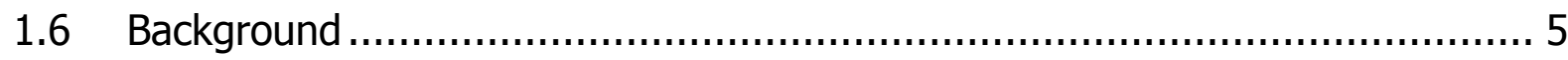

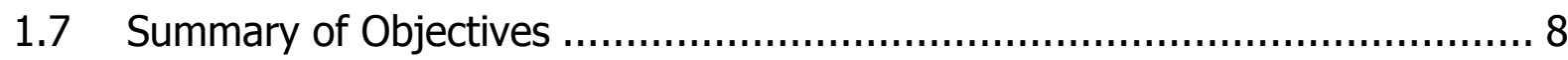

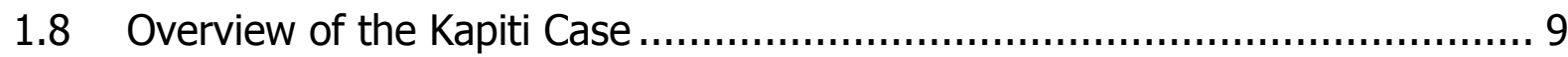

1.9 Definitions: Resilience and Flexibility in Systems ....................................14

1.10 Definition: Water Sensitive Urban Design (WSUD) ..................................16

1.11 Overview of the Starborough Flaxbourne Case .........................................17

1.12 Introducing The Theory of Constraints and the Research Rationale .............20

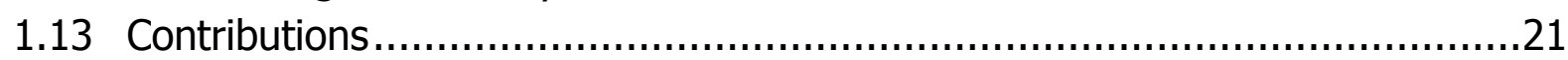

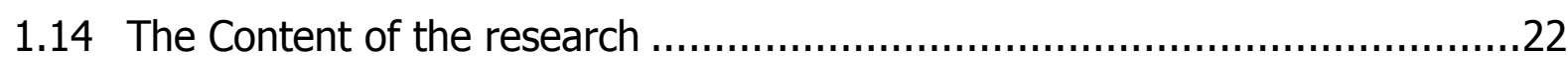

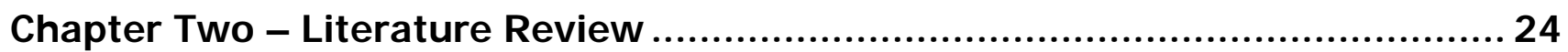

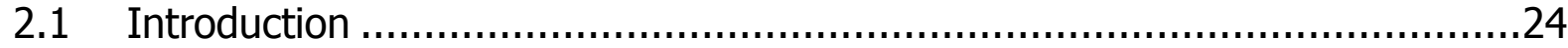

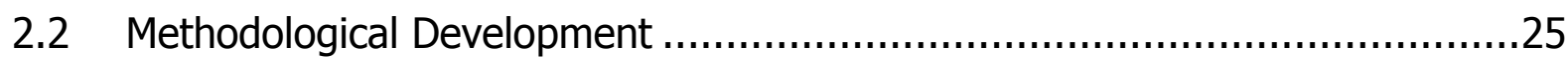

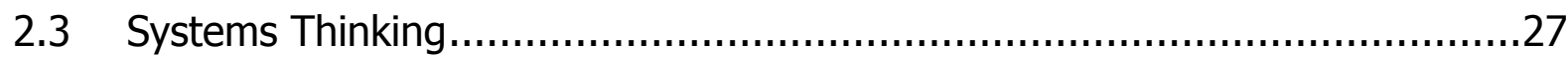

2.4 The Need for a Systems Framework for Decision-making ..........................28

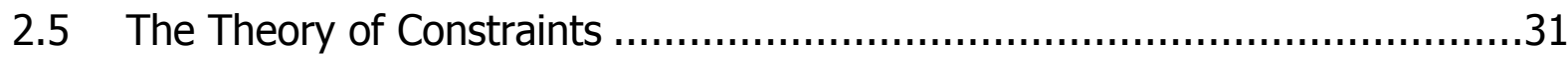

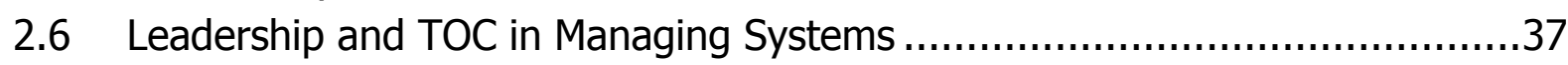

2.7 Identifying Stakeholders with a Stakeholder Typology ...............................38

2.8 The Case for Stakeholder Analysis - Summary ........................................45

2.9 The Case for Managing Systems with the Theory of Constraints - Summary .45

Chapter Three - Methodology

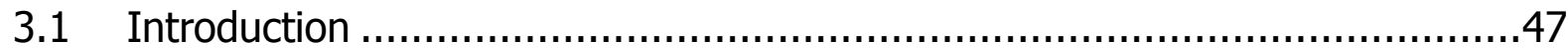

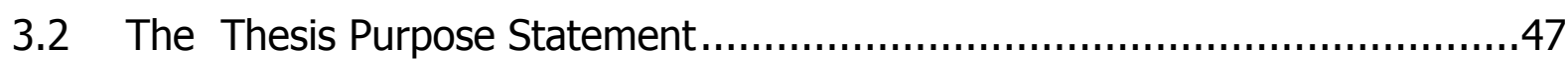

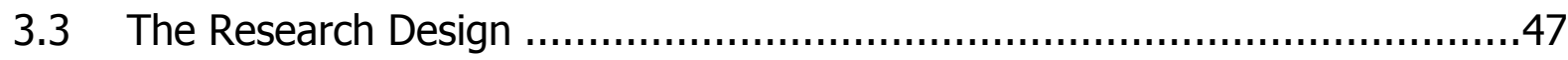

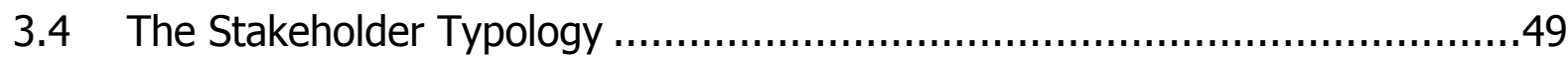

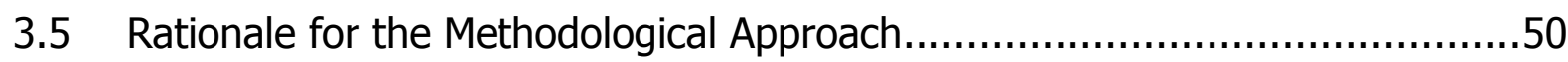

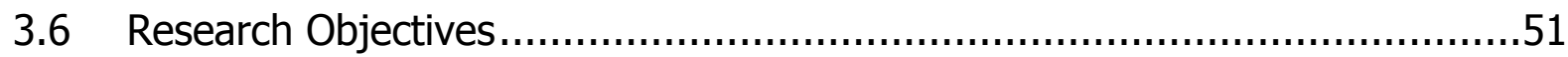

3.7 Description of the Sample Population of Volunteer Participants ...................51

3.8 Summary of the Information Required to Conduct the Study ......................52

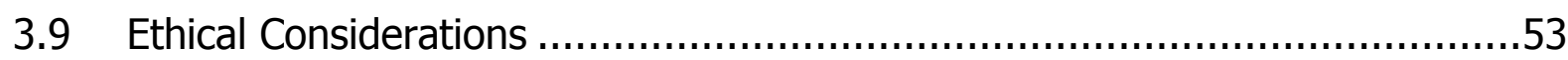

3.10 The Interview Procedure ................................................................54

3.11 Characteristics and Recruitment of the Participants.................................57 


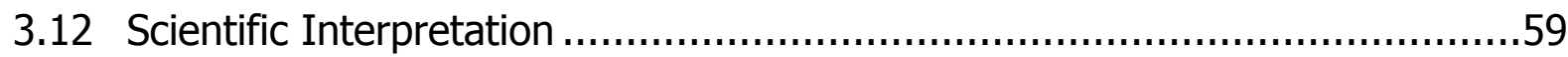

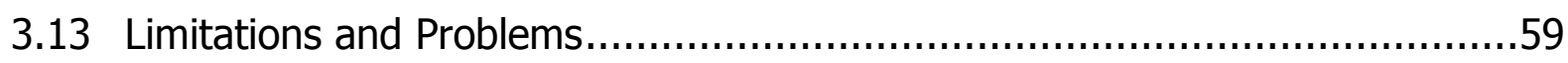

3.14 The Benefits and Scientific Value of the Project .......................................60

3.15 Who Might Apply The TOC Research Methodology? ..................................60

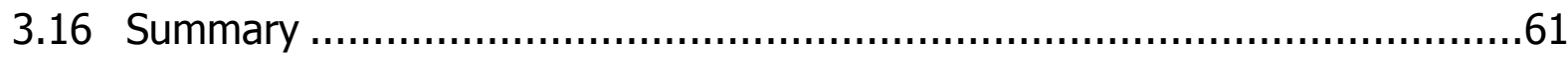

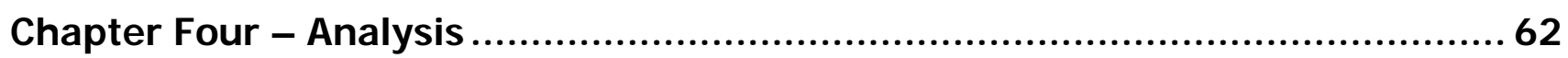

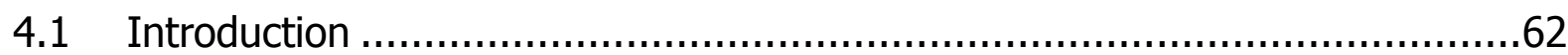

4.2 The Results of the Stakeholder Typology .............................................62

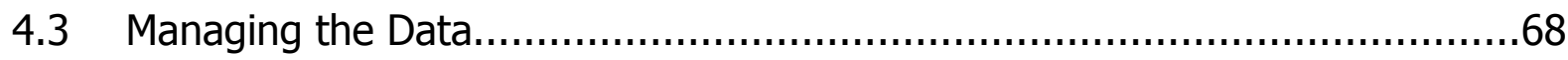

4.4 The Questions of Domestic Water Meters and Capacity ............................69

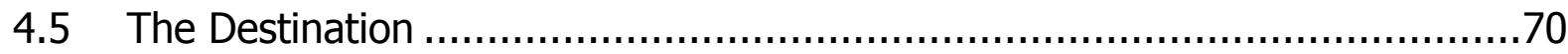

4.6 The Current Reality - What Really is Happening?.....................................76

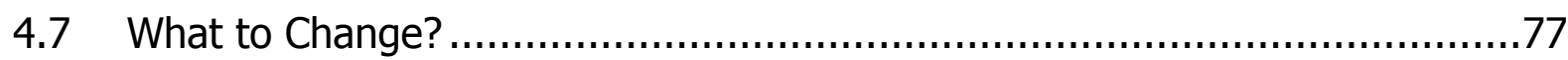

4.8 What to Change To? Presenting The Conflict Resolution Cloud (EC) .............78

4.9 The Conflict Resolution Cloud (EC) of the Kapiti Dilemma .........................79

4.10 Reaching the Destination ....................................................................96

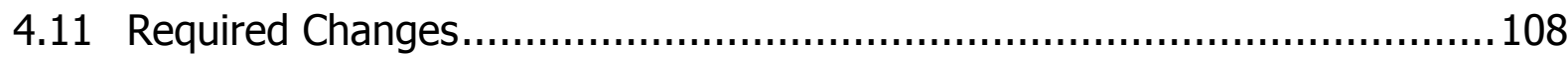

4.12 Testing the Proposed Changes ...............................................................108

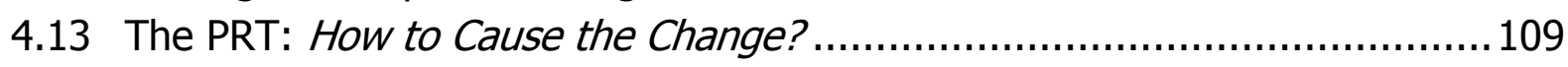

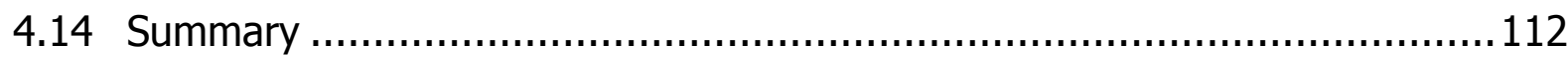

Chapter Five - Interpretation of Findings and Discussion............................. 113

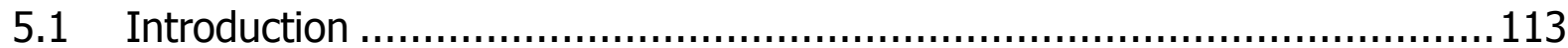

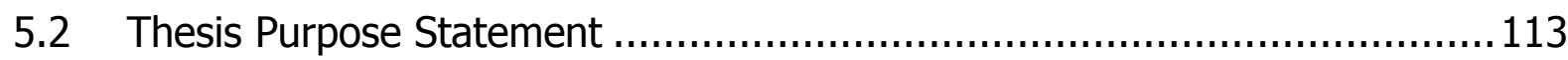

5.3 The Findings and their Significance ...................................................... 113

5.4 Using TOC to Identify the Core Constraint...............................................113

5.5 The Positive Aspects of Applying TOC ...................................................114

5.6 Revealing What to Change and What to Change To with the TOC Tools .....116

5.7 The Causal Loop Archetypes (Senge, 1994) ..........................................117

5.8 Stakeholder Typology........................................................................118

5.9 Increasing Stakeholder Awareness of the System and its Limits ................120

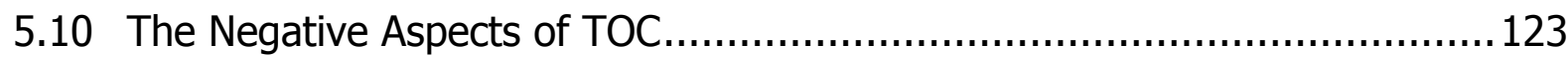

5.11 A Simple Plan ............................................................................ 123

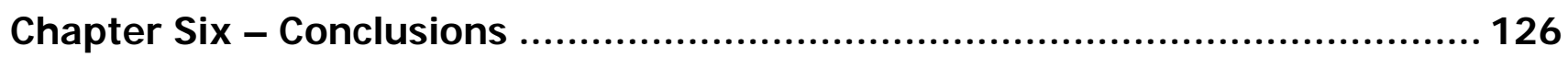

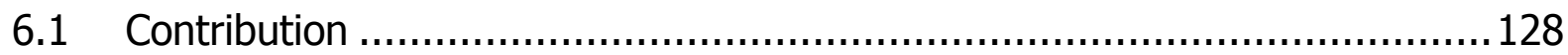

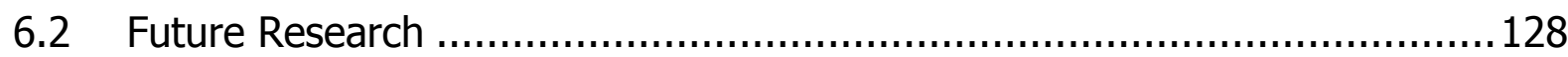

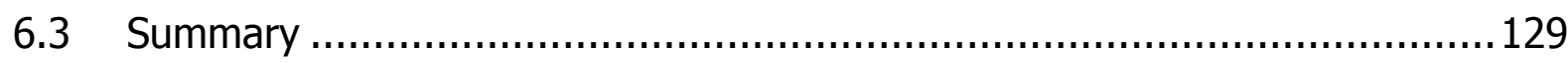

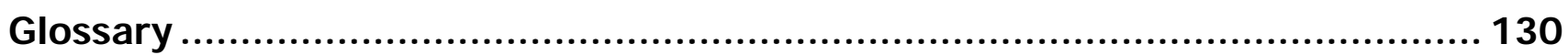

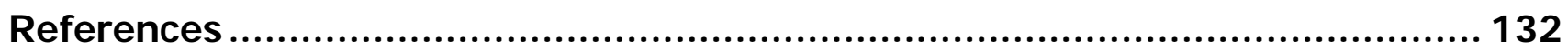

Reports - Commissioned by KCDC and Consulted for the Kapiti Case Study ... 141 


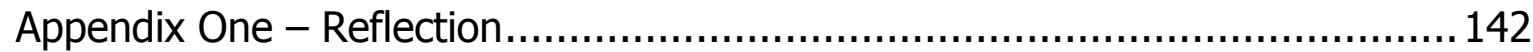

Appendix Two - Three waters strategy .................................................. 142

Appendix Three - Where does our water come from and where is it used?...... 142

Appendix Four - News article turbulence ahead on water take........................ 144

Appendix Five - Information on toxic algal bloom ......................................145

Appendix Six - Be the difference campaign ................................................146

Appendix Seven - Consent and information forms with indicative questions..... 147

Appendix Eight - Presenting the research summary to prospective participants

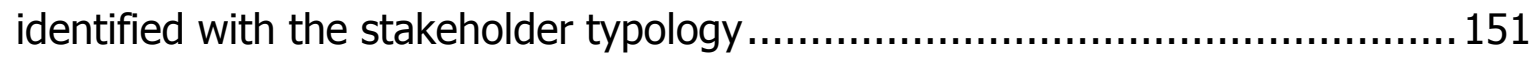

Appendix Nine - Presenting the Dilemma and the Conflict Resolution Diagram to

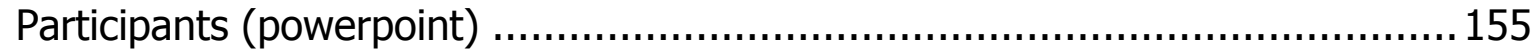

Appendix Ten - The Issues and a Recommendation ..................................156

Appendix Eleven - Presenting the Data.......................................................164

\section{LIST OF FIGURES}

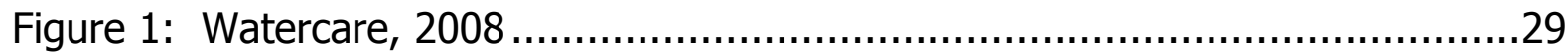

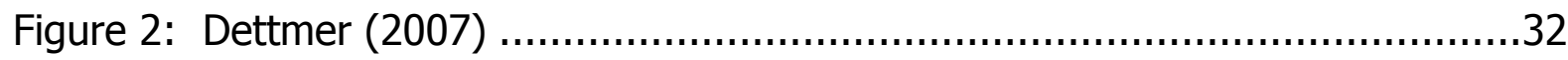

Figure 3: Stakeholder Linkage Model (Rawlins, 2006:4)..................................41

Figure 4: Stakeholder Map of the road pricing project (Elias et al., 2002:305) ......42

Figure 5: Stakeholder Typology (Mitchell et al., 1997).....................................43

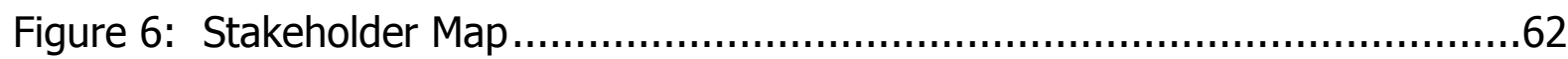

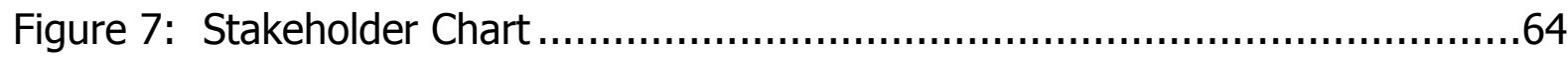

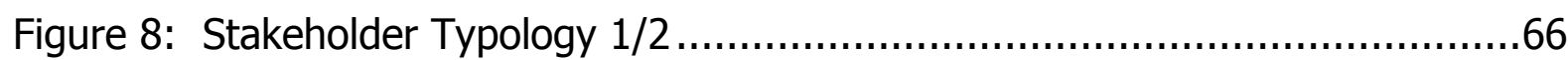

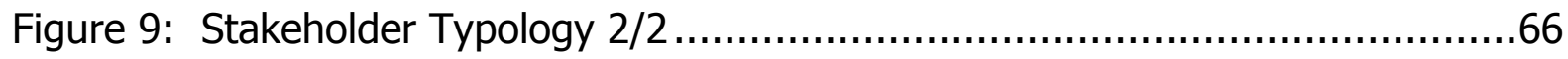

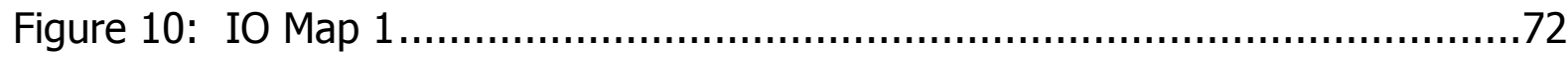

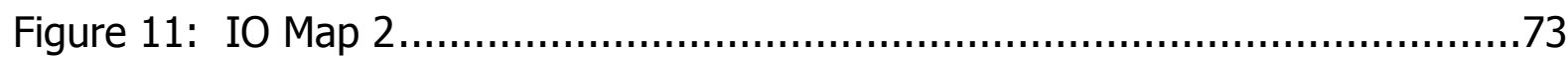

Figure 12: IO Map 3

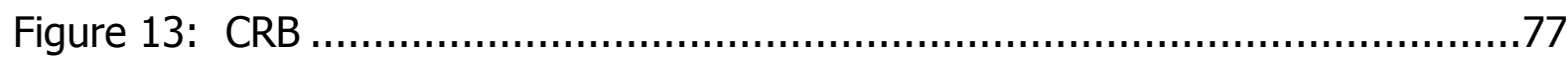

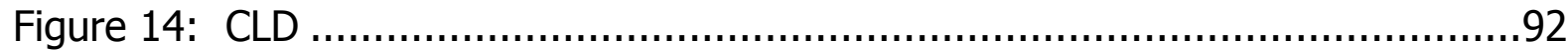

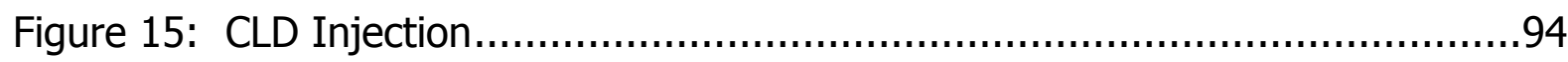

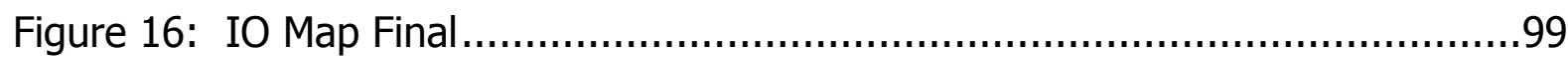

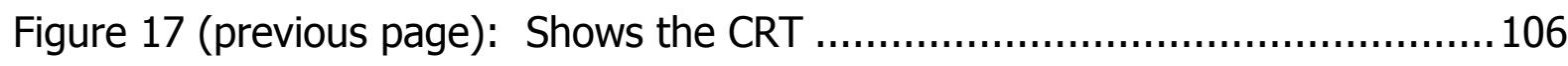

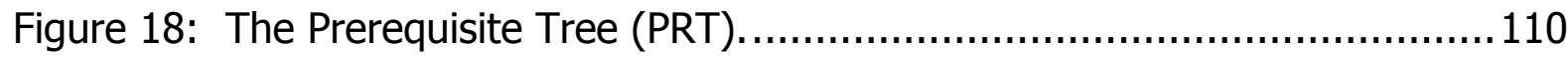

\section{LIST OF TABLES}

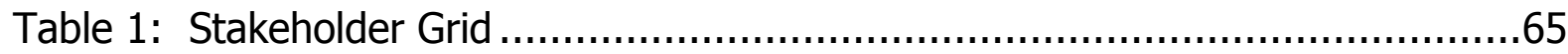

Table 2: Selected Stakeholder Responses ..................................................70 


\title{
Chapter ONe - Introduction
}

\begin{abstract}
Just as most issues are seldom black or white, so are most good solutions neither black nor white. Beware of the solution that requires one side to be totally the loser and the other side to be totally the winner. The reason there are two sides to begin with usually is because neither side has all the facts - Stephen R. Schwambach.
\end{abstract}

\subsection{THE RESEARCH TOPIC}

\section{Investigating the constraints to developing more sustainable environmental and sound business agendas: the case of Kapiti's Sustainable Water Use Strategy.}

This thesis is to fulfil the research requirements for the degree of Master of Management Studies. The researcher explores current approaches to Urban Water Management in New Zealand, and tests a decision-making framework, the Theory of Constraints (TOC) used with a stakeholder mapping process, as a means to identify and overcome the constraints to achieving better outcomes for urban water systems in Kapiti, a coastal community debating 'solutions' to its current and future water security problems.

\subsection{THE RESEARChER}

My love of languages led me to Victoria University as a 'mature student' and I completed my degree in Italian and Linguistics in 2004. My subject choices included some fascinating communications papers. Having achieved respectable passes in organisational communication, discourse communication and socio-linguistics, I took up an offer to undertake postgraduate study at Victoria's Management School, and there I discovered the world of decisionmaking.

It was in my second year of Masters study that I came across 'this thing called the Theory of Constraints' (Goldratt, 1990). Daughter Tessa was having problems with homework: there was too much, it was too hard, she needed constant encouragement...and she was only eleven! Homework was becoming a family nightmare and I had no idea what to do. It was at this time that I discovered Goldratt's Conflict Cloud. Actually, Goldratt calls it the Evaporating Cloud or EC, because it has the effect of making problems disappear. My lecturer, Vicky, sent us home with a task; to take an everyday problem and apply the decision-making tools we were learning about. Could the cloud 
evaporate the problem? Yes, it could, and it did. The answer was in the assumptions we all tend to make when thinking through problems. Once we broke through some wrong assumptions, a plan was made for Tessa and her homework that works to this day. One family crisis averted.

Why the leap from Italian to researching the care of our water? My choice of research problem has everything to do with where we live. Our home rests in a natural gully, through which runs a spring that feeds into a wetland. The spring was seasonally prone to flooding, but over time, we learnt to carefully manage the area, planting appropriately and fencing off stock. Communication with our neighbours and the local farmer was a key part of the restoration process: no amount of planting up-stream would prevent flooding, if downstream neighbours were blocking water-flow with garden rubbish. Flooding is now rare and minor in its effects, and the waterway hosts eel and koura (fresh water crayfish).

A few minutes north from where we live is Kapiti, a stunning coastal district. A string of what started out as small coastal towns has grown in thirty years into a thriving settlement, but with all the challenges such rapid growth brings. As the popularity of the region has increased, water shortages and degradation of waterways are more serious concerns. The problems are sharply in focus in summertime when peak demand and high temperatures threaten to undermine the capacity of the system to provide 'good enough' water. Security of supply is not the only issue. Reduced river flow and warmer weather provide ideal conditions for toxic algal blooms to flourish, along with other contaminants increasing in concentration. The effects are higher water treatment costs and health risks to those entering contaminated water.

In 2006, while I was working as a researcher and writer for a publication on household sustainability, my attention was often drawn to media reports and inflamed debate about Kapiti's water. Public interest and conflict have not abated with time. Rather, the momentum continues, perhaps fuelled by the heightened acknowledgement of the potential effects of climate change (see Wratt, et al., 2006 for a scientific assessment of climatic trends for New Zealand).

The impetus for this study of Kapiti in particular, and water management in general, arose from my observing disappointing outcomes from what on the face of things seemed to be careful and considered decision making. Kapiti has a sound, well-documented water management strategy (Water Matters, 2003) in my opinion. Despite the strategy, parts of Kapiti face increasing risks to the integrity of its water system, with ongoing differences over some key elements of change. I wondered what the core problems might be and whether there 
was some kind of decision-making framework that might achieve better outcomes for the urban water system and the communities it serves. Thus, the work began!

\subsection{DeFI NITIONS AND ASSUMPTI ON}

It is useful to define the terms used in this study. The following definitions are by no means the only ones found in the literature. An appropriate definition was selected by the researcher, based on how closely it is reflective of New Zealand society and how clearly the message is conveyed:

\section{Definition - Sustai nable Development}

\section{Sustainable development meets the needs of the present without compromising the ability of future generations to meet their own needs (World Commission on Environment and Development, 1987).}

This statement has regard for communal needs now and in the future, while implicitly recognising the need for organisations (small businesses/agricultural and horticultural industries/retailers/tourist operators) to remain in business as cornerstones to community wellbeing and prosperity. This definition offers a starting point from which to develop the definition of what constitutes a sustainable urban water system.

\section{Definition - The Urban Water System}

\section{Urban water systems are defined as the natural, modified and built water systems that exist in towns and cities (Parliamentary Commissioner for the Environment, 2000 and 2001).}

The functions provided by the built system of water supply are commonly referred to as water services (PCE, 2001). The urban water system is closely linked with society in as much as circulating chemical compounds such as may be in a cigarette, will eventually end up in the wastewater and then in lesser concentrations in the raw water that is handled by water services. The complexity of interconnections that exists between water and its users are important to take account of as water users both affect, and are affected by the water system (Palme, 2004). 


\title{
Definition - Sustai nable Management
}

The Resource Management Act (RMA) defines sustainable management in section 5(2) as:

\begin{abstract}
...managing the use, development, and protection of natural and physical resources in a way, or at a rate, which enables people and communities to provide for their economic and cultural wellbeing and for their health and safety while; sustaining the potential of natural and physical resources (excluding minerals) to meet the reasonably foreseeable needs of future generations; and safeguarding the life supporting capacity of the water, soil and ecosystems; and avoiding, remedying, or mitigating any adverse effects of activities on the environment (RMA, 1991)
\end{abstract}

Combining the definitions reveals a brief goal statement to describe what communities might realistically aim to achieve through sustainable urban water management:

\section{Definiti On - Sustai nable Urban Water Systems}

Sustainable Urban Water Systems are the water systems - natural, built or modified - existing in or near towns and cities and meeting the needs and reasonable expectations of the present population, while not compromising the ability of future generations to meet their own reasonably foreseeable needs and expectations.

\section{AsSUMPTI ON}

This investigation makes the assumption that developing more sustainable urban water systems as defined in the above goal statement is desirable and achievable.

\subsection{THesis PuRPose Statement}

This qualitative study tests the use of the TOC (Theory of Constraints) systems framework and a stakeholder typology to examine ways that communities can 
gain better outcomes from their investment in urban water management initiatives. The thesis demonstrates the methodology by focusing on Kapiti, a coastal settlement north of Wellington, which has been actively debating and responding to serious water security issues for more than a decade.

\subsection{THESIS OBJECTIVE}

The motivation for this study was to consider how communities might take a more integrated and systematic approach to meeting the challenges of urban water management in New Zealand, in the face of a pattern of decline in the quality of New Zealand's water resources. Thus, a case study in a community resource management setting is described that tests the value of a methodological framework that might meet this objective.

Subsequent to a piloted investigation, a methodological framework was proposed, based on integrating three potentially complementary perspectives and with the aim of representing and ultimately satisfying as many interests or needs as possible, across a range of negotiating parties (or 'system stakeholders'). The Theory of Constraints (TOC) Thinking Processes can provide a logic-based framework for the critical analysis of conflict within dynamic and complex systems (Dettmer, 2007), approaching the barriers to sustainable urban water management as tools for change. This was augmented by the use of a Stakeholder Typology to identify system stakeholders, capturing and representing their perspectives with the TOC mapping tools: Intermediate Objective (IO), Current Reality Tree (CRT), Prerequisite Trees (PRT) and Evaporating Clouds (EC). Finally, Causal Loop Diagrams (CLDs) from Systems Dynamics were introduced to explore and circumvent potential negative outcomes with participants.

This study was seen at the outset to differ from previous social research approaches to Sustainable Urban Water Management in that the TOC systemsbased management philosophy can provide more analytical rigour than typical social research, while also valuing 'soft' information (such as intuition, policies, patterns, mindsets and fears). Coupled with the Stakeholder analysis, and Causal Loop Diagramming in an action research setting, a case study in resource management is described where the value of the combined framework may be seen in the participants' reactions.

\subsection{BACKGROUND}

\section{Definition - SUStai NABLE SySTEMS}

A sustainable system is one that will persist indefinitely without a decline in the resource base or in the social welfare it delivers (Walker and Salt, 2006: 165). 
Sustainable natural systems necessitate living within the means and limits of the environment, protecting natural resources from overuse and degradation, while addressing a wide range of stakeholder interests. Taking the appropriate individual and collective actions to care for and protect our resources now and in the future is an important and urgent goal for our communities. It is not an easy task, given that complexity and fragmentation are traditionally inherent in the management of many of our natural resources. (Richmond et al., 2004; Brown and Farrelly, 2007). As Parliamentary Commissioner, Morgan Williams argued in 2001:

\section{The traditional approach to the management of urban water systems which splits the various parts and manages each separately is outdated. A more integrated, life-cycle approach is required (PCE, 2001:50)}

Historically then, water management problems have been dealt with on a largely ad-hoc basis, with potential to 'become increasingly complex problems to be faced by later managing authorities' (Palme, 2004). Application by the Greater Wellington Regional Council in 2008, to increase water abstractions (the taking of water) beyond their current resource consent, in order to meet peak demand at certain periods, illustrates the dilemma Palme describes (GWRC, 2008; and see Dominion Post article in Appendix 4). With subjectivity around the definition of water quality (Slaney, 2004), there are conflicting views about the threshold at which river or aquifer health may be unacceptably compromised, and with scientists and engineers offering different perspectives and weights of evidence, uncertainty around managing water-related risks continues (Painter, 2004). The Hutt River for example, is afflicted by outbreaks of the cyano-bacterial toxic algal bloom (GWRC, 2008: Appendix 5) and reduced river flows can provide better conditions for blooms to flourish (Richmond et al., 2004). Undesirable effects of toxic blooms include:

$>$ increased costs and technologies to treat the water satisfactorily

$>$ an unattractive river that poses a serious health risk to swimmers and dogs

$>$ potentially lasting ill-effects on river flora and fauna (Smartwater.com, 2007)

The most effective water supply system is achieved by acting on the principle that it is better to start with the highest quality source-water than having to treat it to reach required standards (Melbournewater, 2008). Decision-making 
about New Zealand's fresh water will continue to challenge communities and their managing authorities, as people have diverse and conflicting expectations for water use (Painter, 2004).

Water is allocated by councils according to consents, expressed as a flow rate in litres per second, or as a volume of water that can be taken in a day, week or, occasionally, a month (Robb, 2000). Irrigation uses upwards of $77 \%$ of allocated water in New Zealand, with $16 \%$ used for the public water supply in 2000 (ibid.). The Wellington region, of which Kapiti is the northern-most district, allocates nearly $10 \%$ of the country's total abstracted water, and of this; $40 \%$ was used for irrigation, $4 \%$ for industry, with $56 \%$ used for public supply in 2000 (Robb and Bright, 2004: 42.7). Robb (2000) contends that councils have much to learn from each other, with their approaches to water management depending on a variety of factors, some in conflict. Factors include: the dynamics of a water resource and the ecosystem it supports; the associated recreational, heritage, spiritual and other values; the history of water allocation; the level of information available; and the political environment (Robb, 2000).

New Zealand's low population and industrial base has meant that the adverse effects of poorly managed water systems, water abstractions, and point source discharges have been relatively narrowly distributed, leaving this country's 'clean, green' image largely intact, despite evidence of significant environmental impacts (Richmond et al., 2004:44.18). Resource managers are responsible for ensuring our natural systems are sustainable, within a legal framework with a wide policy umbrella that encompasses energy, climate change, transport and land-use considerations (Atkins, 2007) among others. Managers therefore, need to facilitate the decisions that assist communities to live within the means and limits of the environment - or have a plan to mitigate for the effects of not doing so. Melbourne Water is employing mitigating measures to rescue its citizens from the effects of over-abstraction and intensive land-use in the Goulburn-Broken Catchment, a sub-catchment of the Murray-Darling River basin, with the construction of a 150 billion litre desalination plant (Melbournewater, 2009). Abstraction from underground aquifers raised the water table in the Goulburn catchment until it reached salty deposits close to the soil surface. Pumping salty water away from crops, but disposing it to the Murray River caused other, potentially more serious problems, with the river becoming increasingly salty. Desalination raises the cost of water, and is not without other undesirable effects (Kandel, 2003).

$200,000 \mathrm{~km}$ of major river channels, high ranges and rainfall (Bishop, 1994) combine to ensure that New Zealand has significant fresh surface water (although not always when and where we would prefer it), compared to the 
minimal surface water found in neighbouring Australia, the planet's driest continent. However, with urban catchments representing just three per cent of New Zealand's total land area and well over three quarters of the population living in urban environments, urban catchments are at risk from intensified land and water uses (Richmond et al., 2004). The Goulburn-Broken experience provides a cautionary reminder of the effects of exceeding the environmental limits.

There is no lack of evidence to suggest that sustainable natural systems that address a range of stakeholder interests are an achievable and necessary goal for communities. It is no longer accepted rhetoric that 'action for a more sustainable planet falls short of the practical, and is essentially an ideology for a few 'greenies' to pursue' (Hughes, 1993). This thesis focuses on the 'practical' and has attempted to set aside the more ideological elements of sustainability. The overarching motivation is to test a framework that might assist managers and other stakeholders in caring for the water that sustains communities and grows enterprises, providing some direction on how communities might take a more integrated and systematic approach to meeting the 'many challenges of water management in New Zealand' (Richmond et al., 2004).

Painter (2004) has described the management of water-related risks in New Zealand in recent times and concluded that integrated risk management is inadequate in New Zealand, despite the clear intention of the Resource Management Act (Section Five) to 'promote the sustainable management of natural and physical resources' (RMA, 1991). This investigation does not attempt to address all the issues and pressures of urban water management, but it does seek a clear way to integrate risk concerns and accommodate uncertainty within the decision-making process. The focus is on the management of an urban water system in a rapidly growing community that is struggling to achieve a more secure water supply and healthier catchments, despite the constraints of differing socio-political expectations, periodic climatic extremes, and potentially inadequate infrastructure.

\subsection{SUMMARY OF OBJECTIVES}

$>$ To consider how communities might take a more integrated and systematic approach to meeting the challenges of urban water management in New Zealand;

$>$ To explore the application of TOC/Stakeholder Theory/Systems Dynamics in the domain of resource management;

$>$ To propose constructive approaches to decision making and problem solving in urban water management, employing the TOC Thinking 
Processes to determine what to change, what to change to, and how to cause the change;

D To present the outcomes of this research to stakeholder participants.

\subsection{OVERVI EW OF THE KAPITI CASE}

Kapiti Coast District Council supplies potable water to the Waikanae, Paraparaumu and Raumati areas from the Waikanae water treatment plant. The plant treats water from the Waikanae River with the ability to take groundwater from a borefield in Waikanae when there is insufficient water available from the Waikanae River or when supply is unable to be utilised such as during a bluegreen algae outbreak. The objective is to provide 400 litres per person per day accounting for a 1 in $50 \mathrm{yr}$ drought with an additional allowance of 75 litres per person per day for losses. Projected demand will exceed the available supply from the Waikanae River and the groundwater quality makes it unacceptable even for supplementary supply. The Council has been actively considering additional water sources and options for improving the security of supply from the existing sources since the mid 1990's (SKM, December, 2008).

Urban water systems, in particular, are under increasing pressure to meet the expectations of communities, with water managers required to articulate sensible and sustainable management initiatives that secure water supplies and protect water for its intended use, now and in the future. Water and wastewater infrastructure and management account for a significant proportion of rates spending in New Zealand. In a typical urban example, for every one dollar of rates, urban water and wastewater management costs forty-three cents (KCDC, 2006). Wastewater management comprises the greater proportion at twenty cents, water management seventeen cents, with stormwater costing six cents in every dollar (ibid). Water consumption has a direct impact on rates on more than one level, affecting both wastewater costs and water management costs, as generally the more water used, the more goes down the drain as wastewater (or stormwater when used outdoors).

Kapiti is a coastal settlement north of Wellington, which has been debating and responding to water quality and security issues for more than a decade. The 
Kapiti Community must act to reduce their water use, which is on average much higher than it should be, especially at peak times (KCDC, 2008). The urban water supply must cope with the demand for irrigation, drinking water supplies, and industrial/agricultural/fire-fighting needs. Water services provided by the Council, as described on their website are:

> continuous supply of potable (drinkable) water and water to fight fires

$>$ responsible water-use advice and promotion

$>$ 24-hour response to reticulation failures

$>$ technical advice to ratepayers

$>$ regular testing of water quality

$>$ maintenance of meters, valves and hydrants

$>$ location of water mains and service connections. (KCDC, 2008)

Kapiti has four water supply systems serving four urban communities: Otaki; Raumati, Paraparaumu and Waikanae; Paekakariki; and one rural area: Hautere/Te Horo (KCDC, 2008).

The Kapiti Water System comprises:

$>$ three surface water sources

$>$ eight groundwater bores

$>$ nine treatment plants

$>$ eight pumping stations

$>12$ service reservoirs

$>$ more than 430 kilometres of trunk mains and distribution reticulation

$>$ more than 3000 valves

$>$ more than 2000 hydrants (KCDC, 2008).

The following is from an assessment report (KCDC, retrieved June 2008) prepared under Section 32 of the Resource Management Act 1991, and provides an overview of the salient issues, perceptions and motivations behind a package of actions and alternatives being considered for the Kapiti community and its water. 
Plan Change 75 - Water Demand Management- Section 32 Analysis Report

Sustainable Water Use Strategy

1. The Council published its Sustainable Water Use Strategy (KCDC, 2008), "Water Matters" in 2003, setting out its vision for the management of the District's water resource over the next 50 years. The Strategy recognised that water is a finite resource and identified demand management as the key method for managing Kapiti's water supply.

2 .The Strategy aims to reduce the average peak demand for reticulated potable public water supply to 400 litres per person per day by 2013, made up of 250 litres for essential use, 150 litres for non-essential use and 75 litres per household allowance for leaks. Recent development has proceeded with the assumption of 650 litres per person per day average, but the average in the Waikanae catchment is 700 litres per person per day.

3. It is anticipated that the District has enough capacity to supply water for new development for the next 45 years. However, this conclusion is based on a strategy of managing the demand for water in the District. If the community does not reduce its demand for water, then the limit will be reached much sooner.

Water Demand

4. It is the nature of water supply that it is subject to peaks in demand. There is no immediate problem in meeting the demand for household water. However, in the summer months, demand rises greatly, principally due to the use of outdoor irrigation. There have been problems in meeting this daily peak demand and it would be desirable if this demand for water was smoothed out over the course of the day. The measures proposed in 
the plan change are also aimed at achieving this objective.

5. The use of non-potable water sources was identified as a way to reduce reliance on reticulated water supplies. For the purposes of this policy, non-potable water supplies are regarded as those from sources other than Council's reticulated supply, and include rainwater, greywater and private bore water.

6. The use of potable water is essential wherever the supply may be used for drinking or washing. It is an expense to provide, but is fit for human consumption. However, it is not necessary to use potable water for irrigation, cold water for washing clothes in a washing machine or the flushing of toilets.

7. On average, approximately 400 new houses are built in the District each year, placing additional demand on the Council's water supplies. New development is an opportunity to establish a sustainable pattern of water use from the point when new houses are occupied. This is easiest and most cost effective for the homeowner when a house is built, and water saving measures can be designed in, rather than changing established behaviours.

8. Residential intensification to infill and medium density housing will also intensify demand on local services. Stormwater and wastewater loadings will increase, as will daily potable water demand. Rainwater tanks will reduce stormwater discharges from each site and reusing rainwater in the home will not only reduce potable water use, it will also ensure there is space in the tank to attenuate stormwater.

Regulatory Response

9. Regulatory controls are an essential component of a total water demand management package for the District's water supply. It is acknowledged that this 
measure is not the complete solution to securing the District's water supply and it is expected that it will be complemented by other measures to reduce demand from existing residents and businesses. These include water pricing, water restrictions, leak reduction, education measures such as the green plumber and targeted incentives for retrofitting non-potable water supply systems on existing properties (KCDC, 2008).

On 2 August 2007, the Kapiti Coast District Council approved a plan change requiring all its new homes to either have a 10,000 litre rainwater tank or a smaller rainwater tank combined with an approved greywater reuse system. This is a first in New Zealand, and is just one of a raft of initiatives that respond to the need for Kapiti to reduce peak water use by nearly a third, as part of its Sustainable Water Use Strategy (Water Matters 2003). This reduction is desired partly to meet a condition for the consent granted by the Greater Wellington Regional Council to take water from the Waikanae borefield supplementary water source for the consented period (currently up to ninety days per annum).

Within New Zealand, statutory control of individual dwellings' water supplies fall under the Health Act 1956, the Local Government Act 2002, and the Building Act 2004 (Abbott, 2008), with two other pieces of legislation affecting freshwaters: the Resource Management Act (RMA), and the Conservation Act with its various legislations (Richmond et al., 2004). The Public Sector is urged to achieve 'sustainable development' for their communities, as described in the Key Government Goals to Guide the Public Sector in Achieving Sustainable Development (Department of the Prime Minister and Cabinet, retrieved 2008). Local government must therefore uphold the integrity of the RMA and all other legislative requirements, while keeping paramount the interests of community members now and in the future.

Increasingly, community members are closely involved in the decision-making that affects their lifestyle and their wellbeing through the Annual and Longterm Planning processes with local Councils. Integrated catchment management, also known as integrated water resource management, is a resource management philosophy increasingly endorsed by Councils as a cornerstone to making more sustainable use of a community's natural resources. However, Painter (2004) argues that a majority of water resources in New Zealand are managed in a 'fragmented' and 'unsustainable' fashion, with the current embodiment of an integrated approach failing to adequately 
account for risk or to apply a convincing whole-system perspective that achieves the desired ends.

Kapiti, like a number of New Zealand communities, is challenged with a rapidly increasing urban population, finite water resources and limited income streams. Integrated water management requires significant community investment and careful consideration of alternatives (Painter, 2004), often within a complex network of stakeholders with, at times, incongruous understandings, values and belief systems. Given that with the right information, the best decisions can be made, it follows that good and relevant information is required if communities are to gain the best and most sustainable outcomes from their investment in the management of local resources.

The complexity of the urban water system, as it connects with the social and economic fabric of communities, creates challenges for its managers. If key information and understandings are not synthesised properly, then poor decisions have a habit of following. Can decision-making about urban water be aided with a systems-thinking methodology? This question was the nexus for the case study of Kapiti that demonstrates the use of decision-making framework, The Theory of Constraints (TOC).

\subsection{Defi NITI ONS: ReSilience AND FLeXI BILITY IN SYSTEMS}

The concepts of resilience and flexible design as elements of the urban water system are discussed in this section. The IO (or destination) map prepared with participants early in the study suggested that resilience and flexibility are necessary conditions underpinning a secure water supply. Accordingly, this section introduces and briefly defines these terms as they relate to this investigation.

\section{Resilience is defined as the capacity of the system to absorb change and disturbances and still retain its basic structure and function - its identity (Walker and Salt 2006:113).}

One of the principal assumptions behind resilience as a necessary condition for sustainable systems is that 'social-ecological systems have multiple regimes (or states) that are separated by thresholds, where social-ecological systems are the linked systems of people and nature' (ibid::113). Resilience is described by Walker and Salt (2006:113) using a metaphor of a ball in a basin. The edge of the basin is the threshold or limit, before structural change and a different equilibrium occurs. Resilience is represented by the extent of the distance 
between the ball and the edge or threshold of the basin. The idea is to maintain sufficient distance to prevent the ball from rolling over into another basin (a new state or regime). To use another metaphor: imagine running upstairs with a full cup of coffee. If the cup is full to the brim, the chance of the coffee spilling over is greater than if the cup were only three quarters full. Carrying the same quantity of liquid, but in a larger cup, creates a buffer: the coffee might splash up the sides, but is less at risk of spilling over. The size of the buffer is the extent of the resilience. A series of case studies about resilience and adaptive responses are presented in Resilience Thinking by Walker and Salt (2006). Resilience is discussed in a New Zealand context in Freshwaters of New Zealand, with Suren, McMurtrie and Obrien (2004: 38.1-2) characterising resilience as a necessary condition to river restoration:

\begin{abstract}
Resilience is characterised by the ability of stream communities to recover quickly to their pre-disturbed state following a disturbance $[. .$.$] due to the resistance or$ resilience of aquatic communities, recovery is possible even after relatively large manmade disturbances (2004:38.2) [...] This natural self-healing process of river ecosystems is a basic factor determining the success or failure of restoration activities (Suren, McMurtrie and Obrien, 2004: 38.1-2).
\end{abstract}

Another condition that some study participants indicated as underpinning sustainable systems is flexibility. This term appears to mean different things to different people. Following a search of the literature, and based on what the intention of the participants is thought to have been, the researcher suggests that flexibility is the system's capacity to respond to disturbances (Walker and Salt, 2006). Expanding the metaphor above; keeping a tight-fitting, convex lid on a cup of coffee provides flexible capacity. The cup may be filled to the brim, but the lid ensures the coffee stays where it is supposed to.

Flexibility might also be described as adaptive or transformative capacity:

What matters when a system has been overwhelmed is its adaptive capacity and transformative capacity [...] that means its ability to reorganize in ways that minimize loss and enhance well-being (Walker and Salt, 2006:154). 
Weather phenomena are of increasing concern to New Zealanders, as climatic patterns indicate a shift to more frequent drought in the eastern parts of New Zealand, while some western areas are experiencing more intense periods of rainfall (Wratt et al., 2004:160). This pattern is expected to continue over the coming century (ibid.). Drought and flood can overwhelm a system, signifying high levels of disturbance (Suren, McMurtrie and Obrien, 2004: 38.1-2). A sustainable urban water system would offer alternatives of choice in times of disturbance. These might stem from an urban water system design that includes non-traditional sources of water supply, such as roof water harvesting in urban settings, or non-traditional ways of dealing with deluges of rain, such as swales, rain gardens, a greater concentration of semi and fully permeable surfaces. Other system design features might involve emphasis on onsite water retention or natural channelling of water to augment the more traditional practice of attempting to drain and pipe stormwater rapidly away from where it falls. The 'Christchurch waterway enhancement project' commenced in 1991, provides a compelling and enduring example of the social, economic and environmental benefits that can be achieved from 'water sensitive design' (PCE, 2000: 34), as defined in the next section.

\subsection{Definition: WATER Sensitive URBan Design (WSUD)}

Environmental degradation and supply scarcity arising from a traditionally narrow approach to water management has prompted 'new philosophical discourses' to provide 'alternative, more inclusive and integrated visions for achieving sustainable urban water management' (Brown and Keath, 2007: 1).

Social scientists Brugge et al. (2005) have argued for strategically influencing transition processes to achieve more sustainable outcomes (and see Brown and Keath, 2007). The strategic set of urban design initiatives aimed at facilitating the transition process by maximising sustainable use of the water resource to provide practical choices, particularly in times of system disturbance, have come to be known as water sensitive urban design or WSUD. A related 'discourse', but one associated with designing exclusively to dry conditions, is xeriscaping (see Colorado WaterWise, retrieved 15 May, 2009). The logic behind water sensitive urban design is that there is a finite amount of water, and in some years there will be less water than in others.

WSUD proponents suppose that by grouping plants by their water needs and tolerances, and with regard for the characteristics and natural elements of the site, by conditioning the soil, using mulch to retain moisture, and choosing climate tolerant plant species, water usage can be carefully managed and thus conserved. Runoff can be similarly managed, as in the Christchurch example above, to minimise the risk of flood and reduce pollutants entering waterways. 
WSUD is introduced here as a concept, as it presents under the Intermediate Objective 'technologies' in the Destination (IO) map prepared with participants.

\subsection{OVERVI EW OF THE StaRborough FLAXbouRne CASE}

In Walker and Salt (2006), farmer John Weatherstone offers his perspective on resilience in relation to land and water management. Weatherstone is a farmer who in the 1980's realised that his traditional farming practices were failing to insulate his farm from the pressures of a long and severe drought. He describes how he 'thought through' the resiliency principles that saved his farm, while other farms ceased production:

In a time of crisis, it's not uncommon for a farmer to become introspective. We might not say much, but when the land you've been working for so long dries up and blows away, taking with it your financial security, it makes you think about things (John Weatherstone, 2003).

Resilience, as it applies to farming, has been described as:

The capacity to recover from the impact of drought or other threat and to continue to supply the goods and services that underpin the farming enterprise (adapted from John Weatherstone's description in Walker and Salt, 2006:116).

While transformative capacity or flexibility is:

The capacity to change the way things were always done, while preserving the ability to provide goods and services and to contribute to the wellbeing of the social-ecological system (ibid.).

The case of the Starborough Flaxbourne Soil Conservation Project serves as an opportunity to illustrate the concepts of resilience and flexibility. The Starborough Flaxbourne Soil Conservation Group was formed with the assistance of the New Zealand Landcare Trust (Landcare Trust, 2008) in 
response to more than eight years of drought. Two members were interviewed for this thesis to provide comparative perspectives for the Kapiti case.

By 2004, for Doug Avery, his son, and their families, there were two options: leave the land they had farmed for generations, or make significant changes to the way they farmed. In the words of farmer Doug Avery:

\section{The moment of truth came when I realised that we could not keep on farming as we were, if we were to remain financially and environmentally sustainable - Doug Avery, 2008}

Much of East Coast Marlborough's farmland was seriously parched in 2004. On the Avery's and neighbouring farms, production was threatened as much by erosion from stock picking over scorched earth, as from the lack of water for growing pasture. Farming systems were losing resilience. The extended drought was threatening the livelihood and wellbeing not only of affected farmers, but also by association, the nearby townships and supplier groups with which farmers and their families are essentially linked. The Starborough Flaxbourne (SF) Soil Conservation group was formed, and with nearly three years of collaboration, targeted research and action, and 'soul-searching' (Avery, 2008), their transformation strategy emerged as a success.

Landcare Trust and its partners coordinated an event to raise awareness of the experiences of the SF farmers. They wanted others to learn of the dryland farming techniques that in three years, had contributed to a $54 \%$ increase in profits on the Avery's east coast Marlborough farm, despite record low rainfalls. A national field day held on 14 May 2008 at Bonavaree farm (situated between Seddon and Ward), shared strategies and insights with visitors. The following is an excerpt from the associated report Beyond Reasonable Drought; adapting dryland farming to climate change:

Farmers in this drought-prone district once feared their farmland could become a desert. For 12 years, the traditionally dry area has failed to achieve its $576 \mathrm{~mm}$ long term rainfall average, leaving hillsides cracked and bare and the future looking bleak.

With help from the NZ Landcare Trust, the Marlborough District Council and Ministry of Agriculture and Forestry's Sustainable Farming Fund, the farmers formed the 
Starborough-Flaxbourne Soil Conservation Group and gained funding to look at ways they could turn a profit while looking after their land.

Four years later, the group is upbeat. Techniques trialled are seen as pointing the way for farmers throughout New Zealand experiencing what's widely regarded as the effects of global warming.

"Sustainability is not business as usual with a few concessions, but a new road", is the farming mantra of group chairman, Doug Avery. "Under the old farming system, last season would have left us in tears, with no income and poor stock. However, we've had one of our most successful years ever," he says. [...]

Changed management of lucerne - traditionally grown in the district for supplements and seed - has played a major role in this success story. [...] Not only is Bonavaree Farm more productive, but "we are making ground on damage done to our hills in the last 160 years," says Mr Avery. Rehabilitation techniques include planting saltbush and tagasaste; the conservation work funded by improved production thus profitability. (Landcare Trust, 2008).

One of the significant transformative strategies applied with success by the Starborough Flaxbourne Project has been to graze stock differently, planting lucerne as a feed alternative to a ryegrass and brassica rotation. Seeing their farm as a system was the first breakthrough, according to SF group member Kevin Loe. After the severity and longevity of the drought, by thinking through the interconnections between actions, events such as climate, stock numbers and movements, and importantly, the patterns and mindsets, the necessary changes became more and more apparent.

Articulating a 'mindshift' (a necessary condition proposed by a number of participants in this study) and a 'vision' for the system were also essential. The stages of change have required commitment, collaboration, leadership, and not insignificant investment. However, the returns are now in evidence, as the report referred to above shows. Changes such as planting salt resistant shrubs to minimise erosion, provide greater insulation from the effects of new 
disturbances. This was evident when the effects of unusual and prolonged rainfall in 2008 caused severe flooding and widespread damage across the region. The two farms visited for this study were affected by the deluge, but the effects were short-lived. The same could not be said of a farm and a vineyard the researcher saw close by. Both had significant chunks of land gouged out by the coursing water. Another had pumps working night and day to remove surface water. The positive outcome following the 'mind-shift' and the transformative strategies adopted by the Starborough Flaxbourne farmers have been increased stock yields, decreased erosion, and lower operational expenses - win/win. The farmers point out that a system view is essential to transformation, with one change introducing other, not always desirable, effects that had to be mitigated or avoided.

This and the previous section about resilience and transformation seek to introduce and emphasise three points:

$>$ There is a need for more diverse and effective tools to assist managers to 'see systems' and improve resilience, synthesising the knowledge that will identify risks to the system regime, so transformative (flexible) capacities can be harnessed when required.

$>$ There is a need to test the frameworks that could assist managers and other stakeholders in visualising the system, its structures and patterns, its risks and constraints, and its opportunities for making regime shifts and responses.

$>$ There is a need to provide frameworks to weigh all options, to foresee and forestall the potential undesirable side-effects of change.

\subsection{NTRODUCI NG THE THEORY OF CONSTRAI NTS AND THE RESEARCH RATI ONALE}

Weatherstone's thinking process led him to redesign his farming enterprise and practices, as has Doug Avery and other members of the Starborough Flaxbourne Group. The Theory of Constraints (TOC) Thinking Processes can provide a structured way to logically interpret, connect, and test thoughts and understandings, thereby offering another way to 'think about things'.

TOC is a systems methodology that attempts to capture the views of participants; representing them using logic diagrams to depict desired states, the current less-than-desired reality, together with possible future scenarios, using a series of cause-effect or necessary-condition diagrams. TOC allows the user to vet assumptions to come up with multiple possible solutions. The solutions can then be tested in a variety of ways on paper - to pre-empt the most critical undesired effects, protecting precious resources, like water, as 
much as possible. The rationale for the research is to present a useful application of TOC in the area of sustainable development that may enhance the capabilities of the public sector to meet its goals to 'treasure, protect and enhance the environment' (DPMC, 2008).

The Kapiti Urban Water System is the primary focus of this paper, encompassing the supply, treatment, delivery and end use of water within that community. The successful Starborough Flaxbourne Soil Conservation Project in drought-prone eastern Marlborough is examined as a point of comparison. Building on a recent Australian study by Brown and Farrelly (2007) that identified barriers to implementing Sustainable Urban Water Management (SUWM), this research explores sustainable development opportunities, while attempting to further awareness and understanding of the critical constraints to managing Sustainable Urban Water Systems.

A multi-methodological approach (Mabin, 2006: 51) was taken, combining Stakeholder Mapping with TOC, and Causal Loop Diagrams from Systems Dynamics (SD), to build TOC and CLD logic diagrams representing the views of a representative group of stakeholders. To support the TOC modelling, Dettmer's (2007) 'transformational logic tree' software was used to construct the TOC logic trees that systematically categorise the participants' perspectives.

\subsection{CONTRI BUTI ONS}

This study tests a conceptual framework to logically make sense of a complex and interconnecting network of information, and provide a cost effective and uncomplicated way to disseminate key knowledge among representative interests. The approach to designing the study was to pursue a methodology for logical analysis that would, in a timely manner, reveal problems and opportunities, needs and expectations, common ground and conflicts, and attend to the veiled assumptions that constrain the whole system from achieving its goal. The findings of this research may be expected to assist resource managers in meeting their objectives for more integrated management approaches by facilitating logical decision-making with a system perspective. With the proposed TOC-based methodological framework, Councillors exploring whether to spend $\$ 6$ million on water meters or $\$ 14$ million on storage capacity could be expected to develop increased confidence in their decisions; by systematically identifying the critical constraints that compromise water security and gaining agreement on the steps necessary to meet the range of stakeholder interests.

The findings may contribute to theory and practice on Managing Sustainable Urban Water Systems (SUWSM) and the closely related Integrated Water Resource or Catchment Management. 


\subsection{THE CONTENT OF THE RESEARCH}

The thesis comprises six chapters and related appendices:

\section{Chapter One: Introduction}

The introduction sets out some background and a set of definitions of relevant terms to assist the reader in making sense of this thesis. The researcher provides a thesis purpose statement and offers an explanation as to the motivation behind the choice of topic. The research aims, objectives and assumptions are stated.

\section{Chapter Two: Literature Review}

This chapter presents some background to systems theory and presents an argument supporting the choice to apply the Theory of Constraints to the problems facing managers of urban water systems and the communities that are sustained by them. The reasoning behind using a stakeholder typology to select participants to interview for the study is presented. Issues of sustainability are discussed, and typical problems faced by Local Authorities around shaping more sustainable water systems are identified. Concluding the chapter is a discussion of the concept of 'resilience' and its relationship to managing risk.

\section{Chapter Three: Methodology}

Here, the research purpose and objectives are restated, and the reasoning behind the research design is presented. Interview protocols are discussed and the information that was provided to the selected participants is reproduced. The standard twelve interview questions are included in this section. A brief discussion of the pilot study is provided.

\section{Chapter Four: Analysis}

In this chapter, the interview data and TOC analysis are presented with a discussion of how the data was reduced to a table that presented the responses to the interview questions in relation to the perceived goal, the symptoms, problems, necessary conditions and critical success factors. The outcomes from applying the Thinking Process Tools to the interview data are presented in diagrammatic format. The critical dilemma is revealed in a Conflict Cloud (EC) that was presented to two KCDC Councillors and selected participants. The EC shows clearly the assumptions and the injections best applied to the dilemma of securing the water supply for Kapiti. Peter Senge's archetype (1994 and 2008) of 'the fix that backfires' is presented to frame the concept that the first EC injection is workable only when accompanied by a second stated injection, thus preventing a delayed response to the 'fix' that would place unacceptable strain on the system, thereby risking system failure. 
Concluding this chapter is a summary of the data gathered from participants as it was arranged for the analysis.

\section{Chapter Five: Interpretation of Findings and Discussion}

Here, the researcher synthesises the outcomes of applying the TOC tools with the stakeholder typology. The key constraint to shaping more sustainable systems is revealed in terms of the specific case study. There is discussion of the implications of using two methodologies for a systematic and constructive approach to overcoming the complexities inherent in serving multiple interests.

\section{Chapter Six: Conclusions}

The final chapter of the thesis concludes with some implications and limitations around the investigation. Recommendations are made for future research.

\section{The Glossary}

The glossary provides definitions for a number of terms used in the thesis.

\section{The Appendices}

The appendices contain documents referred to in this thesis where it is likely to be of value to the reader to have ready access to them. 


\title{
Chapter Two - Literature Revi ew
}

\author{
You don't actually need more water; you need better \\ water use [...] There are people using some of the best \\ water in the world on their roses! - Participant
}

\subsection{INTRODUCTION}

Gerald Miller and Henry Nicholson (1976) proposed that 'Inquiry is nothing more than asking questions [...] and providing disciplined, systematic answers to them'. This is a multi-faceted inquiry into natural and built systems, and the people connected with them, with the methodological development taking a 'multi-theoretical orientation' (Littlejohn, 1996: 26). The broad aim of the methodological framework required for this thesis was to systematically identify what the questions should be asking, who should answer them (the stakeholders), and what the answers mean, with questions presented and applied in the context of a community goal. This goal may be as expressed in the participant's statement above: to manage urban water systems more effectively, more sustainably.

In 2001, the Parliamentary Commissioner for the Environment raised the concern that reaching consensus between stakeholders on environmental, social and economic goals for urban water systems was a mounting challenge for communities, with 'community and political tensions surrounding how water services are currently managed' [...] 'evident on the Kapiti Coast as elsewhere' (PCE, 2001: 48). The Commissioner recommended that the Kapiti Coast move beyond the conflict and tensions and agree as a community on a way forward (PCE 2001: 54). A key outcome of that recommendation has been Water Matters (2003), the Kapiti Coast's Sustainable Water Use Strategy, which has guided Kapiti's water management policies and procedures, and promotes a considered approach to water management that accepts there are limits that must be lived within, as defined 'by natural hydrology' PCE (2000: 50) and other factors.

Despite a growing number of Councils adopting Sustainable Water Use Strategies, in 2009, there is continued variation in management principles, responses and outcomes, and urban water management remains a challenge for Kapiti, and indeed for the majority of New Zealand communities (KCDC, 2009, Watercare, 2008). The area of sustainable urban water management attracts considerable interest and some investment, as communities seek ways to adhere to more 'ecologically, socially and economically sound principles' (PCE, 2000: 54). This review of literature and discourse introduces systems 
thinking and theory and presents an application for the Theory of Constraints (TOC) and Stakeholder analysis. Sustainable development indicators (SDIs) are evaluated briefly and the relationship between TOC and leadership is discussed. This chapter concludes by summarising the relevance of stakeholder theory and TOC to this thesis.

\subsection{Methodologi Cal Development}

Sustainable urban water management is 'complex, involving a number of interconnected elements and requiring a multidisciplinary approach' (Thomas, Orton and Brown, 2007), with poor community engagement and a concomitant lack of participation in decision-making cited as 'significant reasons for the failure of the traditional sustainable water planning model' (Thomas et al. 2007, citing Ryan and Brown, 2000).

The area of sustainable urban water management (SUWM) has experienced a 'flood of research' and 'identification of technological tools and design techniques' in recent years (Chapman, 2003). In pursuit of more sustainable urban water systems, local and regional authorities are adopting integrated resource management philosophies (Painter, 2004) and attempting to introduce innovative water and wastewater management tools and practices alongside more traditional ones (Watercare, 2008; Askew, 2004; Abbott, 2008). The outcomes of these initiatives continue to be mixed and there is inadequate understanding as to why outcomes do not always positively reflect the effort, engagement and investment expended (Askew, 2004; Clarke and Brown, 2006:144). The public response to certain water conservation initiatives such as the reuse of wastewater and water-metering is a complicating factor to be explored (Chapman, 2003 and see Three Waters, 2008). Other factors exerting degrees of influence and worthy of investigation include the regulative framework, decision-making processes, economic forces, organisational cultures, and broad societal expectations. All might be regarded as 'critical factors governing the outcomes of sustainable water initiatives' (Chapman, 2003).

While advances have been made in understanding the success factors and the constraints to achieving sustainable urban water systems, these for the most part relate to technological capabilities (Brown and Farrelly, 2007). Mitchell (2006:13) argues that 'we have a long way to go before SUWM could be considered mainstream practice in the water and development industries', while Brown and Farrelly (2007) suggest that SUWM studies remain narrowly focused. The authors argue that most studies to date are deficient, offering limited or no guidance as to how to overcome constraints they identify and make the changes necessary to develop and manage healthy and sustainable 
systems. The questions raised by Brown and Farrelly in their (2007) study of barriers to SUWM were catalysts for this investigation, which sets out to examine the cause and effect logic behind the situation in a New Zealand context. There is a focus on decision-making, while not excluding other factors from analysis.

The literature has identified a need to explore urban water management issues from an institutional and a community perspective; calling for a critical examination of the ways institutional capacity could be improved to reveal and deal with critical constraints and promote the development of sustainable urban water systems (Brown and Farrelly, 2007). This investigation could therefore be expected to contribute to the existing research by involving community members and institutions, and finding out their perspectives on the ways to change so-called constraints into non-constraints or opportunities. A process of thorough inquiry was called for, one that would view the urban water system as a whole - an interacting ecology of actors, relationships, acts, patterns and processes.

\section{EXPlori ng Potential Methodologi es}

The Theory of Constraints (TOC) is a systems framework that captures the perspectives of participants and can 'map the system' (Dettmer, 2007) to identify the leverage points at which change is desirable, necessary or inevitable. TOC has been successfully implemented in production, logistics, distribution, project management, research and development, and sales and marketing for over two decades (Ronen, 2005: 1). More recently, TOC has been successfully applied to non-profits, including complex resource management and delivery systems (Kendall, 1998; Scheinkopf, 1999; Shoemaker and Reid, 2005). TOC's proven capability in making sense of complex systems suggested the framework would offer a number of characteristics that fitted with the research objectives. Sustainable Development Indicators or SDIs (Palme, 2004) were also identified as a potentially effective methodology to apply to this investigation. Justification for the methodology selected and why SDI's were eventually excluded is discussed next.

Many of the most urgent problems for freshwater are not currently able to be practically managed solely at the level of the urban water system, with Palme (2004) arguing that sustainable development is complicated by its demand for far-reaching responsibilities and its non-compatibility with the prevalent individual short-term perspective. Palme investigated Swedish Urban Water Systems and came to the conclusion that Sustainable Development Indicators or SDIs have potential for improving outcomes for sustainable development 
initiatives. The impression gained by the researcher, on reviewing the literature on SDIs, was that it would be useful to test SDI's contribution within the context of New Zealand urban water. However, weaknesses have been identified in SDIs concerning the accommodation of stakeholder interests, credibility, benchmarking and future-orientation (Palme, 2004). The success of SDIs used in Swedish SUWM studies was weighed against the timeframe that would be required to apply the SDI framework to an acceptable standard for a Masters thesis. In addition, it became clear after a more comprehensive search of the SDI literature that gaining supervisory guidance on SDIs within the desired research context would prove challenging. It was decided that the constraints of timeframe, combined with the evident weaknesses in the SDI methodology, discounted it as a framework for this study.

The researcher suspects that applying the Sustainable Development Indicators within the context of a systems framework like TOC and using the TOC tools to validate the SDIs, may overcome one or more of the weaknesses associated with SDIs, thereby filling a gap in the SDI framework. TOC identifies and values stakeholder interests, it expects and caters to ongoing change, and it tests for validity in assumptions that not only makes it a valuable problem solving tool on its own, but may be useful within an SDI framework. It is regretful that the scope of this research was not able to reveal and test specific SDIs as they might apply to the case of managing Kapiti's water. Further research would be desirable to ascertain how SDIs could be best worked into an overarching TOC framework, measuring any contribution this makes to SUWM research and outcomes.

\subsection{SYSTEMS THINKING}

Ronen et al. (2006:11) describe a system as a series of interconnected components acting together towards a common goal. This complex and holistic entity may be a biological system, an engineering system, or an organisational system (ibid.). An overarching system goal drives all activity, even if it is simply a 'broad, high-level vision' (Senge, 2008:154).

\section{A vision must track the contours of reality; it has to have accuracy and not simply imagination and appeal (Heifetz, 1994:24).}

As Heifetz (1994) argues, the system goal is required to be realistic and achievable. In his $\mathrm{PhD}$ thesis on linking individual and organisational learning, Daniel H. Kim (1993) noted that managers systematically misperceive feedback and cannot transfer lessons learned from one setting to another. Kim surmised 
that new problem solving approaches were needed to respond to the inevitable shifts in paradigms that occur as 'profound change' is experienced. Essential to improvement was the linking of individual understandings and learning with organisational objectives. Kim and colleague Peter Senge (author of The Fifth Discipline and Fieldbook, and recently The Necessary Revolution 1994, 2008) opened up the field of inquiry into complex systems, focusing discourse on new paradigms that they proposed would bring a more fundamental understanding of problems and their effects, even within complex settings.

Kim and Senge argued for a change in thinking about problems and solutions, on the basis that many of the problems tackled are inevitable symptoms of a much deeper problem that is not obvious and the root cause may stem less from actions, and more from perceptions or mental models:

To be effective, perceptions must be valued equally, or
more than, actions [...]. What is needed may not be a
change of action, but a change in perception. How we
think, act, and value are all associated with our particular
view of reality. In order to create a new 'reality' we must
discover how our current world view affects the way we
perceive and respond to problems (Kim, 1993:24).

This study assumes that perception contributes to both problems and solutions (Kim, 1993) and tests a methodology that responds to this.

\subsection{THE NEed fOR A SySTEMS FrameWORK fOR DECI SI ON-MAKI NG}

\section{Have the best water you can at the start - Participant}

Water is a precious community resource, warranting careful and considered management to protect the integrity and sustainability of supply. Thus, the 'profound change' (Kim, 1993) motivating this study is the increasing pressure on fresh water resources in New Zealand. Recent statistics from Watercare in Auckland indicate that population growth and industrial development pose a serious threat to that region's water security within the short term if per capita use remains constant (Watercare, 2008). This message is echoed across New Zealand. Increasing pressure on water supplies puts comparable pressure on the wastewater system. In addition, the resource supplying the community may suffer degradation and diminishing resilience (or capacity to cope with disturbances like drought or flood), with source water becoming more costly 
and difficult to treat to an acceptable standard. This is an excerpt from the Watercare Strategic Plan 2008:

\section{DEMAND CONTINUES TO GROW}

The main driver for water demand in Auckland is population growth. The patterns of demand vary from year to year but a steady increase is evident over the longer term. Daily and seasonal demand patterns tend to be consistent over the years while reflecting influences such as the weather. Weekday demand is normally higher than weekend daily demand, with morning and evening peaks. Demand in the summer months is much higher than in the winter. February monthly demand is commonly $20 \%$ higher than demand during July, and daily demand can be $40 \%$ higher than an average day during winter. A peak daily demand of 1.5 times the average daily demand is currently adopted for planning purposes.

The total annual water demand in the Auckland region has increased significantly over the past 10 years. The total annual demand in 1994 was 112 million cubic metres. The total demand in 2003 was 124.5 million cubic metres. This is primarily the result of regional population growth, but it is also influenced by consumer behaviour.

\section{INFLUENCING CONSUMER BEHAVIOUR}

The greatest single influence on Auckland water consumers' behaviour was the 1993-94 water crisis and the accompanying intense media campaign designed to reduce consumption. Since then, per capita demand has remained lower than in the pre-drought period. Some of this may be due to lasting behaviour changes. Other factors include the installation of water saving devices such a low-flow shower heads, dualflush toilets and even perhaps bricks in toilet cisterns. The installation of water metering throughout the greater Auckland urban area - still rare around the world - also encourages frugality. Immediately prior to the drought gross per capita consumption in the region was about 330 litres per person per day. This reduced to as low as 270 litres in the immediate post-drought period as a result of a wide range of demand savings initiatives. Today, the regional consumption figure is about 300 litres per person per day. If, for example, the current gross per capita figure of 300 litres per person per day was reduced to about 290 litres, the daily demand figure for 2020 would be reduced to about 415,000 cubic metres a day, a saving of 15,000 cubic metres a day on the current forecast of 430,000 cubic metres a day. Alternatively, if consumption behaviour was to return to the levels prior to the 1993-94 drought, the 2020 figure could be as high as 460,000 cubic metres a day - requiring roughly the equivalent of another Waikato Water Treatment Plant.

Three Waters, 2008

Figure 1: Watercare Strategic Plan, 2008

Watercare combines the six local water network operators around Auckland (Ecowater Waitakere City Council, Manukau Water, Metrowater, North Shore City Council, Rodney District Council and United Water) and the Auckland Regional Council. Their water management plan is designed to be implemented by them in order to 'promote the sustainable, efficient and wise use of reticulated water resources in the Auckland region'. 
As is evident from the above excerpt, water security is an increasingly pressing issue for all communities. Council's Annual Plans, Long Term Community Plans, various national initiatives to protect natural resources, including Regional Policy Statements and the Draft National Policy on Fresh Water, and legislation such as the Building Act and the Resource Management Act, combine to impact on community outcomes. The Local Government Act (2002) promotes the accountability of local authorities to their communities. It requires local authorities to identify all reasonably practicable options and consider the benefits and costs of each option in terms of the current and future social, economic, environmental and cultural well-being of the district or region (LGA, 2002).

With New Zealand communities adopting a consultative approach to urban planning, community members contribute to the discourse on decision-making, with their responses to discussion documents having the potential to influence outcomes for landscape, air, and water. Required reading for informing responses may amount to hundreds of pages. The same can be said for informing elected government representatives. Hence, there is a need to formulate a conceptual framework that logically makes sense of a complex and interconnecting network of information and people, to inform decision-making about managing water systems in New Zealand communities. In particular, value could be gained from finding a way to link stakeholders' needs, understandings and expectations, with the technological and social mechanisms available to manage a community's natural assets. In other words, a systems view is needed.

Following the reasoning of Senge, (2008) and Kim, (1993), a meaningful systems study requires that 'we see the systems that we have shaped and which in turn shape us' (Senge, 1994:343). Senge describes two fundamental aspects to seeing systems: 1 ) seeing patterns of interdependency and 2) seeing into the future (1994:343). Senge (1994:58) has noted that so-called solutions that 'merely' shift problems from one part of a system to another often go undetected, because those who 'solved' the first problem are all too often different from those who inherit the 'new' problem. This insight reveals a place for a systematic and focused methodological framework that assists with thinking about ways to bring about improvements. To do this might entail the use of cause and effect thinking and sufficiency logic to interpret the real constraints and their impacts on the goal of the system. An effective framework would have to provide a cost effective and orderly way to synthesise germane knowledge and to facilitate its exchange among representative interests. The success of the framework may be measurable by whether, in a timely manner, the practitioner could successfully tease out the core problems and 
opportunities, the needs and desires, the common ground and conflicts, underpinning desirable or undesirable outcomes. The Theory of Constraints was chosen for this task.

\title{
2.5 THE THEORY OF CONSTRAI NTS
}

The thinking processes focus on the factors that are currently preventing the system from achieving its goals (Mabin et al. 2001:172).

The Theory of Constraints is a set of six logical tools for thinking that can be used individually or in concert (Dettmer, 2007:29):

\begin{abstract}
As a system based philosophy, TOC is based on three interrelated premises: 1 ) every system has a goal and a set of necessary conditions that must be satisfied if its goal is to be achieved. 2) the overall system's performance is more than just the sum of its component performances; and 3) very few factors or constraints, often only one, limit a system's performance at any given time (Shoemaker and Reid, 2005:21).
\end{abstract}

TOC is essentially a methodology for understanding and managing change. Dettmer (2007) proposes that the TOC methodology can provide the answers to four questions, all in relation to change:

What is the standard (the destination)?

What to change?

What to change to?

How to cause the change?

The majority of TOC practitioners to date have paid attention to the last three of the questions above. However, in the 2007 edition of Goldratt's Theory of Constraints, Dettmer proposes that it is helpful and timely to identify a destination (a set of intermediate objectives and a goal) first. Scheinkopf (1999:23) appears to support this view by starting with defining the system parameters and purpose, while Cox et al. (2003) present a variation. These authors suggest using the destination map, not at the outset, but in the final analysis, as a tool to answer the question how to cause the change? 
The addition of the destination (or IO) map follows the early work of TOC creator, Eliyahu Goldratt (see the Goal, 1992). The IO map is prepared in answer to the first question what is the standard? The requirements are structured in a tree that represents the normative situation for the system what should be happening or what you want to be happening (Dettmer, 2007: 23). The rationale for the IO map is that through developing a picture of what should be happening, a variation between what should and what is happening can be revealed (Dettmer, 2007). The following figure shows Dettmer's (2007: 29) interpretation of how the four questions relate to four applicable logic trees:

\begin{tabular}{|l|l|}
\hline State of Change & Applicable Logic Tree \\
\hline What is the standard? & Intermediate Objectives Map \\
What to Change? & Current Reality Tree \\
What to Change to? & Evaporating Cloud (EC), Future Reality Tree \\
How to Cause the Change & Prerequisite Tree, Transition Tree \\
\hline
\end{tabular}

Figure 2: Dettmer (2007)

\section{Methodologi cal Appli cati on for Sustai nable DeVelopment}

The TOC logic trees and logic rules serve to identify and address system constraints, providing a meaningful and safe way of thinking through problems, with solutions and their potential effects on other parts of the system thought through and validated before they are applied. This 'road-testing' is a salient feature of The Theory of Constraints (TOC) according to Davies, Mabin and Balderstone (2005), who have described and compared TOC with a series of other Management Science methodologies.

\section{A MODEL FOR THINKI NG}

The TOC methodology essentially provides 'a model for thinking' (Clarke and Clegg, 1998), incorporating 'rigorous criteria for validating the connections between one element and another' (Dettmer, 2007: 31). TOC is a means to predetermining the effects of change, by identifying cause-effect relationships (Davies et al., 2005). Derived from the work of physicist, Dr Eliyahu Goldratt, and described in his landmark work What is This Thing Called the Theory of Constraints? (1990) the enduring concepts of the Thinking Processes are testament to their efficacy in solving system problems. Though conceptually TOC remains consistent among TOC practitioners, there is some variation on the ways of applying the tools, and on whether all or a selection of tools are 
applied. This evolution continues, generally in the context of making it easier or quicker for the tools to be applied. The development of computerised programmes such as Dettmer's (2007) TLT software has also derived some changes.

\section{A Focus ON THE CONSTRAINT}

Despite ongoing debate on ways of applying the suite of TOC tools, TOC appears to derive its strength as a systems framework from its fundamental philosophy that every system has a core problem or constraint that dominates the entire system (Mabin and Balderstone, 2000). Goldratt's (1990) and later versions of the Thinking Processes (Goldratt, 1992; Cox et al. 2003; Dettmer, 2007; Kendall, 1998; and Scheinkopf, 1999) are united in that they provide a logical and systematic methodology that enables the researcher to focus on the critical constraint and deal with it to 'get the best out of the whole system' (Mabin and Balderstone, 2000:2).

Although Goldratt promoted the TOC Thinking Processes as a way to promote continuous improvement in industry, he also believed that they could be applied to just about any aspect of daily life as a means to improve outcomes. Scheinkopf (1999:25), Dettmer (1997:12) and Kendall (1998:203-236) highlight TOC's value in overcoming the constraints of running non-profit organisations, suggesting that non-profits can seek out and deal with undesirable effects (UDEs) affecting 'throughput'. Their argument is that although throughput has been defined as the 'rate at which the system generates money through sales' (Cox et al. 2003:372) it does not, in fact, have to have a monetary connection. Scheinkopf (1999) suggests that throughput carries a broader definition, related to the attainment of purpose. An indicator such as membership numbers could be substituted for money through sales, providing the required tangible evidence of achievement of purpose, or otherwise. Kendall (1998) describes the throughput of the Scarborough Public Utility, a non-profit, in terms of 'value delivered to customers'.

The idea that the systematic approach of TOC could be applied as effectively to the problems of a non-profit organisation sparked the researcher's interest in applying TOC to problems in managing urban water systems more sustainably. TOC has the potential and the flexibility to deal with changing problems, actors and settings, valuing hard and soft data that involves economic, social and ecological factors, and does not exclude intuition.

\section{Pai nting A ‘Bigger Picture’ usi ng the CRT/ B and the eC}

Dettmer (2007), Cox et al. (2003), Scheinkopf (1999) and Kendall (1998) depict TOC as a straightforward thinking framework that 'paints a bigger 
picture', enabling a whole system interpretation. Hence, patterns, trends, events, structures, mental models and assumptions affecting the system and its goal may be scrutinised systematically with the TOC tools. Using the TOC thinking processes, the constraints affecting the best functioning of the system are able to be identified by the people close to the system (the stakeholders). Once one to three core constraints are recognised, then the necessary actions can be determined that will gain the most desirable outcomes.

The TOC methodology provides the means to sift valid from invalid assumptions. A premise behind applying the TOC thinking processes to understand systems is an acknowledgement that problems, symptoms and cause-effect relationships exist, and that it is both possible and necessary to identify one or two core constraints or root causes (Dettmer, 2007). The Current Reality Tree (CRT) or a branch of this (CRB) has been used in this regard and more recently, in combination with the CRT or used on its own, the Evaporating Cloud (EC) has become a popular way to uncover the most critical issues and their undesirable effects. Arguably, the most simple of the TOC tools, the EC requires that a common goal or vision can be agreed by both sides of a conflict or tension situation. The step-by-step methodology maps organisational and individual goals and agrees the necessary conditions or prerequisites, and a set of assumptions around them. Using this approach, a picture of the system conflict develops in a transparent fashion that can be readily understood by the system stakeholders. A key premise for articulating conflict in an EC is that diametrically opposed views may be underpinned by erroneous (referred to as invalid in TOC terminology) assumptions. Explicitly stating and understanding the assumptions underlying the two opposing sides of a dilemma can therefore reveal opportunities that will lead to better outcomes for the system.

\section{Application}

The EC appears to demonstrate particular value for research where the researcher has ongoing interaction with the subjects and must quickly synthesise conflicting viewpoints and their background with clarity and accuracy. It can be used alone or when required, combined with other TOC tools to examine conflict and reveal solutions. The core conflict cloud is a modified version of the EC, involving first identifying what the root cause of all the system problems might be (some practitioners combine this step with the five focusing steps), and then preparing a 'core' CRT to show how the conflict leads to observed symptomatic effects. Shoemaker and Reid (2005) found that the core conflict cloud revealed the 'significant majority of the identified UDEs' (undesirable effects) in their study of a public service organisation. In this example, the researchers worked with water utility workers and customers 
using the EC, and found they could expand the services of the utility by using 'non-traditional resources', such as training the customer services team to advise their customer how to turn off their water, so unnecessary urgent callouts were reduced. This 'injection' was embedded in the core CRT, which arose from preparing a number of ECs with customers and workers, based on the goals for each department, and having reached consensus on an overall goal for the organisation. The injection was able to be further validated through preparation of the Future Reality Tree (FRT).

\section{ReACHI NG THE SySTeM Goal}

All of the TOC thinking process tools combine to assist with mapping the necessary sequence of actions required to achieve the desired goal (Mabin et al., 2006). However, as Scheinkopf (1999:223) suggests, which tools are chosen depends on the context of the research problem.

H. William Dettmer, in his 2007 book The Logical Thinking Process, has reformulated some elements of the TOC Thinking Processes in order to reduce the complexity involved in constructing what can be cumbersome and timeconsuming reality trees to depict current and future situations. However, as discussed above, Dettmer (2007) insists that the TOC practitioner should never neglect the first step in conducting research with invited participants generating a map of the necessary conditions (or the intermediate objectives, otherwise known as IOs) to attain the system goal. Dettmer refers to this set of objectives as a destination or IO map.

The TOC methodology offers a complete set of problem solving tools and logic rules, which are described below: The Five Focusing Steps, IO Maps, Current reality Trees (CRT), Prerequisite Trees (PRT), Future Reality Trees (FRT), Transition Trees (TT), and the Categories of Legitimate reservation (CLR). For a description of the tools and rules, and how to apply them see Cox et al. (2003), and for a slightly different perspective see Scheinkopf (1999), with Dettmer (2007) providing further variation on the TOC methodology.

Following Scheinkopf's (1999) recommendation to select only the tools that are necessary, five of the TOC suite of Thinking Process tools were selected and applied to the system issue. These contribute to the research design for this thesis and comprise: the five focusing steps (see Scheinkopf, 1999:7), which guided the formulation of questions for the participants, the aforementioned IO map refined at various stages of the research process, the Evaporating or Conflict Cloud (EC), two Current Reality Trees (CRT/B) and the Prerequisite Tree (PRT). The five focusing steps are 'based on the reality of physical constraints' (Scheinkopf, 1999: 17) and involve identifying the weakest link in the system, the constraint that once removed, would provide the greatest 
measure of system improvement. The five steps follow an iterated progression with system improvement as its premise.

The IO map comes next. It paints a picture of the ideal system from the perspective of those interviewed. Once this map is negotiated, the next step is find out what is actually happening in the system and where the gaps are between 'where we would like to be' and 'where we are' (Dettmer, 2007). This step involves analysing the cause-effect logic relationships between problems or constraints and objectives with the aim of foreseeing and forestalling problems and undesirable effects. The Current Reality Tree (CRT) is an important TOC tool, which provides the basis for understanding complex systems and identifying the undesirable effects within them (Dettmer, 2007), while the Current Reality Branch has the same basis, but is described as reflecting that part of the system most at risk of affecting the goal.

Construction of the CRB/CRT may take place before or after that of the EC, and is a useful complement to it. This investigation required the user to construct a branch of the CRT (the CRB), which was carried out before the EC, as per Dettmer (2007), with a more detailed CRT prepared after. Constructing the PRT was the final step in this research.

\section{Capturing Feedback}

A systems study may benefit from some way to show positive and negative feedback (Dettmer, 2007). Thus, Dettmer (2007) incorporates feedback loops in the various TOC diagrams, such as IO and CRT maps. Feedback loops 'help set up the conflict' (Cox et al., 2005) described by participants. It was decided to follow Cox et al., 2005:53 and use causal loop diagrams (CLDs) to indicate positive or negative feedback. An archetype model (Senge, 1994 and 2008) describing the 'fixes that backfire' was settled on as a means to depict feedback. Preparing a CLD showing a 'fix', and then depicting the negative feedback (or balancing loop) can assist in surfacing the missing conditions that would continue to jeopardise the goal if they were not recognised and dealt with. Cox et al., (2005: 53) argue that depicting feedback in a causal loop can be a viable alternative to the CRB, when the details might hide the bigger system at work.

\section{SUMmary Of ApProaches by Practiti ONers}

Three leading TOC Practitioners reviewed by this researcher offer slight variations in the steps they take to carry out a TOC analysis:

Dettmer (2007) says:

IO map -> CRT -> EC -> FRT -> PRT -> TT/Executive Summary Tree 
Scheinkopf (1999) says:

System boundaries and purpose -> EC -> CRB (CRT) -> (CLD) -> FRT -> PRT $->T$

Cox et al. (2003) says:

Business system model $->$ EC/EC/EC (Generic Cloud of 3 ECs or Core Conflict Cloud) -> CRB/T -> EC -> FRT -> PRT -> TT -> IO map for System Improvement

The researcher has borrowed from the three models as suitable for the research context. The approach was more influenced by Scheinkopf (1999) and Dettmer (2007). However, some characteristics are shared with Cox et al. (2003), inasmuch as the authors' eight TOC questions were adapted for this thesis, and a final IO map was prepared.

\subsection{LEADERSHIP AND TOC IN MANAGI NG SYSTEMS}

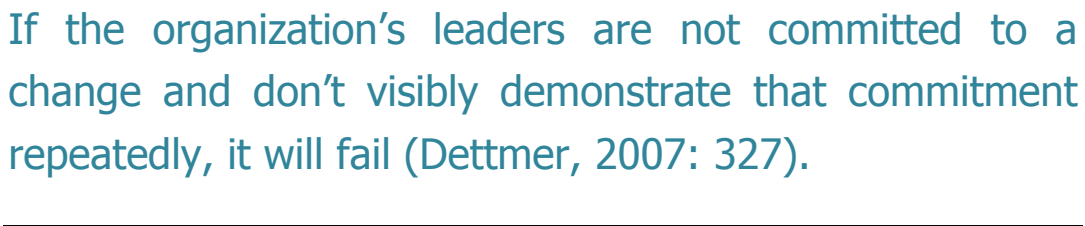

Leadership is embedded in the organisational ecology (Burgelman, 1991 and Heifetz, 1994:24) and is a critical component of change. Within any complex organisation or 'systems ecology' (Burgelman, 1991), it must be acknowledged that the absence or presence of sound and involved leaders makes a difference to outcomes. Early in this investigation, it emerged that leadership was perceived as an issue that the TOC thinking processes might shed light on.

\section{Right now the new governance works well [...] we have a good leader in the new Mayor, but where is the information coming from? We need information in the right place at the right time - we need good quality knowledge that makes sense - Participant}

Dettmer (2007) suggests that TOC success stories go hand in hand with sound leadership and stresses the significance of leadership, as it affects change, and as it impedes or enhances the effectiveness of a systems approach. TOC is 'most beneficial' 'as a leadership tool', according to Mabin, Forgeson and Green (2001: 185). The authors contend that 'clear vision' is required to initiate and 
manage change (the IO map would provide this vision) along with a systematic approach to managing resistance. TOC can provide an overall framework to utilise resistance, according to Mabin et al. (2001). The authors' work focused on managing change in a bank merger environment. They concluded that resistance can in fact be harnessed to facilitate change, and that 'TOC can be very useful for answering the question how to lead change?' (Mabin et al. 2001: 189).

In accepting the view that there is a compelling relationship between leadership and change, and that resistance is a precursor to change, one may then accept the utility of embedding the 'contested concept of leadership' (Jackson and Parry, 2008) within the TOC systems framework. This acceptance is underpinned by the notion that sustainable natural systems are ultimately a vision or goal for the future and that leadership plays a part in articulating and achieving that vision. On this basis, some form of leadership may be viewed as an undisputed necessary condition to achieving the system goal and the research design has been reflective of this. This study attempts to discover the kind of leadership participants believe is required, and in what part of the system an absence or presence of the necessary type of leadership would have the most direct affect on the system goal. The TOC Intermediate Objectives (IO) map (see Dettmer, 2007) offers a means to 'think through' the answer to this question with participants.

\subsection{IDENTIFYING STAKEHOLDERS WITH A STAKEHOLDER TYPOLOGY}

Rawlins' (2006) award-winning review of the literature in stakeholder theory, stakeholder management, and public relations led him to observe that studies in these three areas are not consistent in the way they identify key stakeholders or publics. Rawlins (2006) focused his review on attempting to answer the question How much attention does each stakeholder group deserve or require? In Rawlins' words:

Once organizations have identified their stakeholders, there is a struggle for attention: who to give it to, who to give more to, and who to not give it to at all. Sacrificing the needs of one stakeholder for the needs of the other is a dilemma with which many organizations struggle. When these conflicts arise it is important to the success of the organization that it has prioritized each stakeholder according to the situation (Rawlins, 2006). 
Thus, Rawlins, (2006) presents an interpretation of a stakeholder typology that 'prioritises stakeholders through a four-step process':

1) Identifying all potential stakeholders according to their relationship to the organization

2) Prioritizing stakeholders by attributes

3) Prioritizing stakeholders by relationship to the situation

4) Prioritizing the publics according to the communication strategy (Rawlins, 2006)

Stakeholders have been described as 'any group or individual who can affect or is affected by the achievements of the firm's objectives' (Freeman, 1984; and see Elias, Cavana and Jackson, 2002:303). Freeman's (1984) groundbreaking work on stakeholder identity as an element of strategy raised the proposition that one generic stakeholder map could be prepared around one strategic issue and that stakeholders could be recognised according to the two dimensions of 'interest' and 'power'. Mitchell et al. (1997) are also notable for their contribution to the area of stakeholder analysis, with Agle et al. (1999) providing empirical evidence as to the effectiveness of Mitchell et al.'s 1997 theoretical model of stakeholder dynamics. Mitchell et al. (1997) had developed Freeman's concept of stakeholder dimensions, arguing that classes of stakeholder can be identified according to how many, if any, of the following three attributes they display:

$>$ Power

$>$ Legitimacy

$>$ Urgency

Power means the ability to impose will in a relationship; coercively, normally, or through utility.

Legitimacy according to Suchman (1995), is where there is a general perception among related parties that the 'actions of the entity are desirable, proper or appropriate within some socially constructed system of norms, values, beliefs and definitions' (in Elias 2002:304). 
Urgency suggests Mitchell (ibid.) is the degree to which stakeholder claims call for immediate attention. Urgency is the dynamic component in the process that enables stakeholders to attain salience in the minds of managers, based on the assumption that managers are more likely to react to immediate problems or opportunities than long term ones.

Elias et al. (2002:304) discuss these attributes and present a stakeholder typology based on the measure of attributes. The typology is tested using a case of Research and Development that addresses issues of congestion, safety and community severance along State Highway One between Paremata and Paekakariki, north of Wellington. Combining Freeman (1984) and Mitchell et al.'s (1997) approaches to stakeholder analysis, Elias et al. (2002) demonstrate a systematic methodology for analysing stakeholders, which is based on the participant's interest in the system issue, and measured by the attributes they display, balanced with the attributes of each of the other stakeholders.

Elias et al. (2002) describe their approach as using Freeman's (1984) three levels of analysis: rational, process, and transactional; and incorporating Mitchell et al.'s (1997) framework for interpreting stakeholder dynamics to determine stakeholder salience or 'the stakeholder management capability' (Elias et al., 2002:309) within the project under scrutiny. The authors' testing of the combined methodologies is an attempt to provide a systematic and meaningful way to answer the questions: who are the stakeholders; what are their interests; and how might these change over time? (Elias et al., 2002:309). The researcher reviewed Rawlins (2006) and Elias et al. (2002) with a view to answering similar questions.

Essentially, three categories of stakeholder require representation in this investigation (Elias et al., 2002). The first are members of the public or consumers. The second are members of the managing authority. These stakeholders would be representatives from local government. The third category is the legislative authority. In the context of the urban water system, this would involve representation from central government. All three categories exercise some degree of authority over, or a legislative interest in the success of the system under investigation for this thesis.

In New Zealand communities, authority can be legitimised by gaining the right to vote or to have submissions heard, so community members may gain authority (or salience), and they may also lose it. The concept of interpreting stakeholder dynamics is based on the premise that the salience of stakeholders changes according to their involvement with the strategic issue: stakeholders may join, while others may terminate their involvement, submissions may carry weight, or not, with the measure of power, legitimacy and urgency varying 
accordingly. The following model presents Rawlins' (2006:4) interpretation of the first in a four step strategy for identifying stakeholders by relationship. This linkage model serves as a model to compare and contrast with the generic model tested in Elias et al., (2002) and reproduced later.

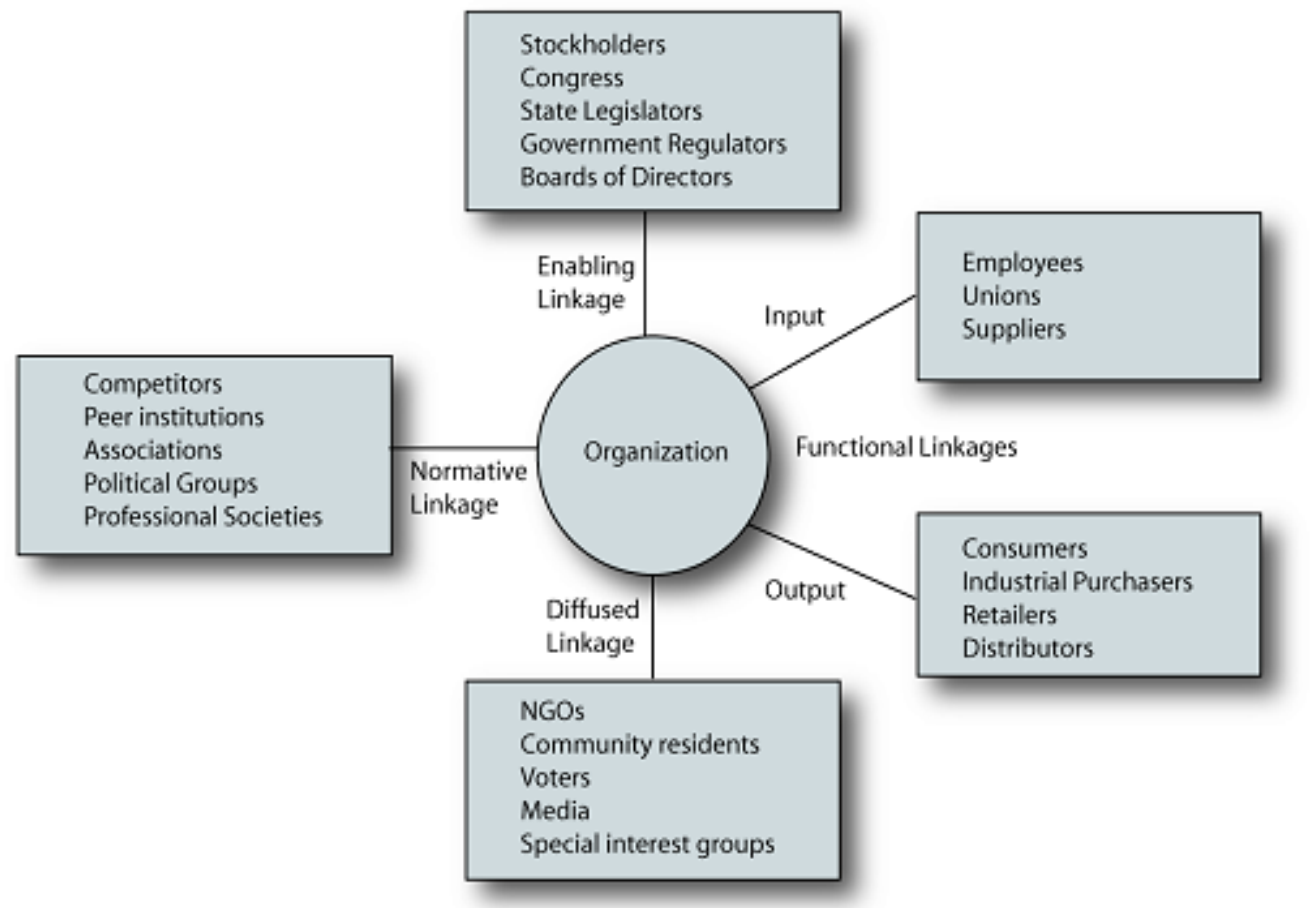

Figure 3: Stakeholder Linkage Model (Rawlins, 2006:4)

The enabling linkages identify stakeholders who have some control and authority over the organization [...] These stakeholders enable an organization to have resources and autonomy to operate. [...]

Functional linkages are those that are essential to the function of the organization, and are divided between input functions that provide labor and resources to create products or services (such as employees and suppliers) and output functions that consume the products or services (such as consumers and retailers).

Normative linkages are associations or groups with which the organization has a common interest. Stakeholders in the normative linkage share similar values, goals or problems and often include competitors that belong to industrial or professional associations. 
Diffused linkages are the most difficult to identify because they include stakeholders who do not have frequent interaction with the organization, but become involved based on the actions of the organization. These are the publics that often arise in times of a crisis. This linkage includes the media, the community, activists, and other special interest groups (Rawlins, 2006:4).

While, the linkage model appears to accommodate complexity, for this management problem, the researcher initially favoured using the simple and generic structure of the stakeholder map first presented by Freeman (1984), and in Elias et al. (2002). Specific stakeholders linked with the strategic issue were identified according to the ten categories that appear in the figure below. Note the two directional arrows, illustrating the nature of the relationship between the stakeholder and the system issue.

The following figure reproduces the stakeholder map for the Road Pricing R\&D Project that appears and is tested in Elias et al. (2002: 305). An adapted version of this map, substituting 'urban water system' for the strategic issue, is in the analysis.

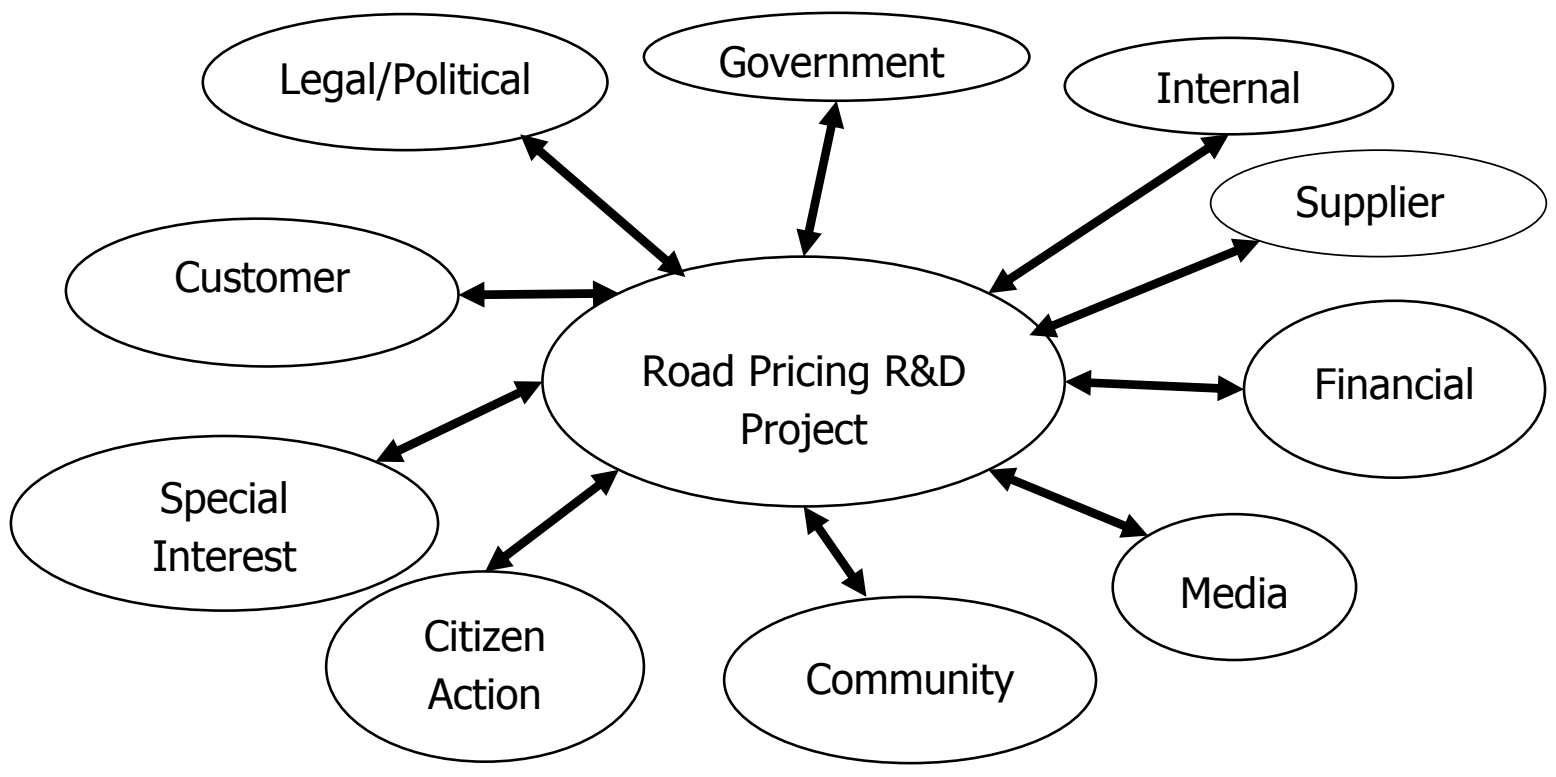

Figure 4: Stakeholder Map of the road pricing project (Elias et al., 2002:305) 
A second step in Rawlins' stakeholder analysis is to prioritise by attributes. This model, as it appears in Rawlins (2006), is almost entirely consistent with the attribute model in Elias et al. (2002). Rawlins (2006) suggests using the combination of the three attributes of power, legitimacy and urgency to develop a strategy to prioritise stakeholders. Latent stakeholders possess only one of the attributes; expectant stakeholders possess two attributes, and definitive stakeholders possess all three attributes.

Elias, et al. (2002) apply Mitchell et al.'s (1997) typology of stakeholder salience to consider whether stakeholders are dormant (power only), discretionary (legitimacy only), demanding (urgency only, dominant (power and legitimacy), dangerous (power and urgency), dependent (legitimacy and urgency), definitive (all three attributes). If individuals or groups do not possess any of the attributes, they are not considered stakeholders.

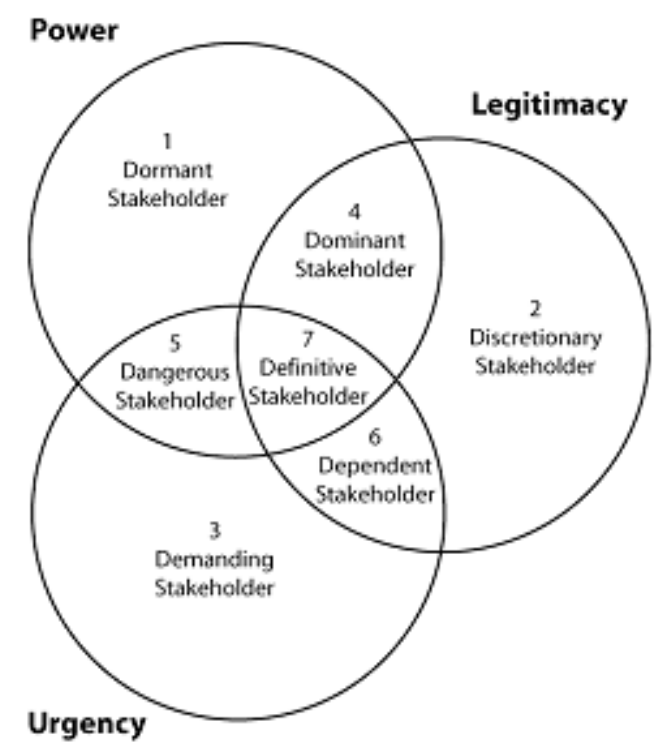

Figure 5: Stakeholder Typology (Mitchell et al., 1997)

Two further steps complete the stakeholder analysis, according to Rawlins (2006): Step three; prioritise stakeholders by relationship to the situation, and step four; prioritise publics by communication strategy and combine to categorise by the type of situation and by the type of public.

This investigation did not require communicating with 'publics' as would be desirable for Rawlin's research field of public relations. Thus, step four is not reviewed further in this paper. However, step three is relevant. This step considers the extent to which people connect themselves with the issue and whether they think they can do something about it (Rawlins, 2006). This would appear to indicate that situational experience is valued. Hence, despite there 
being no explicit connection between stakeholders and the specific system, the extent of similar experience and particularly, demonstrable understanding of a situation, is considered a 'normative' (Rawlins, 2006) linkage. The researcher viewed this as an important element of the stakeholder typology in terms of the strategic issue under investigation. The normative linkage may identify people with a contribution to make or something to gain from a strategic issue, through their common interest: this could be a shared goal or experience. This investigation identified a number of people external to the case study area, including two farmers from a rural setting, some distance from the case study. The farmers' connection to similar goals and experiences of the urban community of Kapiti identified them as having stakeholder salience, perhaps more than farmers and horticulturalists in the case study region, who generally have ready access to water, and have not undergone significant hardship or necessary change, due to climatic conditions in their region.

The question of linkage is approached in Elias et al. (2002) via the generic map that identifies stakeholders, based on whichever of the ten stakeholder groups they represent, by their connection to the one strategic issue, and by considering the dynamics of legitimacy, power and urgency. The typology in Elias et al. (2002:308) therefore also provides the opportunity to prioritise a specific stakeholder, according to their level of experience with a similar strategic issue, but it does not appear to go so far as Rawlins' (2006) linkage model to validate the stakeholder relationships, other than at the attribute level.

Elias et al. (2002) propose that the stakeholder engagement process is managed through rating the level of attributes at any one time and determining how salient the stakeholder's views are in that moment in time. For the purposes of the research problem, the researcher concluded that the salience was a useful theme to understand, but of lesser import than the need for both public and private interests to be fairly represented in the context of this type of community problem, with a balance of perspectives desirable. Thus, potential stakeholders were selected according to their representation in three groups: consumers, the managing authority and the legislative authority, and then Elias's (2002) stakeholder map was used, ensuring representation in each of the ten categories. Finally, the stakeholder dynamics and the various linkages (enabling, functional, normative, and diffused) were considered, ensuring there was a fairly even distribution of attributes. The process and transactional analyses conducted in Elias et al. (2002), as a means to determine stakeholder capability, though valid for the strategic issue of concern to their research problem, was thought to be beyond the requirements of this study. 


\subsection{THE CASE FOR STAKEHOLDER ANALYSIS - SUMmARY}

A systems view requires that a broader, deeper perspective is formed. It is desirable to construct a 'picture' of the patterns, trends, events, processes and mindsets and assumptions (Senge, 2008: 173) that can categorise what is happening in the system and what should be happening. Surfacing veiled assumptions and perceptions from unlikely participants, through the use of a stakeholder typology, may serve to identify deep-seated constraints that otherwise remain hidden from view. To fulfil the research objective, the stakeholder typology needed to balance stakeholder participation across the three elements of legitimacy, power, and urgency, and also consider situation, common interest and diffused relationships. This was accomplished by using the following steps 1) Preparing a stakeholder map, 2) drawing up a stakeholder chart of prospective stakeholders, 3) preparing a grid of specific stakeholders and 4) using the stakeholder typology (Rawlins, 2006; Elias et al. 2002) to better understand the stakeholders and their relationship attributes in terms of the system problem. The Stakeholder Typology for this thesis investigation is presented in the Analysis, while its contribution is discussed in the Conclusion.

\subsection{THE CASE FOR MANAGIng SYSTEMS WITH THE THEORY OF CONSTRAINTS - SUMMARY}

The performance of a system depends on a few constraining factors (Ronen, 2006). TOC meets the requirement for a straightforward thinking framework to identify these constraints. It enables a whole systems view, where changes are taken account of in all parts of the system, focusing on a few key areas as levers, without losing sight of their system-wide impacts. With the TOC thinking processes, the necessary actions can be determined that will deliver the most desirable outcomes.

Sustainable Management is required for the public sector to meet its goals to treasure, protect and enhance the environment (DPMC, retrieved 19 February 2008). The Theory of Constraints offers a robust framework and a set of thinking process tools to identify constraining factors to achieving more sustainable systems. The thinking processes provide the means to thoroughly understand the system and to improve it by surfacing assumptions and revealing their undesirable effects that prevent the system from meeting its goal. Viewpoints and perceptions from various institutions and community members that influence the urban water system's performance identify what in the current system is performing well and what is not, what part people play in the system, what are the significant 'wants' and 'needs' and what is the overall goal of the system. Thus, participants together paint a picture of the urban 
water system now and in the future. By using the TOC thinking processes to develop a precise picture of 'what to change' and 'what to change to', a stepby-step 'road map' for change can be created (Mabin et al., 2001:171). This can guide the system participants in making the changes required. 


\section{Chapter Three - Methodology}

\subsection{NTRODUCTION}

This chapter describes the study's research methodology. It begins by describing the researcher's motivation to conduct a study of this kind and presents the rationale for the research design. The manner of data collection is presented, together with the process of managing and articulating the rich and varied perspectives gathered during eighteen interviews with twenty participants.

\subsection{The Thesis Purpose Statement}

This qualitative study tests the use of the TOC (Theory of Constraints) systems framework and a stakeholder typology to examine ways that communities can create better outcomes from their investment in urban water management initiatives. The thesis demonstrates the methodology by focusing on Kapiti, a coastal settlement north of Wellington, which has been actively debating and responding to serious water security issues for more than a decade.

\subsection{THE RESEARCH DESIGN}

Kapiti is an area the researcher knows well, a motivation in the choice of system to study in depth. In 2006, while working as a researcher and writer for a publication on household sustainability, the researcher was struck by the volume of letters to the editor and media reports regarding Kapiti's water issues (see particularly the Kapiti Observer). Public interest, discussion, and conflict seem to have increased with time, possibly fuelled by the heightened acknowledgement of the potential effects of Climate Change and due to rapid growth that it appears, has yet to be matched by infrastructure investment.

The researcher's proximity to the subject under investigation influenced the research design. Being part of the social fabric under investigation has the potential to deliver a degree of subjectivity that good research should not reflect (Tolich and Davidson, 1999). On the other hand, it is widely accepted that 'understanding the world begins with daily experience' (Tolich and Davidson, 1999:37). A theoretical framework was required that would accommodate self-interest and offer an element of 'testability'. Furthermore, as the literature examined noted that difficulties in making decisions about managing urban water involve understanding behaviours as much as understanding technical factors (Watercare, 2008; Brown and Farrelly, 2007; Slaney and Weinstein, 2004), the design had to identify the assumptions that were behind the constraints on the system and validate them or otherwise. Finally, the design had to provide for reflexivity (Bassett, 1995:1528), with the 
investigation involving the researcher having an 'ongoing conversation' with some of the participants in order to test the framework and the 'solutions'. The researcher therefore settled on the framework that had worked so well for her own personal dilemma (see the introduction).

The research design had to capture some or all of the following, based on the literature, the researcher's intuition, and her experiences at Council water workshops:

$>$ Perceptions and expectations about rainwater tanks and about water meters (in reference to council plan changes);

> Understandings and expectations about the water cycle and about systems that recycle or redistribute water. In Australia for example, desalination has become popular, and the relevant agencies have only recently begun to monitor ecological or climatic impacts caused by removing the salt from quantities of water and discharging changed water somewhere else (see Kandel, 2003 and Walker, 2006 for the relevance of this);

$>$ Understandings and expectations about urban water - where it comes from and where it goes (in reference to Thomas et al., 2007);

$>$ Education: What could the Council and other managing authorities do better, what are they getting right? Is there enough education to support the Council strategies to conserve water? Is central government doing enough/anything to encourage people to use less water? Does Education make a difference? How much?

> Assistance and incentives to conserve water: What is happening now, what should happen?

Subsequent to a piloted investigation, a methodological framework was proposed, based on integrating three potentially complementary perspectives. It was proposed to combine the Theory of Constraints (TOC) with a Stakeholder Typology to identify 'typical' and 'atypical' system stakeholders, capturing and representing their perspectives using the TOC Thinking Processes, while Causal Loop Diagrams (CLDs) from Systems Dynamics, constructed with some participants, could be used to explore and ideally, circumvent, potential negative outcomes. Thus, a case study in a community resource management setting is described that tests the value of the combined framework. 


\subsection{THE STAKEHOLDER TYPOLOGY}

The TOC methodology can aid the researcher in making sense of complexity to determine the current reality. Its techniques are tried and tested by practitioners and managers to aid the design of interviews and analyse the resulting data. However, TOC is by and large a business tool and makes the assumption that the researcher has the information required to identify the required participants. Managing the urban water system involves managing the complex relationships among stakeholders (Painter, 2004). Therefore, a second theoretical framework was introduced to assist with identifying the appropriate participants to interview from among a diverse group of potential candidates, all stakeholders of the system under investigation.

The decision to include a methodology that assisted in selecting participants for the study emanated from a dilemma that must face many researchers: who must be interviewed, within the limits of the budget, the timeframe and the thesis requirements? The aim of the researcher was not only to test the TOC framework and to produce a thesis, but also to make a contribution to the way decisions are made about New Zealand's fresh water. For this reason, the researcher identified a type of hybrid stakeholder framework that appeared to offer a robust method for selecting the most appropriate people, with value to contribute. The aim of combining the methodologies was therefore, to gather the perspectives that would be representative for the water system concerned and surface a pattern of reality not limited to, or by, any homogeneity of the interviewees.

The Stakeholder Typology described and tested by Elias et al. (2002) in their study of stakeholders in a Research and Development project on congestion and community severance problems in the Wellington region, appeared to offer the means to achieve the research aim stated above. Particular benefits of a stakeholder typology to this investigation are that it offers a methodological platform that it takes account of the external environment 'in a systematic way' (Elias et al. 2002:304). A generic and systematic process is provided for identifying potential stakeholders that takes account of both implicit and explicit relationships, therefore not discounting the stakeholder with an experiential ('situational' or 'normative linkage' according to Rawlins, 2006) relationship with the research problem. This situational experience (validated by reference to Rawlins, 2006) raised the possibility of interviewing farmers from a different catchment. Hence, the Starbrough Flaxbourne farmers were invited to participate, according to their experiences in dealing with a long and severe drought. The story of the Starborough Flaxbourne experience was presented at a Ministry for the Environment award ceremony attended by the researcher in 2008, immediately following preparation of the stakeholder 
typology that identified farmers as an important stakeholder group. Hence, the opportunity to gain the perceptions of these farmers was taken. It is notable that most stakeholder organisations identified by the stakeholder typology were known to the researcher, easing the task of identifying and then approaching potential participants to ask them to volunteer to be interviewed.

\subsection{Rati onale for the Methodologi Cal ApProach}

\section{Methodological validity involves asking how well matched is the logic of the method to the research questions and their explanations (Bloomberg and Volpe, 2008:86).}

The researcher wished to adopt a way of explaining reality (Senge, 2008:174) that would investigate the deep level assumptions of the actors involved, finding connections between the assumptions and the critical problems that lie in the way of meeting the system goal. Accordingly, the stakeholder typology (Elias et al., 2002:309) was applied to determine a purposeful selection of community members and other stakeholders, who were then personally invited by the researcher to take part in the study. Taking account of all the factors described above led to the study design based around personal interviews which included the surfacing and validating of a great deal of information, for which TOC appeared to offer a fitting theoretical foundation. TOC is a widely acknowledged framework for thinking about and understanding complex systems (see Dettmer, 2007; Mabin et al., 2005). Its rationale in this context was to identify the key constraints to gaining better outcomes for the urban water system under scrutiny, but not to limit the research's application to other areas.

As the intention was to study a complex water system and its problems, with diverse interests and understandings inherent, the methodology needed to value everybody's viewpoints equally, while revealing the rich knowledge and veiled assumptions that hold potential to overturn constraints when challenged logically. In observing the issues and complexities, the media attention, and the evident polarisation around particular concerns like water metering, the researcher reasoned that a deep, systemic understanding of the people, events, patterns, trends and mental models was required (as depicted by the iceberg model in Senge, 2008:174). The methodology also needed to be uncomplicated because it requires close stakeholder involvement. By informing thinking and efforts through the use of an appropriate and straightforward thinking methodology, managers might be better equipped to more effectively 
design and facilitate the necessary conditions for better outcomes for urban water systems in New Zealand.

The assumption was made that community wellbeing, and therefore community success, depends on reliable access to wholesome water now and in the future. With this in focus, the researcher addressed the following two research questions:

$>$ Can a systems-thinking framework, in this case the Theory of Constraints used with a stakeholder typology, aid managers and the community in their decision-making to gain better outcomes from their investment in urban water management?

Dhat are the most necessary conditions to improve outcomes for Kapiti's urban water systems?

\subsection{RESEARCH ObJeCtIVES}

The research objectives are to logically describe and understand:

> The current system (what is the destination and what to change?)

> The system objectives and common goal, along with the underlying necessary conditions (what to change to?)

> The critical issues that are perceived as barriers to attaining the desirable system goal

> How to make the change happen, by homing in on the critical issues and necessary conditions using systems thinking, necessity logic and cause and effect logic.

\subsection{DesCri PTI ON OF THE SAMPLE POPULATI ON OF Volunteer Parti CI PaNTS}

The researcher reasoned that though a survey of randomly selected participants in the case study area would be a valid means to surface the perspectives of a representative group of community members; a survey was an expensive instrument for a master's thesis and would not have yielded the depth required for a TOC analysis.

The outcome of the stakeholder typology was to reveal the following participants should be involved:

> Department of Building and Housing (DBH),

$>$ Ministry of Health $(\mathrm{MOH})$ and the

$>$ Greater Wellington Regional Council (GWRC); 
> Managing stakeholder Kapiti Coast District Council (KCDC)

> Managing iwi (mana whenua - see glossary)

$>$ Other participants selected because they have some stake in the water system under study, or they have a stake in a comparison system in Seddon, Marlborough.

This research involved acquiring qualitative data and presenting it in the TOC framework. Systematic analysis and crosschecking with respondents then validated the data. The rationale for such a scientific approach to qualitative research is provided by Huberman and Miles (1998). They describe subjectivity, when unaccompanied by transparency, as limiting the value of applying one area of research to another area. Valid and reliable research is therefore maintained through:

$>$ a reflective overview of sampling and analytic processes

$>$ clear reasoning regarding the value of the literature reviewed

$>$ a rationale of how data applies to supporting the conclusions of the study (Cavana et al., 2001:136).

$>$ an approach to the research design that is trustworthy and ethical (Denzin and Lincoln, 2005).

Adhering to the principles, advances the value the study provides to the organisational literature on decision-making, and to the broad field of resource management.

\subsection{Summary of the I nformation Required to Conduct the Study}

The Kapiti community has particular value as a case study, due to the managing District Council since 2001, having commissioned a number of scientific reports about parts of the water system (of six key reports, some have been referred to by participants or were sourced as background to the research design and are therefore referenced). An additional factor is the record of consultation with the community and a number of notable and not entirely successful decisions that could bear analysis.

A notable milestone for Kapiti involved the release of a strategy for managing their water in 2003 (Water Matters). The 2003 strategy provides terms of reference for determining the value of the research methodology used in this study. A report prepared by the Parliamentary Commissioner for the Environment (PCE) entitled Whose water is it? (PCE, 2001) that followed the earlier groundbreaking Leaky pipes and muddy waters (PCE, 2000) provided 
impetus for the Council's strategy document and reveals the background to the problems faced today. Two other essential documents referenced are both by engineering consultants Sinclair Knight Merz (SKM) and dated September 2003 and December 2008. These reports consider the options for securing water to respond to future growth with their top recommendation in both years - to construct storage ponds. This coincides with the key recommendation drawn from this investigation; to build a series of staged storage ponds according to measured demand peaks, but to apply other strategies to deal with the constraint of unreasonable demand.

The Council rates demand had been initially proposed as a cost effective way to survey the public to gain a representative understanding of public perception, knowledge, wishes and desired effects. A survey was not however, required, once the TOC logical process was settled on as a framework from which to design the research. In addition to the interviews per se, a number of participants provided a wealth of other relevant information. This included survey questions, responses and analyses of Kapiti Coast residents' views about their water and wastewater. Paekakariki surveys were undertaken in 2003, with Te Horo residents surveyed in 2004.

\subsection{Ethical Considerations}

With regard to the ethics of the study, an application to undertake the interviews with participant stakeholders in the urban water system was granted after consideration by the Human Ethics Committee for Victoria University, Wellington. In different settings, different moral and ethical principles dominate. Social scientists are advised to adhere to five core principles for determining a desirable standard of ethical conduct (Tolich and Davidson, 1999). This study followed the guiding principles of the Victoria University Human Ethics Committee (see Appendix 7), encompassing those below (adapted from Tolich and Davidson), to ensure the research remained ethically accountable:

$>$ Do no harm

$>$ Voluntary participation

$>$ Informed consent

$>$ Avoid deceit

> Maintain the degree of confidentiality agreed with participants in the research agreement. Participants in this study agreed to their opinions being attributed to their name (with reasoning for this is in the following 
paragraph), although not necessarily to their organisation. This has been taken into account in the reporting of the findings.

Early in the investigation, the researcher applied to the Human Ethics Committee for leave to request participants to be named. All participants subsequently agreed to their comments being attributed to their name, though not all wished to attribute their comments to an organisation with which they were affiliated. Identifying participants is a departure from the generally accepted procedure in qualitative studies. However, the sharing of knowledge and perspectives in a systematic and transparent manner (the researcher adopted the term 'thinking out loud') is in keeping with the intention of the research design: to foster a supportive environment for stakeholder engagement, revealing deep insights and critical understandings by encouraging stakeholder participants to share their 'thinking out loud'.

\subsection{THE I NTERVI EW PROCEDURE}

Participants agreed to answer a set of questions during a semi-structured interview. They were informed that the questions were designed and responses analysed using the logical thinking processes of the Theory of Constraints (Dettmer, 2007, Cox et al., 2003, Shoemaker and Reid, 2005, Scheinkopf, 1999, Schragenheim, 1998 and Goldratt, 1990).

As a first step, the TOC interview protocols were developed. A pilot study with two participants, Stu and Karen, was used to determine the value and sense in the questions constructed. Stan, another participant and an advisor to the study, provided feedback on the questions so they could be refined to gain the desired information. The initial outline for the pilot questions was drawn from Goldratt's Eight Questions (see an excellent description of applying the eight questions to build a picture of the critical realities and assumptions in Cox et al. 2003:90). The TOC five focusing steps (Scheinkopf, 1999: 7) were found to keep the focus on the core issues impeding the system goal.

As a result of discussion with the pilot participants, a set of twelve, rather than the original eight questions was developed. H. William Dettmer, in his 2007 book The Logical Thinking Process, re-formulates some elements of the TOC model in order to reduce the complexity involved in constructing what can be cumbersome and time-consuming reality trees to depict current and future situations. The new questions were designed according to the Dettmer (2007) model and the original eight questions were re-worded somewhat, to reflect context and language use in the interviewer's world. The eight questions as they are usually applied were developed in the United States and exhibit signs of this. The questions were adapted to afford identical outcomes, according to 
the feedback from the two pilot participants, from Stan, and with advice from a fellow Masters (now PhD) student, Garoon Pongsart.

The questions' aim from the outset is to find out people's perceptions of what a successful water system looks like and what are the critical conditions necessary to its existence. This information was used to prepare an Intermediate Objectives (IO) map (as recommended by Dettmer, 2008:22), focused around an overarching goal for the water system that provided the starting point for the study. The IO map is a destination finder - one should always begin any endeavour with the end in mind, according to Dettmer. Hence, the IO map provides a clear picture of the ideal water system in the eyes of the interviewees.

The interview responses provided a great deal of rich and valid data, which was analysed with TOC methods and tools. Some data reduction was necessary in order for the analysis to be manageable and meaningful. Coding is one means to identify the categories of interest or themes and organise data (Tolich and Davidson, 1999:141). By use of thematic coding (see Bloomberg and Volpe, 2008: 101-107; Denzin and Lincoln, 2005; Tolich and Davidson, 1999) the similarities can be assembled and differences noted across the interviewees.

The researcher grouped the data under the categories relevant to TOC - goal, CSF (critical success factors), NC (necessary conditions), UDE (undesirable effects), problems or symptoms, and injections. The statements were then assessed for similarities and differences, so that a number of very similar statements were reduced to one. In this manner, the results of the data were reduced down to a one page IO map that would be as generic for the water system as possible, with the CRB (Current Reality Branch), and an accompanying EC (Conflict Cloud) to identify, analyse and solve the core dilemma. The IO map was shown to participants in an early form, and discussed with a randomly selected few, to determine the validity of each entity. Note that 'an entity is a complete idea, expressed as a statement' (Dettmer, 2007:36). The outcome of the discussions is depicted in later IO maps shown in the analysis. A CRT map completed after the EC showed the gaps between the current and desired realities, with a PRT (Prerequisite Tree) then used to examine obstacles in detail and find ways around them.

Appendix 11 shows the completed table of participants' notated answers to the 12 questions, and other related comments, while also grouping the participants by their combined responses, as used to construct the analysis. The same twelve questions - with minor adjustments in deference to context - were used for in-depth interviews with volunteer participants. Following the stakeholder 
mapping process (Elias et al. 2002; Rawlins, 2006), representatives from appropriate stakeholder groups were selected as interviewees, based on their level of interest in the case study urban water system. There were essentially three categories of stakeholder requiring representation: The first are members of the public (Consumers). The second are members of local government (Managing Authority); namely the Kapiti District Council and the Greater Wellington Regional Council. The third category are linked to Central Government (Legislative Authority) and exercise authority over, or have a legislative interest in, the urban water system, and include the Ministry of Health and the Department of Building and Housing.

Twenty participants were selected using the stakeholder typology and eighteen interviews were conducted. Five or more representatives from each of the three stakeholder categories were interviewed, with all ten sub-categories participating. Although Councillors were not part of the data collection process, two KCDC Councillors contacted the researcher during the data analysis stage and contributed to the process of interpreting data during the step to prepare the Conflict Resolution Cloud (EC). The Stakeholder Typology in Elias et al., (2002) shows Councillors are part of the internal stakeholder group. However, in view of the fact that the 2007 Kapiti elections were seen to be polarised around water issues, it may be fair to assume Councillors are present in both groups - Political and Internal. Initially, the legal political sector did not appear to have representation. However, pilot interviewee Stan Abbott is also an advisor to the Ministry of Health on water quality and risks. Thus, he appeared to fit the Legal/Political sector.

Participants from $\mathrm{KCDC}, \mathrm{DBH}, \mathrm{MOH}$ and GWRC made it clear that the viewpoints expressed by participants were not necessarily the viewpoints of the organisation they belonged to. This finds accord with a key TOC concept; that personal viewpoints and perceptions are desirable and valid, whether the problems are thought to be organisational or otherwise. Another TOC concept relates to the importance of gaining in-depth understanding of the organisations or groups of which participants are part. This does not necessarily mean studying the organisational hierarchy of who reports to whom and why. Organisations are storehouses of expert knowledge, implicit and explicit understandings, interests and viewpoints. The stakeholder model combined with the Thinking Processes offered a logical way to target a crosssection of people and deliver the desired system level understanding of events, structures, patterns, processes, and mental models.

Details of names and the roles of participants are recorded in the table of data, while their organisations and groups are listed here: 
$>$ Ministry of Health - Public Health, Paul

$>$ Department of Building and Housing, Bruce

$>$ Consultants to District and City Councils across New Zealand - Connell Wagner, David

> Kapiti Coast District Council, managing local authority, Gael and Ben

> The Greater Wellington Regional Council, managing regional authority, Tony and Murray

$>$ Residents' Association Member, Stu

> Grey Power Kapiti Coast, Trevor and Betty

$>$ Other Residents, Murray, Bob, Karen

$>$ Members of Kapiti Water Action Group (KWAG)

$>$ Te Âti Awa, managing iwi, Daniel

$>$ Science and legal, Stan

One participant, Paekakariki resident, Bob Zuur, had worked for the Ministry for the Environment when the PCE 1999 and 2001 reports were prepared and was interviewed for the 2001 report. MfE were therefore not approached as an organisation, as it was felt that Bob's views would adequately reflect that part of the typology.

Viewpoints and knowledge were captured from interviews, a group discussion with KWAG members, and a discussion of the findings with two KCDC Councillors. Workshops held by Kapiti Coast District Council provided opportunities to gather further rich input from both Councillors and the Public, aiding the researcher in designing the study, developing the questions and surfacing potential constraints that could be tested using the TOC tools.

\subsection{CHARACTERISTI CS AND RECRUITMENT OF THE PARTICI PANTS}

Personal contacts were the means to recruit participants. A number of participants were included through the researcher attending seminars, conferences and discussion groups (some on water issues). This was useful for obtaining participants with expert knowledge on one or more (but by selection - not all the same) areas of the water system. All the participants were stakeholders in the Urban Water Systems of either Kapiti, or Seddon (in Marlborough) and were selected according to the stakeholder typology described and to an extent because of the 'snowball' effect. Snowballing (Tolich and Davidson, 1999) describes a situation where participants introduce other participants to the researcher. 
Participants were informed by reading the thesis purpose statement and a research question with the background to it in a brief outline document as reproduced below. An information sheet accompanied the outline. Participants were emailed a PowerPoint presentation of the research design and objectives (Appendix 8) following an initial discussion with the researcher and before their interview. It can be helpful to the participant organisations to have the questions or at least the research objectives prior to the interview as it assists the organisation to select the appropriate representative where necessary (Hart, 2005). The information sheet (Appendix 7) was left with the participant, explaining who was carrying out this research and its purpose. Participants were informed of what they needed to do, and of their rights as participants, including being made aware of issues of confidentiality. The participants were provided with contact information for the researcher, the supervisor, and the University.

The following twelve questions are indicative of what was asked of each interviewee:

\section{I nterview Questions*}

1. What is the overall system goal in your view? (The best outcome for the community now and in the future).

2. What are the two or three things that must be delivered on to meet the system goal? (These are necessary requirements or the Critical Success Factors).

3. What key (perhaps three) elements or activities are required to realise the Critical Success Factors? (These are necessary conditions.)

4. Which Critical Success Factors or necessary requirements aren't being met properly in your view?

5. What are two or three obstacles that get in the way of meeting the overall system goal?

6. Which do you see as the most serious obstacle in the way of meeting the system requirements?

7. What is the (undesired) effect of this obstacle on meeting the system goal?

8. Regarding the undesired effect you describe, why do you put up with it?

9. Do you feel there is one overriding objective being jeopardised by the undesired effect you describe?

10. Is there something specific - action/policy/technology- causing the undesired effect?

11. What is the undesired effect in conflict with - if anything? Describe the conflict? Are there two clear opposing viewpoints, what are they? 
12. Can you identify one root cause for the obstacles or conflicts that are getting in the way of achieving the system goal?

* These questions, adapted from Cox et al. (2003:90) and Dettmer (2007: Chapter 3), are designed to be both necessary and sufficient enable the researcher to perform a TOC analysis: to build a cause-effect map of the problem issues, causes and consequences, and to develop a solution.

\subsection{SCIENTI FIC I NTERPRETATI ON}

All the stakeholders' effort and points of view are equally important in deciding the success of any transformation from a problematic management system to a more successful one. However, some stakeholders exert a greater influence on the system, or are more influenced by the system than others, and this may be in a legal or technical capacity. Stan Abbott, Director of Roof Water Research at Massey University reviewed relevant parts of the study requiring technical or scientific interpretation.

\subsection{LIMITATI ONS AND PROBLEMS}

Combining more than one methodology and drawing them together in the research environment in a synchronistic fashion proved challenging, particularly as this researcher had limited experience of stakeholder analysis or CLDs prior to the study. Notwithstanding there are valid arguments against mixing methodologies (Mingers, 2003), equally, there are compelling supportive arguments. Mabin et al., (2006) for example, used the TOC Thinking Processes to complement CLDs to develop 'fundamental solutions'. On reflection, the experience combining TOC with a means of identifying stakeholders and workshopping some of the TOC representations using a simple 'Fix that Backfires/Fails' archetype (from Systems Dynamics) produced a rich and valid 'picture'.

Another perceived limitation that emerged during the analysis relates to the need for a timely approach to capturing and representing data. This was particularly important when the researcher was interacting with some participants, and data therefore had to be represented in the TOC trees or 'Clouds' within a short timeframe. Typically, TOC practitioners propose that a comprehensive Current Reality Tree is necessary to articulate a research situation properly. Thus, effort went into constructing a complex CRT, before it became apparent (following Dettmer, 2007) that a Current Reality Branch (CRB) would capture much of the necessary information, aligning with the 'simple' approach to complexity that was the aim of the research design. This finding reflects a growing mood among TOC practitioners that tools can be selected according to the problem and the context (Scheinkopf, 1999). Cox et al. (2003:162) have described the direct construction of a Current Reality Tree 
as a time consuming task that may act as a constraint to conducting the TOC analysis. Dettmer (2007) proposes a solution to this dilemma, advising that the practitioner should first attempt a Destination (IO) map to assist in pinpointing the area of focus to develop Conflict Clouds and CRBs, reducing the effort required for CRTs. The researcher thus followed Dettmer (2007).

\subsection{The Benefits and Scientific Value of the Project}

Recent and continuing interest in sustaining our natural resources for the ongoing benefit of future generations has produced a wealth of literature on Sustainable Urban Water Management (Chapman, 2003). However, the majority of the literature is exploratory (Brown and Farrelly, 2007). Much research attempts to identify what the barriers are, with small reflection on how to turn barriers into opportunities (ibid.). The studies most quoted in New Zealand are Australian, unsurprising when one considers that Australia is the Earth's driest continent. In addition, Australia's vast mining reserves, although generating much wealth, also diminish water reserves, with desalination and other large scale 'fixes' the focus of much endeavour. New Zealand, on the other hand, has fewer people and less GDP to support desalination plants or other expansive technological efforts to supply more and more water. Cultural perspectives may also be valued differently. Thus, critical constraints and opportunities experienced in Australia may differ compared to New Zealand. Among the more obvious differences are climatic conditions and scale (with climatic influences like drought acting as triggers to behaviour change), in addition to rules and values. Hence, New Zealand must also study its own Urban Water Systems to establish what needs changing here and what outcomes are desirable in the New Zealand context.

\subsection{WhO Might APPLY THE TOC ReSEARCH METHOdOLOGY?}

Environmental Science and Research (ESR) undertake interpretive research into water and wastewater systems from time to time, for which TOC might be a useful tool. At the time of writing in 2008, ESR was involved in studies of the Tasman water system and the wastewater system in Porirua. ESR and similar organisations could usefully augment such research with the logical framework and systematic approach to thorough enquiry provided by a TOC/Systems Thinking approach. The KCDC Councillors who took part in the discussion of findings provided positive feedback that by applying the thinking processes using the Conflict Resolution Cloud, information surfaced that was needed to deal with the dilemma under debate. 


\subsection{SUMMARY}

This research was designed to offer a fresh picture of the Urban Water System and the challenges faced by its managers and the community it serves, by analysing the case of Kapiti through the lens of the Theory of Constraints. TOC, a decision-making systems framework, was combined with a stakeholder typology to probe beneath surface events and take account of complex patterns, trends and mindsets that influence the system. Participants determined by the stakeholder typology were asked to talk about their urban water system. They identified problems and knowledge gaps and decided on a shared system goal with supporting necessary conditions. The TOC tools were introduced to logically identify the constraints and conflicts that impede system performance. Critical problems could be identified and solutions tested, with a view to meeting the high goal of a more sustainable urban water system. 


\section{Chapter Four - Analysis}

\subsection{Introduction}

This chapter provides the outcomes of interviews with all the participants and the results of attending a series of KCDC water workshops, where the issues affecting the community's water system were discussed and debated. The researcher attended the workshops as part of the audience, and did not contribute to the public debate.

\subsection{THE RESULTS OF THE STAKEHOLDER TYPOLOGY}

In accordance with Elias et al. (2002) and Freemen (1984), the stakeholders were divided into the ten categories shown in the Stakeholder map in Figure 6:

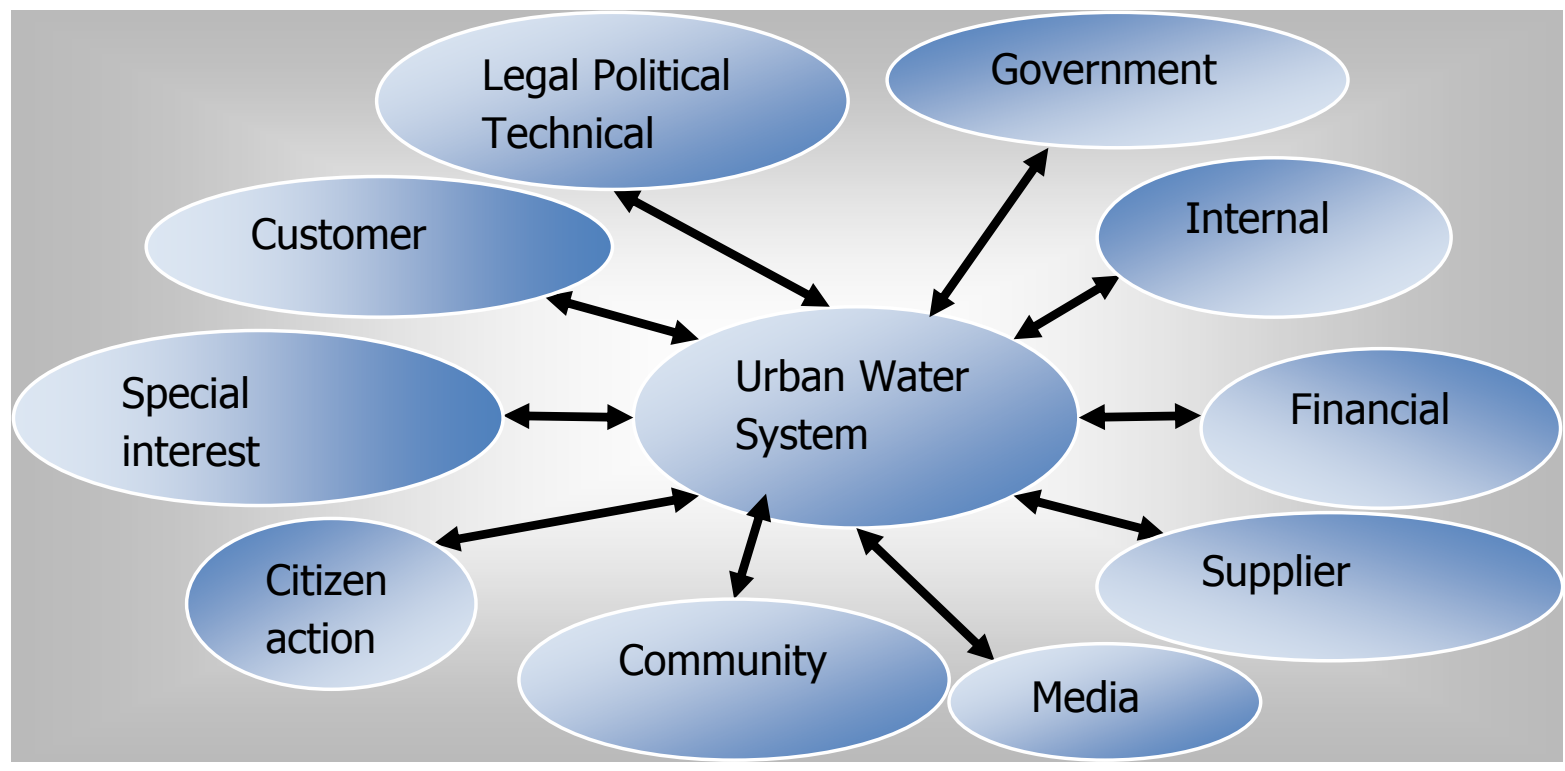

Figure 6: Stakeholder Map

The Stakeholder typology in Figures 8 and 9 was constructed between July and September 2008 to provide a way of identifying and validating stakeholder participants, in the context of the strategic issue under investigation. The typology intends to show the stakeholders by classification of attributes, as they relate to the urban water system. As this is a dynamic process, with stakeholders moving from one classification to another depending on circumstances and timing, the typology of stakeholder attributes is suggestive rather than concrete, acting as a useful adjunct to the (Rawlins, 2006) linkage model.

To fulfil the research objective, it was assumed that the stakeholder typology needed to balance stakeholder participation across the categories identified in the Stakeholder map, and across the elements of legitimacy, power, and 
urgency (see Elias et al. 2002:304). There was also a desire to consider situation, common interest and diffused relationships, following Rawlins (2006).

This was accomplished with the following steps:

1) Preparing the stakeholder map (Figure 6) above that identifies the generic categories of participants with linkages to the urban water system

2) Drawing up a stakeholder chart (Figure 7) of prospective stakeholders by category

3) Preparing a grid (Table 1) of specific stakeholders identified by the researcher as representing the categories

4) Using the stakeholder typology (Rawlins, 2006; Elias et al. 2002) to better understand the stakeholders and their relationship to the system problem (Figures 8 and 9)

Figure 7 (next) shows the Stakeholder chart of prospective stakeholders. 
Internals

- Regional and District Councillors

- Mayor

- Council Staff

- Community Boards

\section{Customer}

- People connected to water supply

- Ratepaying citizens

- Non-ratepaying citizens

- Visitors

- Dischargers

\section{Community}

- Local IWI (Te atiawa \& Ngati Raukawa)

- Farming/Fishing Communities

- Businesses

- Residents

- Recreational Water Users

\section{Financial}

Media

- Funding Sources Rates

- Central Government Funding Agencies

- IRD

\section{Legal/Political}

- Political Parties

- Councillors

\section{Citizen Action}

- Kapiti Water Action group Paekakariki (KWAG)
- Kapiti Observer

- Dominion Post

- Local Radio

- Blogs

\section{Government}

- Ministry for Environment

- Ministry of Health

- Department of Building \& Housing

- Kapiti Coast District Council

- Greater Wgtn Regional Council

- Nearby local authorities

Special interest groups

- Department of Conservation

- Be the Difference Regional Council campaign

- Forest \& Bird

- Greypower

- Residents Associations

\section{Technical/Supplier}

- URS

- Connell Wagner

- SKM

Figure 7: Stakeholder Chart 
Table 1 is the Stakeholder grid showing the specific participant stakeholders relevant to the Kapiti Urban Water System.

\begin{tabular}{|c|c|c|c|c|c|c|c|c|c|}
\hline Govt & Internal & Financial & Supplier & Media & Community & $\begin{array}{l}\text { Citizen } \\
\text { Action }\end{array}$ & $\begin{array}{l}\text { Special } \\
\text { Interest }\end{array}$ & Customer & $\begin{array}{l}\text { Legal } \\
\text { Political } \\
\text { Tech }\end{array}$ \\
\hline $\mathrm{MOH}$ & $\mathrm{KCDC}(2)$ & $\begin{array}{l}\text { GWRC (2) } \\
\text { (and } \\
\text { Govt) }\end{array}$ & $\begin{array}{l}\text { CW - } \\
\text { David }\end{array}$ & $\begin{array}{l}\text { Kapiti } \\
\text { Observer } \\
\text { (not } \\
\text { participant } \\
\text { but info } \\
\text { source- } \\
\text { letters } \\
\text { articles } \\
\text { Mayor's } \\
\text { comment) }\end{array}$ & $\begin{array}{l}\text { Iwi - Daniel } \\
\text { (and Special } \\
\text { Interest) }\end{array}$ & $\begin{array}{l}\text { Grey Power } \\
\text {-Trevor } \\
\text { (and } \\
\text { Customer/ } \\
\text { Special } \\
\text { Interest) }\end{array}$ & $\begin{array}{l}\text { SF Group } \\
\text { (2) }\end{array}$ & Karen & $\begin{array}{l}\text { Stan } \\
\text { (and } \\
\text { special } \\
\text { int.) }\end{array}$ \\
\hline \multirow[t]{2}{*}{ DBH } & $\begin{array}{l}\text { Council } \\
\text { (2) } \\
\text { (EC/CLDs } \\
\text { Feb/Mar } \\
2009 \text { - } \\
\text { also } \\
\text { Legal/ } \\
\text { Political) }\end{array}$ & $\begin{array}{l}\text { Rate- } \\
\text { payers } \\
\text { (9) } \\
\text { (and in } \\
\text { other } \\
\text { parts of } \\
\text { grid) }\end{array}$ & & & $\begin{array}{l}\text { Betty } \\
\text { (and also } \\
\text { Customer/ } \\
\text { Special } \\
\text { Interest) }\end{array}$ & $\begin{array}{l}\text { KWAG (3) } \\
\text { (and } \\
\text { Customer/ } \\
\text { Community }\end{array}$ & & $\begin{array}{l}\text { Stu } \\
\text { (and } \\
\text { community) }\end{array}$ & \\
\hline & & & & & $\begin{array}{l}\text { Bob (and } \\
\text { Customer/ } \\
\text { Legal/Tech) }\end{array}$ & & & Murray & \\
\hline
\end{tabular}

Table 1: Stakeholder Grid

The following two figures ( 8 and 9 ) show the dynamics of stakeholders at a point in time. 


\section{Dangerous}

(Power \& Urgency)

Possibly GWRC - on resource consent issues
Dependent

(Legitimacy \& Urgency)

Iwi

Some Special Interest Groups

Ratepayers - variable
Urban Water System
Definitive

(Power, Legitimacy \& Urgency)

KCDC managing authority

GWRC depending on issue

Managing Iwi in some contexts

Central Government depending on issue

Figure 8: Stakeholder Typology 1/ 2

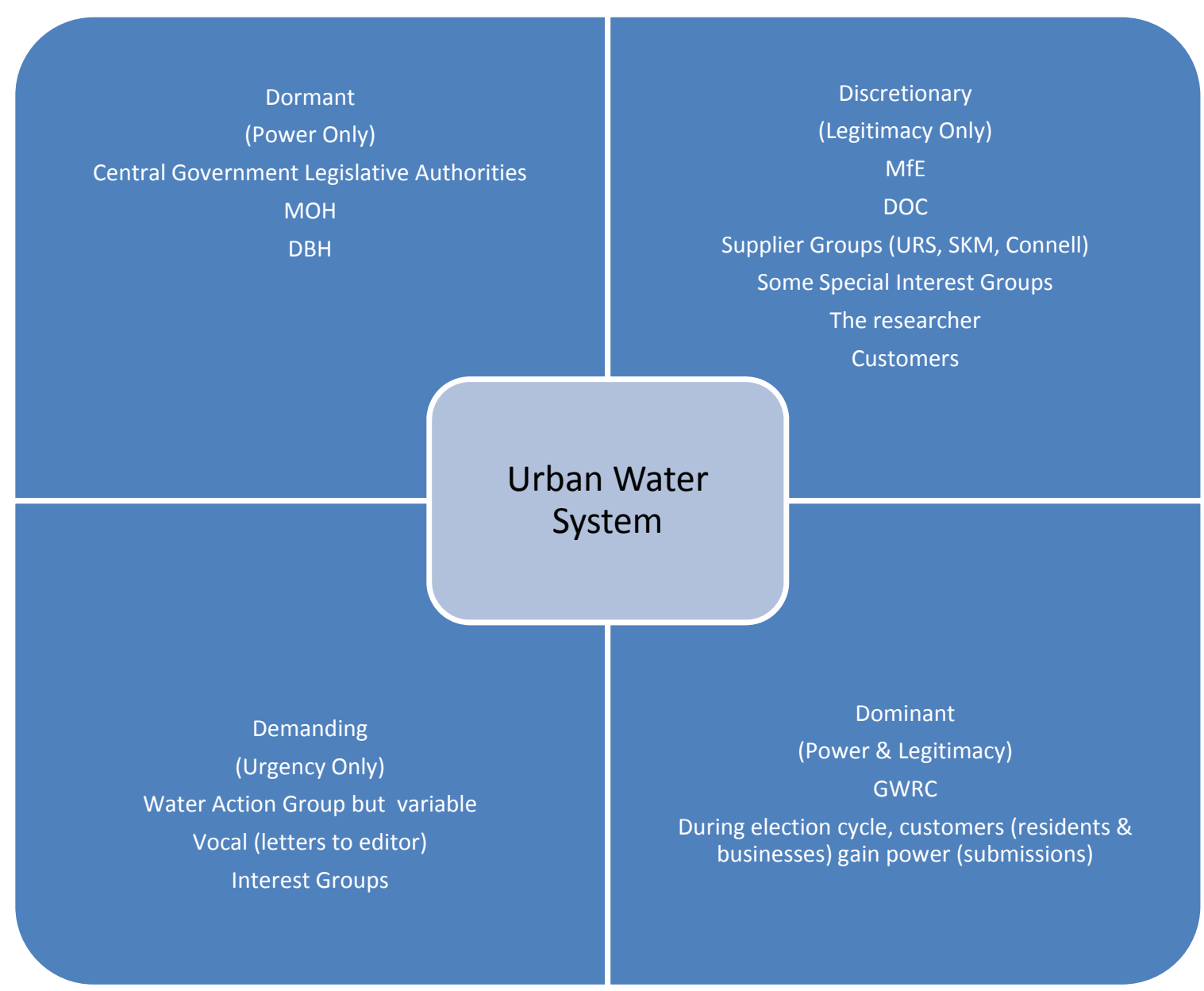

Figure 9: Stakeholder Typology 2/ 2

Non Stakeholder

(No power, Legitimacy or Urgency)

\section{Media}

Political
(Legitimacy Only)

$$
\begin{aligned}
& \text { MfE } \\
& \text { DOC }
\end{aligned}
$$

Supplier Groups (URS, SKM, Connell)

The researcher

Customers
GWRC

uring election cycle, customers (residents \& businesses) gain power (submissions)

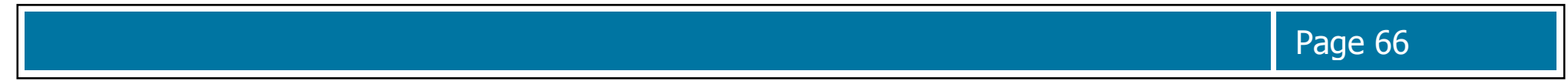


The stakeholder typology developed by Mitchell et al. (1997) is intended to capture the dynamics of stakeholders in respect to salience and time (Elias et al. 2002). Figures 8 and 9 show the dynamics of stakeholders in the Kapiti Urban Water System in approximately September, 2008. The salience of stakeholders changes as their power, legitimacy and urgency changes (ibid.). In considering the attributes of the various participant stakeholders, though the researcher referred to the 'prioritising' questions below, their interpretation was flexible. This was due to there being no narrow requirement for emphasis on prioritising generally definitive (Rawlins, 2006) stakeholders. The following is from Mitchell, et al. (1997):

$>$ Power - can they influence the organisation to do things it would not otherwise do?

$>$ Legitimacy - does the stakeholder have a legal, moral or presumed claim that can influence the organisation's behaviour? This could include having some investment in the organisation.

$>$ Urgency - requires organisation to respond to stakeholder in a timely fashion when the claim is of a time-sensitive nature, or when the claim is important or critical to the stakeholder.

The selected participant stakeholders represent a balance of power, legitimacy and urgency. The Stakeholder Typology used in this investigation therefore has a different emphasis from that in Mitchell et al. (1997), in that the researcher did not intend to select participants based on their stakeholder management capability, as defined by their 'stakeholder salience' (see Elias et al. 2002: 304 and 308). This conforms to the TOC philosophy that every participant perspective is valid (Dettmer, 2007). Stakeholder salience is of lesser import than the need for both public and private interests to be fairly represented in the context of this type of community problem, with a balance of perspectives desirable. Thus, potential stakeholders were selected according to their representation in each of the ten categories. Finally, the stakeholder dynamics and the various linkages (enabling, functional, normative, and diffused) were considered, ensuring even distribution of attributes. The process and transactional analyses conducted in Elias et al. (2002), as a means to determine stakeholder capability, though valid for the strategic issue of concern to their research problem, was thought to be beyond the requirements of this study. Elias et al. (2002) researched a multi-faceted road-pricing project, with importance placed on the categorising of stakeholders due to their relative salience to the timing of the project and their capacity at that time to add value to it.

Thus, following the mapping of participants using the generic map (Freeman, 1984), the greater emphasis, in terms of the stakeholder modelling required for 
this thesis, came to be on the linkages (Rawlins, 2006), or the connection between the system and the participant, with care taken to ensure the participant stakeholders were represented in each of the linkages. The linkage model in Rawlins (2006) appeared to provide a logical and systematic means to validate the selection of each of the participants. The justification for the selection of the Starborough Flaxbourne participants is their situational linkage to the system problem, described in Rawlins (2006) as a 'normative' linkage. The normative linkage may identify people with a contribution to make or something to gain from a strategic issue, through their common interest: this could be a shared goal or experience.

This investigation identified a number of people external to the case study area, including the two farmers from Marlborough, some distance from the case study. The farmers' connection to similar goals and experiences of the urban community of Kapiti identified them as having stakeholder salience, perhaps more than farmers and horticulturalists in the case study region who generally have ready access to water, and have not undergone significant hardship or necessary change, due to the climatic conditions in their region. The 'community' and 'consumers', comprising around a third of the participants on the stakeholder grid (see Elias et al., 2002), have either a diffused or a functional (output) linkage. However, a normative linkage is also possible, given that a high proportion of the community members/consumers interviewed appeared to share common concerns and goals for their urban water system. KCDCs role in the thesis stems from a functional (input) linkage, while $\mathrm{MOH}, \mathrm{GWRC}$ and to an extent DBH demonstrate enabling linkages.

\subsection{MANAGI NG THE DatA}

The participant stakeholders and the interview procedures are described in the Methodology 3.9 and 3.10. The participants' comments were grouped according to the themes identified as necessary to build destination (IO) maps and current reality trees (CRT), with the data reduced for the TOC analysis by grouping similar responses together.

Each statement (or a generic version of a set of similar statements) was written on a post-it note and the responses were grouped against each of the twelve questions. Different coloured post-its were used to keep track of each of the entities required for the TOC analysis, with themes such as [secure water supply] or [living within limits] emerging through this process as CSFs (critical success factors) in the IO map.

Each set of statements was checked as to whether they were in fact necessary conditions, undesirable effects, problems, a statement of conflict or a goal statement. Some of the statements were then moved to a more appropriate 
area. For example: a participant might answer a question designed to surface a critical success factor or goal with a statement that other interviewees had identified differently, or that the researcher intuitively believed might be more suited to a different category. In that case, the researcher would group the statement as perceived by the participant initially, but use a different colour post-it to signal a need to later validate, or otherwise, this entity and its position in the TOC hierarchy.

Through the grouping of responses by roughly similar themes, it became easier to manage and attribute all the data. It also became clear that the validity of the different perspectives was not weakened by attributing them broadly, rather than to specific interviewees. It should be stressed that though data was put into four groups, this was more from a data management perspective, than due to any views developed by the researcher that the groups were indicative of general homogeneity. There were enough similarities across one or more of the question responses (or categories) to achieve the aim of grouping of stakeholders in a practical way, in order to reduce data down, while still valuing differences.

\subsection{THE QUeSTI ONS OF DOMESTIC WATER METERS AND CAPACITY}

A proposed introduction of water meters as a tool to manage water demand in Kapiti has met with controversy. In light of the quite clear division among Councillors, witnessed by the researcher at Council workshops debating the proposal, a question about water meters was deemed appropriate.

Questions: Water meters - do you support their introduction? Are there any conditions under which you would support them?

Sixteen of the eighteen interviews involved participants answering questions about water meters. Due to the relevance to the goal of some method of managing demand down to target levels, the responses of participants are noted. The table below shows the responses based on one answer per interview.

\section{I nCReasing CAPACity With Augmented Centrali sed Supply}

A number of participants proposed that storage is a necessary condition to meeting the urban water system goal. The views of all the participants have been represented in the table as far as the researcher could assess the interview responses, bearing in mind there was no precise question on storage for Kapiti. Some participants referred specifically to pond storage, while others spoke of dams, and one talked about the Otaki pipeline proposal. Thus, the 
term 'storage' has been replaced with 'augmented centralised supply' in the table.

\section{NCREASI NG CAPACITY WITH ONSITE SYSTEMS}

Onsite rainwater (R/W) harvesting was also proposed as a necessary condition by a number of participants. Some of these people also endorsed the policy of KCDC to have new buildings install R/W tanks and greywater systems, and/or generally supported WSUD policies. For clarity, rather than talk to the variety of options proposed by each participant, which is not the goal of this thesis, the support for R/W tanks is recorded.

It is worth noting that a participant who stated explicit opposition to onsite $\mathrm{R} / \mathrm{W}$ tanks was referring to their part in 'demand management', and was not in favour of the Kapiti plan to top up onsite tanks from a centralised town water supply. The participant felt that people in possession of large capacity onsite water storage could become accustomed to using a great deal more water than would be sustainable if drought were to affect their tank supply. Thus, they would be 'topped up', maintaining an unfair advantage over other water users. Kapiti staff responded that the proposed top up limit of 600 litres per site per day is designed to discourage this pattern of behaviour.

\begin{tabular}{|l|c|c|c|c|c|}
\hline & $\begin{array}{c}\text { Yes } \\
\text { Absolutely }\end{array}$ & $\begin{array}{c}\text { Yes } \\
\text { Conditionally }\end{array}$ & No & $\begin{array}{c}\text { Undecided } \\
\text { Open } \\
\text { mind }\end{array}$ & $\begin{array}{c}\text { No } \\
\text { Discussion } \\
\text { about the } \\
\text { topic }\end{array}$ \\
\hline Water Meters? & 5 & 7 & 1 & 3 & 2 \\
\hline Augment Centralised Supply as NC? & 3 & 5 & 1 & 3 & 6 \\
\hline Onsite R/W Tanks as NC? & 11 & & 1 & - & 6 \\
\hline
\end{tabular}

Table 2: Selected Stakeholder Responses

\subsection{THE Destination}

One should always begin any endeavour with the end in mind (Stephen R. Covey, 1989).

This study began with an idea to agree a 'clear, unequivocal goal statement' (Dettmer, 2007:23) among participants. The vehicle for this is the IO or Destination map, which Dettmer (2007) argues is critical to the success of the thinking processes. Originally, Goldratt had proposed eight questions that he 
believed could get to the root cause of any system problem. The IO map posed a minor dilemma in terms of these questions. By applying the IO map, more than eight questions were required, with the goal and supporting success factors to be agreed. Hence, this study asked twelve standard questions, with four of them designed by the researcher and the other eight slightly adjusted to fit the study's intent, setting and actors. The questions can found at the end of section 3.11 of the Methodology.

The participants' comments were grouped according to the themes identified as necessary to build destination (IO) maps and current reality trees (CRT). These are briefly: common goals, necessary conditions, critical success factors, problems and symptoms, undesired effects, and critical conflicts or constraints. Comments are in response to the set of twelve TOC questions, with a further one or two contextual questions that put particular emphasis on the case of Kapiti's Water Strategy.

The responses were used to prepare Destination maps (IO), a Conflict Resolution (or Evaporating Cloud) Diagram (EC) and a Current Reality Trees and branch (CRT and CRB). The aim of the questions was to establish what people view as the Goal for their water system, the critical success factors (CSF) that must be met to achieve the goal and a set of supporting necessary conditions (NC). Additionally, the constraints to meeting the necessary conditions were sought. These are notated as Problems, Undesirable Effects (UDE) and Conflict (core conflict or conflict UDE). Of the set of TOC diagrams, the original IO map was designed at the outset with the help of early participants. The second, more detailed map was prepared after feedback from participants, while the final one was drafted with input from all the participants. 
Below is the original IO map or destination finder showing the desired intermediate objectives as envisaged by the researcher and prepared with pilot participants.

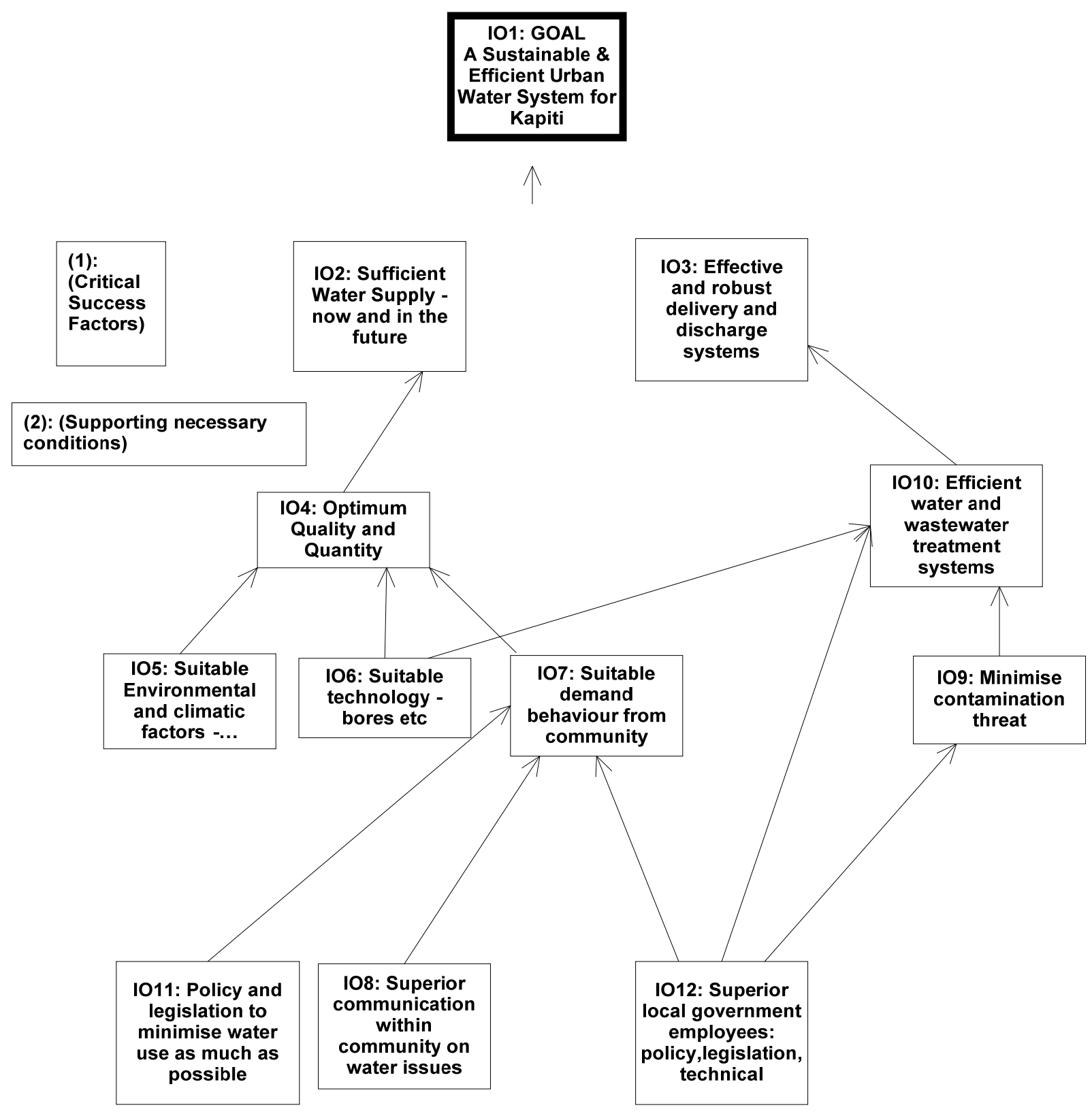

(1): Somewhere in here goes trust, leadership and will and perhaps knowledge or understanding 
This is a later IO map that was prepared with input from staff of participant Council KCDC.

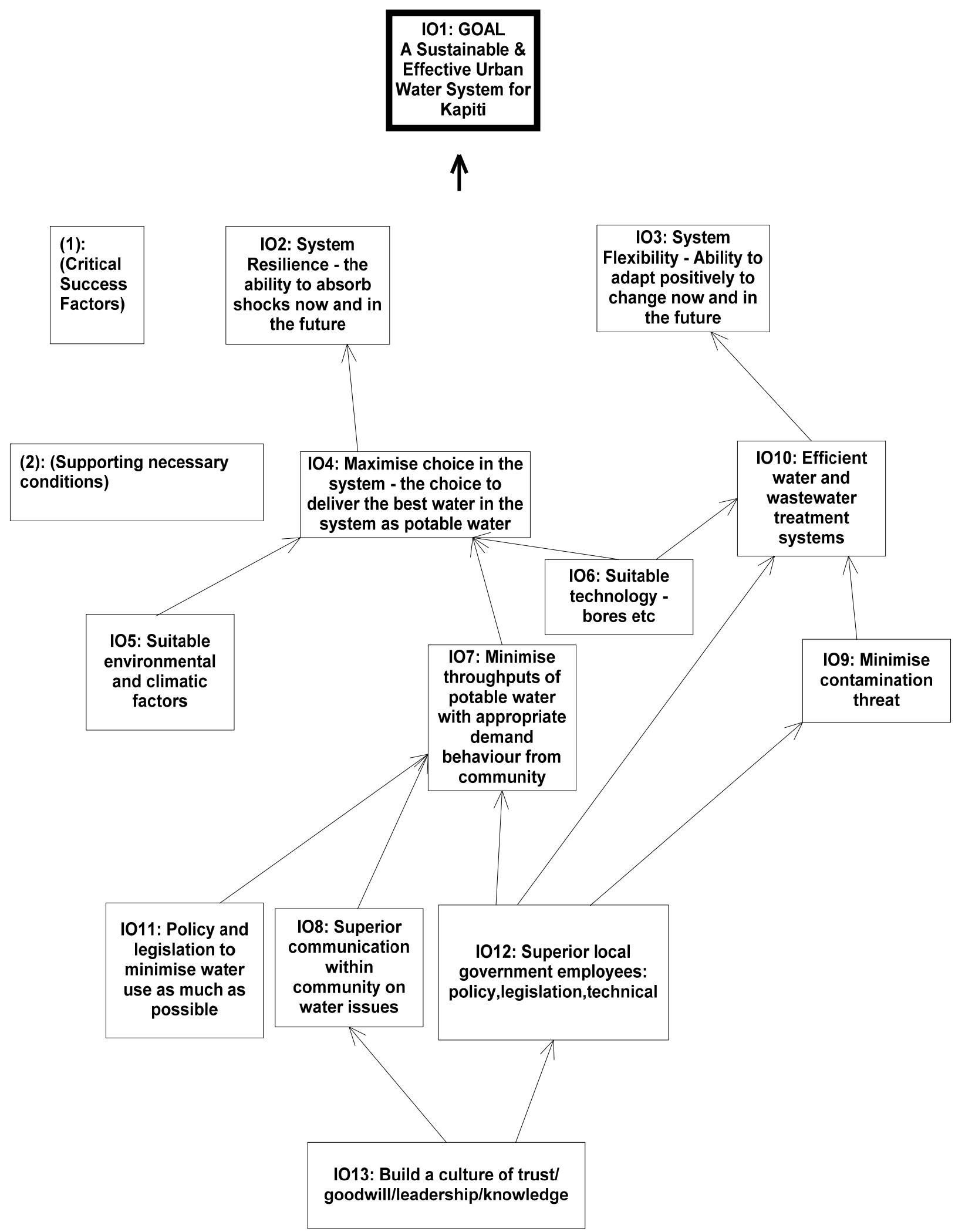




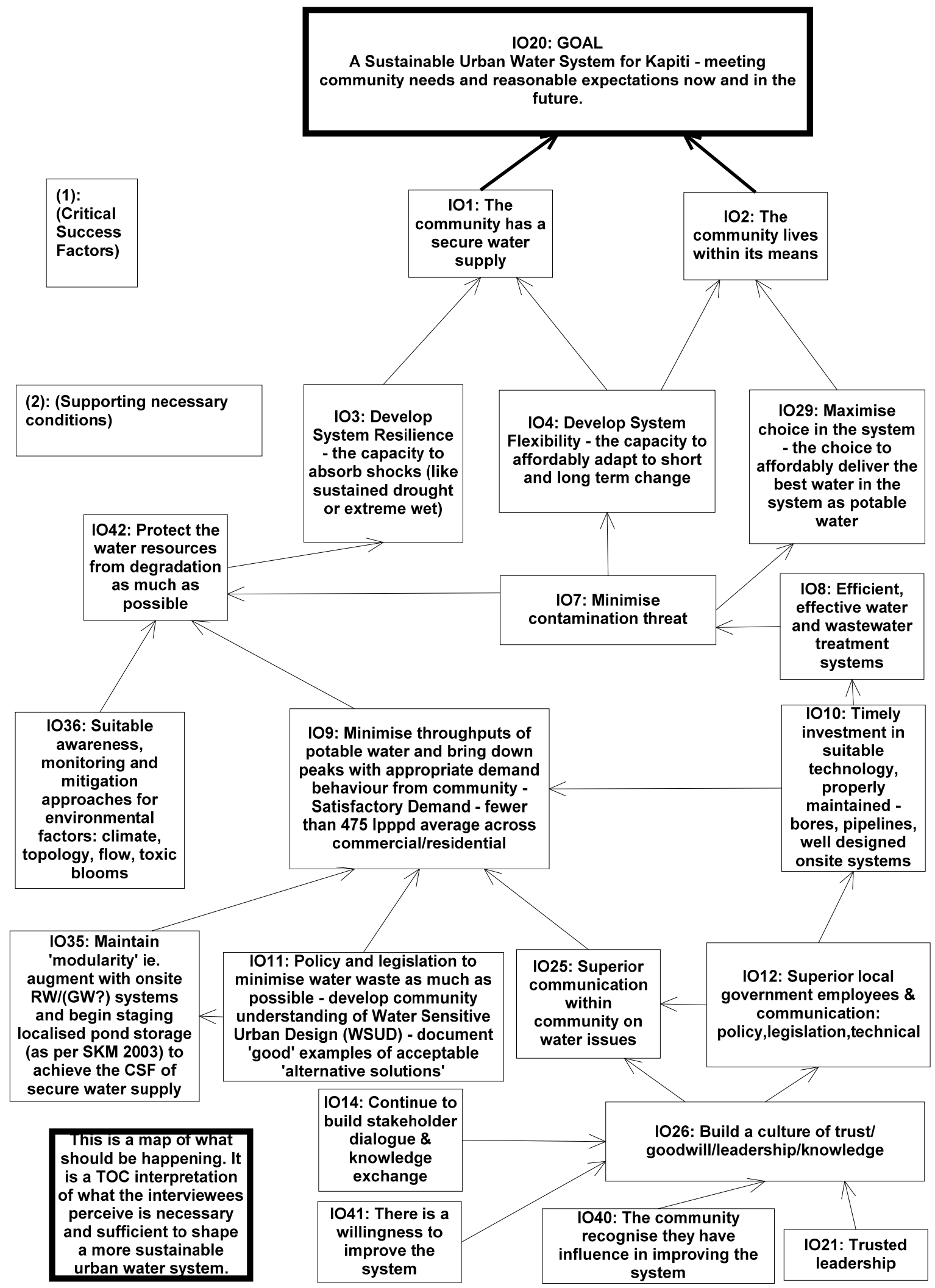

Figure 12: 10 Map 3 
The IO map in Figure 12 above shows what should be happening, reflecting the vision of all participants. It is a TOC interpretation of what the interviewees perceive is necessary to shape a more sustainable urban water system. The two CSFs necessary for the goal provided the starting point to prepare a CRB and a Conflict Cloud that revealed a potential solution to the critical dilemma facing Kapiti - as illustrated in the set of EC diagrams and explanations. 


\subsection{The CuRRENT Reality - What Really Is HAPPENI ng?}

The next figure shows a Current Reality Branch (CRB). The CRB helps illustrate what is happening in the part of the system that has most impact on the system goal.

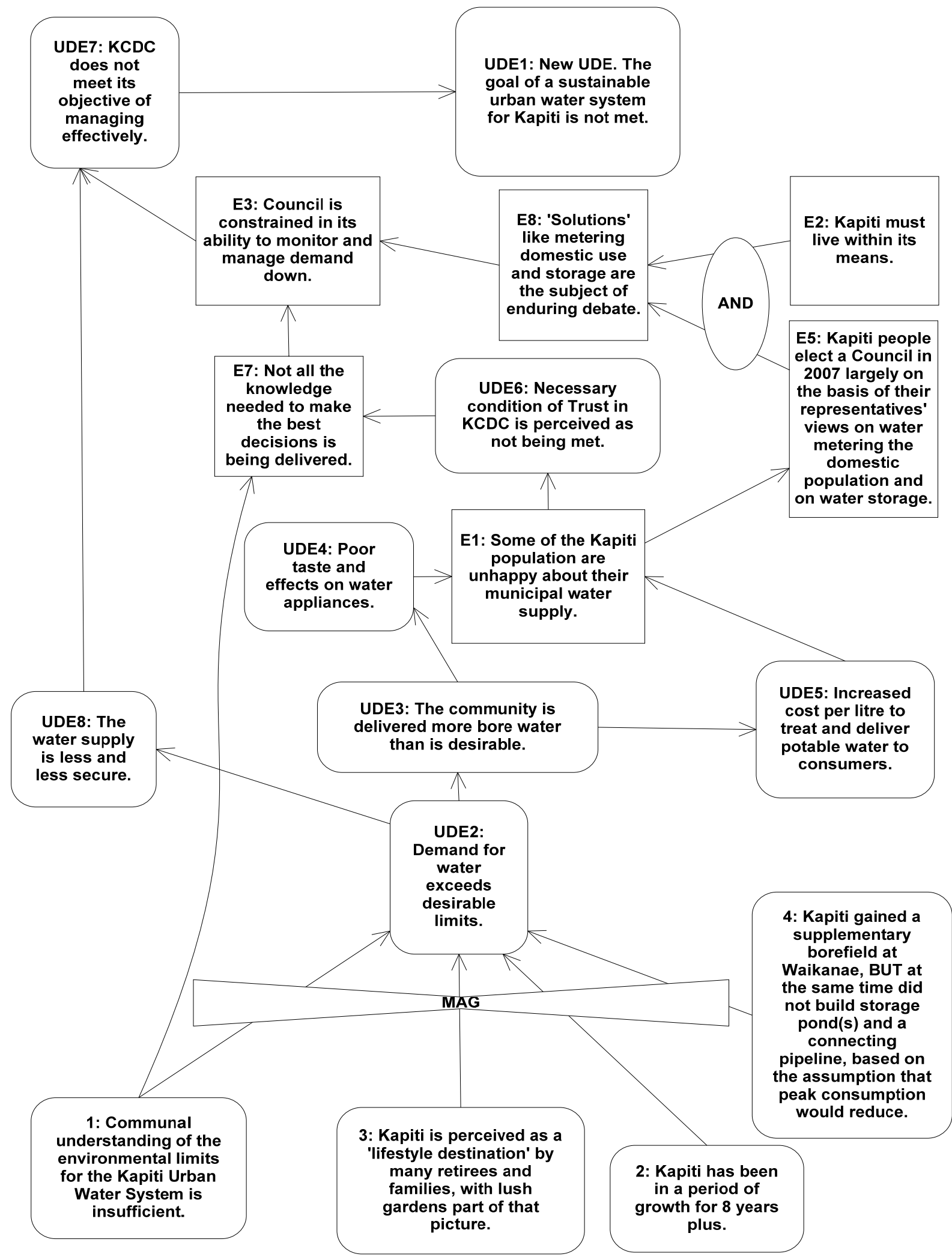


Figure 13 shows the Current Reality Branch (CRB), focusing on the dilemma facing Waikanae/Paraparaumu/Raumati. The CRB was prepared in conjunction with the EC. It reflects the part of the system most likely to impede the attainment of the goal. It reflects what is happening in the system now. The UDE signifies an undesirable effect. The MAG shows four entities combining in a magnitudinal way to influence UDE2. One or more of these acts as a critical constraint to achieving the goal. Intuition and directed questioning identified the most likely cause of demand exceeding desirable limits. The EC was used to verify and solve the conflict arising from the constraint. Entities 1 to 4 all have a relationship to peaks in demand for water beyond reasonable limits. This peak demand is the critical constraint that keeps the system from meeting its goal. Having focused on one part of the system, using the participants' viewpoints, a broader CRT can be constructed that can be compared with the final, most objective destination (IO) map of the system. This is shown later in the analysis in Section 4.10 .

\subsection{What to Change?}

CRBs and CRTs are sufficiency-based logic trees used to compare reality with system benchmarks in order to isolate what needs changing in a system. As such they only need to reflect the part of the system that is unfavourable (Dettmer, 2007:92). Note that despite three other catchments being part of the urban water system under investigation, the part of the system this thesis focuses most attention on is the catchment of Waikanae/Paraparaumu/Raumati, whose population has been faced with challenges in meeting water security objectives for some years now.

Read the CRB thus:

\section{If...}

Entities 1, 2, 3 and 4 exist together

\section{Then...}

Demand for water exceeds desirable limits

$$
\text { If... }
$$

Demand exceeds desirable limits

\section{Then...}

The community is delivered more bore water than is desirable 


\section{If...}

The community is delivered more bore water...

\section{Then...}

Costs increase (for treatment at the Waikanae Water Treatment Plant)

AND...

Water has poor taste and has effects on appliances

\section{If...}

Costs increase or the taste of water is poor and appliances are less reliable (due to bore water being used instead of river water)

\section{Then...}

Some of the Kapiti community are unhappy about their municipal water supply

ETC.

If...

KCDC does not meet its objective of managing effectively

\section{Then...}

The Goal of a sustainable urban water system for Kapiti is not met.

\subsection{What to Change to? Presenting The Conflict Resolution Cloud (EC)}

Once we know what to change, we have to find what to change to and how to do it (Dettmer, 2007). The EC or conflict resolution diagram assists with the first of these, what to change to. The EC is needed because generally there is some conflict or tension preventing the best solution from being implemented when it is required. Dettmer describes the EC as a kind of 'creative engine' that allows us to invent 'breakthrough' solutions to 'nagging' problems (Dettmer, 2007: 24).

The following section synthesises the viewpoints, information and background provided by participants and addresses Kapiti's dilemma regarding risks to water security for the Waikanae, Raumati and Paraparaumu region. The EC or Conflict Cloud articulates the most visible and pressing conflict, among a series of other tensions identified by participants and faced by the Kapiti community, in their attempts to improve water security and sustainability. 
In line with Bassett (1995) this ongoing 'conversation' has been treated as an integral part of the research. Following a presentation of the EC to study participants on 12 February 2009, two KCDC Councillors contacted the researcher requesting a presentation of the findings of this investigation and the EC. This meeting took place on 3 March 2009 and the following captures the content of the presentation and the series of discussions around it.

\subsection{The Conflict Resoluti on Cloud (EC) Of THE KAPITI Dilemma}

The following reproduces the content of the series of PowerPoint slides presenting the dilemma and its background. It provides a summary narrative, together with explanatory notes. For space and clarity in this reproduced document, the assumptions are reproduced separately - when presenting the conflict to participants, injections are more usually read alongside the relevant assumptions:

\section{BACKGROUND}

> In 2003, consultants reported that there was a high risk of Kapiti requiring stored water capacity of between $80,000 \mathrm{~m}^{3}$ and $220,000 \mathrm{~m}^{3}$ by 2006 (SKMa, 2003).

$>$ It is now 2009, and Kapiti's high demand for water has not been adequately managed down to desirable levels (of 400 litres per person per day) that abates the risk of requiring storage in at least one catchment.

$>$ There are (RMA) consent rules around how often the supplementary borefield can be used and how low the Waikanae river can go (expressed in cubic meters per sec flow) before supplementary supply is called for.

> In the 2003 investigation, the possibility of combining storage solutions with the Waikanae borefield via a pipeline was signalled as one with strong benefits. A clear benefit was improved stored water quality through the groundwater supply reducing algal bloom risk.

> In April 2004, consultants reported the results of the resource evaluation and project costs, recommending that completing the Waikanae borefield supplementary supply was a minimum requirement to ensure short term security of supply for Waikanae, Raumati and Paraparaumu (URS, 2004). 
> Problems: NZ wide degradation of recreational water quality, significant drought periods and catastrophic flooding, rapid growth not necessarily matched by infrastructure/mitigation investment.

$>$ Sources of discourse: Ongoing reporting of water issues in the media, letters to the editor, reports commissioned by Council, PCE reports (2000 and 2001).

> Rationale for the researcher's interest: for a period, the researcher was writing on water sustainability issues for a national website: topic and Masters requirement to undertake research emerged together.

\section{I dea for a Theoretical Framework}

A review of Elias et al. (2002) stakeholder map and typology (a complement to systems thinking about community severence issues north of Wellington) and Rawlins (2006) led to an idea to use TOC with a framework for stakeholder engagement.

TOC Theory of Constraints: A way to merge soft intuition and socially constructed reality with hard data and get to the heart of the assumptions underlying decisions to signal clear direction in inflamed situations.

The Necessary Revolution by Senge (2008): Iceberg model (there is a lot going on under the surface: events, patterns, trends, forces, structures and mental models) - complementing the TOC approach.

CLD feedback loops: Early interviews suggested 'the fix that backfires' archetype - the borefield 'fix' backfired because demand peaks and averages did not reduce as predicted and because people do not like the taste and effects of the bore water. Had the storage option been pursued with the borefield ' $f i x$ ' in 2005, water quality would be less a concern as the waters could be 'mixed' - but high and particularly peak consumption need addressing.

How does the framework deal with the issues?

D Stakeholder Typology

> IO Mapping

$>$ Conflict Clouds

> CLD (Causal Loop Diagrams based on a systems archetype)

$>$ Current reality branch (CRB) 


\section{The EC: What to Change and What to Change to?}

'Most conflict in complex systems is embedded in the CRT and requires an approach that transcends the system' (Dettmer, 2007:172). The Evaporating Cloud depicts what is happening now, not what we think should be happening (Dettmer, 2007). It provides a systematic way to examine a core conflict and the assumptions that lie behind it, to reveal the beginnings of a solution. The EC often emerges as a logical step after constructing a CRT or a branch of a CRT, the CRB (as for this research problem).

Attention essentially focuses on the elements depicted in the CRT, which are different in the IO, thus revealing the gap between where 'we currently are and where we are striving to be' (Dettmer, 2007:169). The EC answers the question What to change and begins to answer What to change to, by suggesting injections that are alternatives, or opposites, to the causes in the existing reality.

The injections developed in an EC can form the foundation layers of a Future Reality Tree (FRT) to reveal more about What to change to and How to make the change happen. The sufficiency characteristic of the FRT makes it a reliable tool to test the validity and depth of the EC and the CRT/B. With the construction of either a PRT or a FRT, the CRT/B and the EC can capture a broad view, avoiding the time constraints that generally accompany high detail and precise analysis. Goldratt has been quoted 'It is better to be aproximately correct, than precisely incorrect' (in Dettmer, 2007:225).

Comparing the CRT and the IO reveals that IO 16 [a secure water supply] is not being properly met. UDE8 from the CRT [the water supply is less and less secure] and E2 [the community must live within its means] become the catalysts for the EC, appearing as two statements of requirements. UDE8 in the CRT showed the gap between what is required [a secure water supply] (IO16) and what is actually happening in the system [the water supply is less and less secure]. 
Now that the critical requirements...Kapiti must [B. Have secure water supply] and [C. Live within its means] are known, the prerequisites can be identified as shown below.

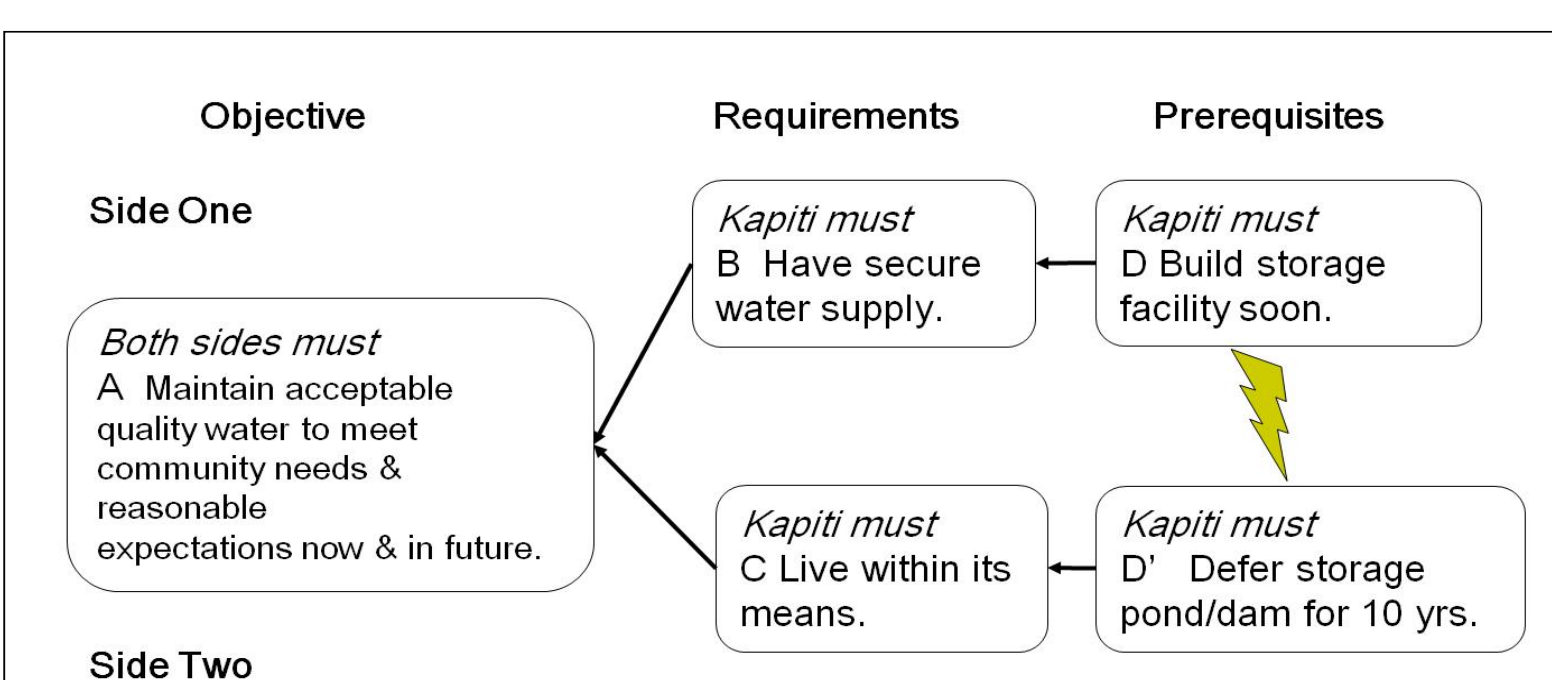

Side Two

Read: in order to have $\boldsymbol{A}$ we must have $\boldsymbol{B}$, and in order to have $\boldsymbol{B}$, we must have $\boldsymbol{D}$.

On the other hand, in order to have $\boldsymbol{A}$ we must have $\boldsymbol{C}$, and in order to have $\boldsymbol{C}$, we must have $\boldsymbol{D}^{\prime} \boldsymbol{\&}$ not $\boldsymbol{D}$.

But $\boldsymbol{D}$ and $\boldsymbol{D}^{\prime}$ cannot occur simultaneously.

This is the KCDC dilemma debated by Councillors at a February 2009 workshop for the LTCCP.

The above conflict cloud captures the core dilemma debated on 12 February 2009. The needs of each side of the EC are 'non-negotiable necessary conditions, outcomes that must be satisfied to meet the common objective' (Dettmer, 2007:186).

\section{Method}

First, articulate the conflicting needs of each side...

We must do [PREREQUI SITE] in order to satisfy [REQUI REMENT].

Then articulate the conflicting wants of each side...

In order to have [REQUI REMENT], we must do [PREREQUI SI TE]. 


\section{Quick method for resolving the dilemma:}

Ask: "How could we achieve $\boldsymbol{C}$ while doing $\boldsymbol{D}$ ?

Objective

SIDE One

\section{Both must}

A Maintain acceptable quality water to meet community needs \& reasonable expectations now \& in future.

\section{SIDE Two}

Requirements

Kapiti must

B Have secure water supply.
Prerequisites

Kapiti must

D Build storage facility soon.

Could live within its means because some types of storage are cheaper, payback can be longer.

Could enhance social capital and live (more) within its means by securing water supply through building storage soon.

Kapiti must

C Live within its means.
Kapiti must

D' Defer storage for 10 years.

\section{securing water supply through building storage soon.}

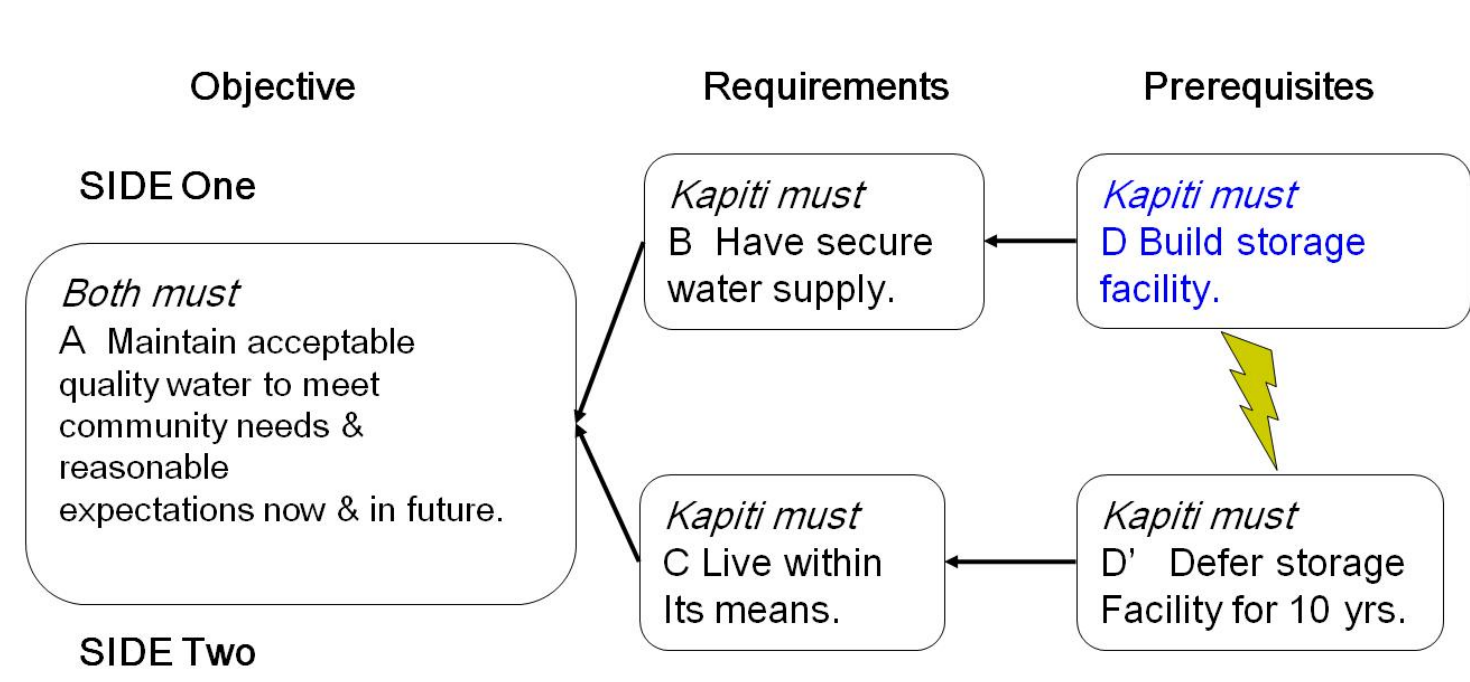

Alternatively, how could we $\boldsymbol{B}$ while doing $\boldsymbol{D}$ '?

Apply incentives that save water, meters, optional meters or meters in 'wasteful' locations (Waikanae, Otaki) B \& D'.

And/or partner with private enterprise to make tanks/recycling more affordable so water use significantly reduces (Brisbane). Conditional on ethical, trustworthy partnerships with well-considered and diverse companies, and careful guidelines negotiated so design \& equipment meet conditions for the goal. 


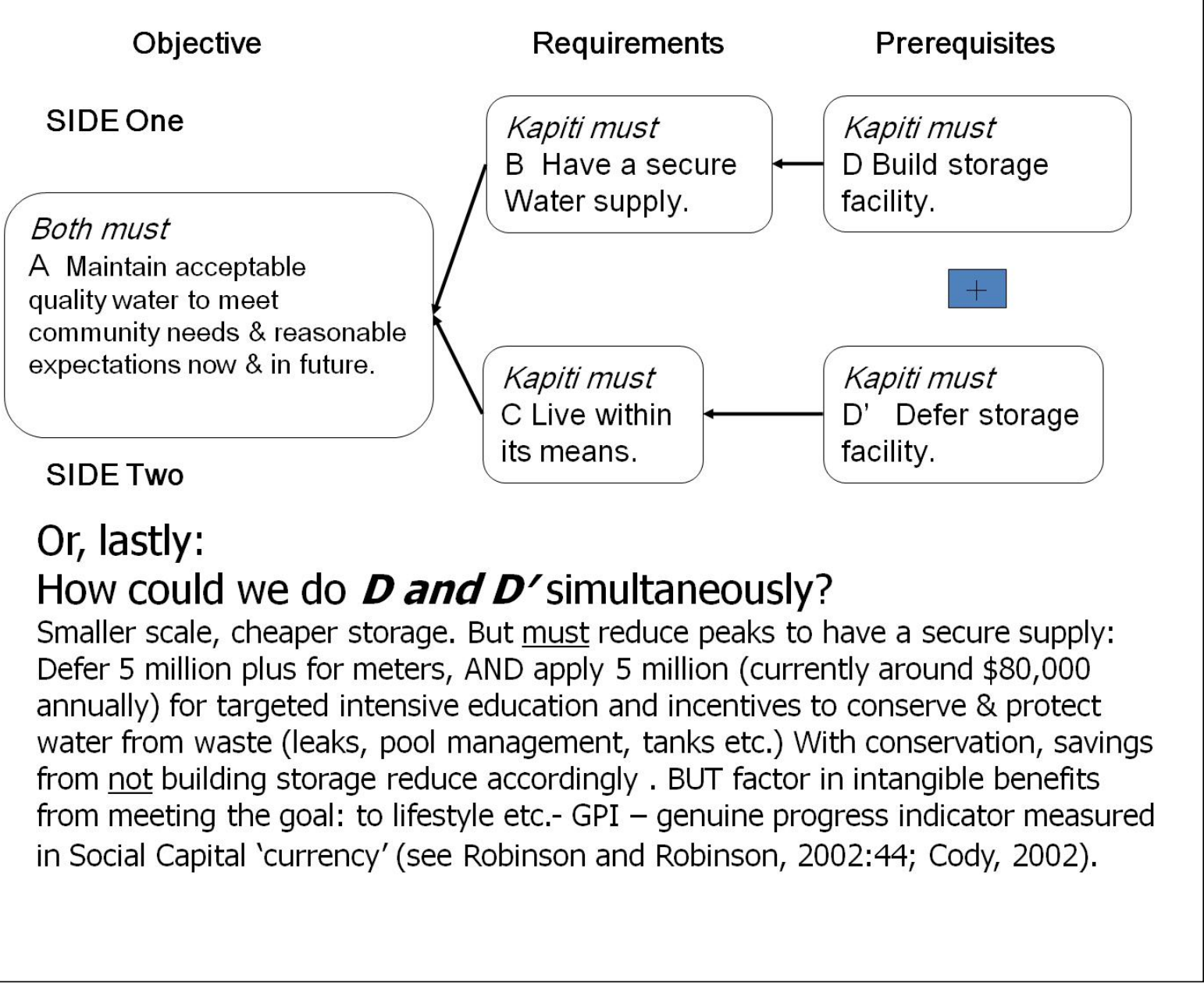

Then, if the dilemma remains unresolved: 1 . List out assumptions underpinning the arrows (the reasons why we believe the relationships exist) and 2. Identify weak assumptions and find ways of breaking them.

\section{Assumptions}

A. Maintain acceptable quality water to meet community needs and reasonable expectations now and in future. This is a valid objective because...

$>1$. These are human rights.

$>2$. The wellbeing of current and future generations is dependent on how we manage our precious resources.

> AB. In order for Kapiti to achieve A. Maintain acceptable quality water to meet community needs and reasonable expectations now and in future Kapiti must $\mathrm{B}$. Have a secure water supply because...

$>1$. This is a minimum requirement for quality of life.

$>2$. This is a minimum requirement for meeting reasonable lifestyle expectations. 
3. Benefits from tourism, trade and from people moving into the area would be in jeopardy if the security of the water supply is at risk. Hence $B$, a secure water supply, is a requirement for $A$.

> BD. In order for Kapiti to B. Have a secure water supply, Kapiti must D. build a secure storage facility because...

$>1$. Demand at peak times is unsustainable within current supply conditions, and peaks are a constraint that must be overcome.

$>$ 2. Peak demand has not dropped significantly since 2004 (see URS, 2004), when storage was deferred based on the assumption that average consumption of potable water would reach 475 litres per person per day by 2009 , and peaks could also be managed down to that level.

$>3$. The cost of not building storage is to not be able to meet peak demand in the near future, which will put the resource consent in jeopardy and the goal $A$. will not be met.

$>4$. There are periods when low flow or other conditions in the Waikanae River prevent its being used as a source of raw water by the Waikanae Treatment Plant.

$>$ 5. When water from the Waikanae River is not suitable, a supplementary source must be used. To date this is supplied by the Waikanae Borefield.

$>6$. The taste and undesirable effects of bore water are unacceptable to some ratepayers, so they object to a system that relies solely on bores when river water is unsuitable.

$>$ 7. The community has grown and continues to grow, and system capacity should be linked to the rate of growth, given that more people generally means more rates.

$>$ AC. In order to Maintain acceptable quality water to meet community needs and reasonable expectations now and in future, Kapiti must $\mathrm{C}$. Live within its means because...

$>1$. Maintaining the water system is one of the greatest costs for Council and if there is not enough money, water quality may suffer.

$>2$. If water quality suffers, there may be risk to the health of system inhabitants.

$>$ 3. Appropriate repairs and maintenance, upgrades, testing water quality, treating water and sewage etc are ongoing requirements that must be funded, or Council and hence the community will lose control of Kapiti's water resources (to the Greater Wellington Regional Council).

$>$ 4. Ratepayers have certain expectations about how their rates are spent and are supported in those expectations by the Local Government Act 2002, so Council must be prudent.

$>$ CD'. In order that...Kapiti C. Lives within its means, Kapiti must D'. Defer the proposed storage facility for 10 years because...

$>1$. Storage is so expensive. 
$>$ 2. Kapiti has other big expenditure items to fund (Aquatic Centre for example) and cannot afford them all.

$>$ 3. It is only necessary to build storage, if demand continues to be unreasonably high.

$>$ 4. Many people think that meters (or a package of other incentives) will deliver the same or better outcomes for less cost.

$>$ DD'. Kapiti cannot Build Water Storage now and Defer building water storage for 10 years...

$>$ 1. Cannot do both: Because water storage costs $\$ 23$ million according to Council staff (12 February 2009) and the community cannot spend that and live within its means, without precluding storage options in 10 years.

\section{Next}

Check the assumptions to validate or identify weak assumptions, using Cox et al. (2003) coding signifying valid or invalid. Look for possible ways of breaking weak assumptions (termed injections)...

A. Maintain acceptable quality water to meet community needs and reasonable expectations now and in future. This is a valid objective because:

1. These are human rights. Valid

2. The wellbeing of future generations is dependent on how we manage our precious resources today. Valid

Check that AB. In order to for Kapiti to A. Maintain acceptable quality water to meet community needs and reasonable expectations now and in future, it is needed that Kapiti must B. Have a secure water supply because...

1. This is a minimum requirement for quality of life and meeting reasonable lifestyle expectations. Valid

2. This is a minimum requirement for meeting reasonable lifestyle expectations Valid

3. Benefits from tourism, trade and from people moving into the area would be in jeopardy if the security of the water supply is at risk. Valid

Hence B, a secure water supply, is a requirement for A.

There are no assumptions to break for AB.

BD. In order for Kapiti to B. Have a secure water supply, Kapiti must D. build storage capacity because: 
1. Demand at peak times is unsustainable within current supply conditions, and peaks are a key constraint that must be overcome.

Valid not only due to peaks, but also because there are times when river flow and toxic algal bloom prevent the river being used for raw water, or require bore water to be mixed with river water.

$>2$. Although peak demand is a constraint that has the potential to be overcome, demand has not dropped significantly since 2003/4, when pond storage was deferred based on the assumption that average consumption of potable water would reach 475 litres per person per day by 2009 . Valid

$>3$. The cost of not building storage is to not be able to meet peak demand in the near future (within five years - KCDC Review doc., 2009), which will put the resource consent in jeopardy and the goal A. will not be met. Valid - Peak demand is a critical constraint.

$>$ 4. There are periods when low flow or other conditions in the Waikanae River prevent its being used as a source of raw water by the Waikanae Treatment Plant. Valid

$>$ 5. When water from the Waikanae River is not suitable, a supplementary source must be used. To date this is supplied by the Waikanae Borefield. Valid

$>$ 6. The taste and undesirable effects of bore water are unacceptable to some ratepayers, so they object to a system that relies solely on bores when river water is unsuitable. Weak - Acceptance could grow given no other options. Starborough Flaxbourne example.

$>$ 7. The community has grown and continues to grow, and system capacity should be linked to the rate of growth, given that more people generally means more rates. Valid and links to idea of staged storage BUT as in Starborough example, cunning planting (lucerne) and WSUD measures can mitigate undesirable effects of growth processes.

AC. In order to maintain acceptable quality water to meet community needs and reasonable expectations now and in future, Kapiti must C Live within its means because:

1. Maintaining the urban water system is one of the greatest costs for Council (43 cents for every rates dollar in a typical urban community) and if there is not enough money, water quality will suffer and lower water quality has costly side effects (social and economic). Valid

$>2$. If water quality suffers, there may be risk to the health of system inhabitants. Valid 
$>$ 3. Appropriate repairs and maintenance, upgrades, testing water quality, treating water and sewage are ongoing requirements and must be funded, or Council and hence the community will lose control of Kapiti's water resources (to the Greater Wellington Regional Council). Partly valid - consider Christchurch water enhancement project success with cost savings from WSUD (1991).

$>$ 4. Ratepayers have certain expectations about how their rates are spent and are supported in those expectations by the Local Government Act 2002, so Council must be prudent. Valid

> CD'. In order that Kapiti must C Live within its means, Kapiti must $\mathrm{D}^{\prime}$ Defer the proposed storage facility for 10 years because...

$>$ 1. Storage is so expensive. Can storage be managed for a significantly lower cost? $\$ 23$ million may be an overestimate. The figure for one pond storage option was \$7.3 million in 2003 (SKM, 2003). A $600,000 \mathrm{~m}^{3}$ pond could be sufficient if people's water use patterns change for the better. With storage, water scarcity will not jeopardise growth, so potentially there will be more rates in the future to fund a longer-term pay back. This fact may make avoiding $\mathrm{CD}^{\prime}$ more acceptable to ratepayers

$>$ 2. Kapiti has other big expenditure items to fund and cannot afford them all. Valid - but weak...there are priorities and people differ in what they perceive is most important...aquatic centre versus water storage for example but Kapiti can defer other items potentially or find a cheaper storage option.

$>$ 3. It is only necessary to build storage if demand continues to be unreasonably high. Valid - but bore water quality would remain a problem and in more than six years per capita water use has not been managed down to target levels (see KCDC Review doc., 2009). Also, how important is maintaining lifestyle choices - or look for new choices - as in Starborough Flaxbourne?

$>$ 3. There is a growing perception that meters (or a package of other incentives) will deliver the same or better outcomes for less cost. Valid, there is a perception, but this assumption requires exploring. Thus: Meters for 5-6 million combined with buying land for storage in 10 years time cannot alone meet $A$. Therefore...Weak assumption the outcome from installing meters is no guarantee of securing the water supply for W/P/R...Even if growth slows, peak demand ( $>1000$ Ipppd in Otaki and $>700$ pppd in W/P/R) has to reduce by more than the $15-25 \%$ reduction meters are predicted to bring (see Appendix 10). Meters are not without undesired effects: Selwyn farmers are having ongoing issues with meter reliability and bore water. If storage is not 
provided, we need to explore the assumptions around meters in more detail. Look for undesirable effects using systems dynamics or TOC or Negative branch. Meters do not address water taste and effect concerns, although they assist in achieving the IOs of resilience and flexibility.

BUT storage capacity may provide more flexibility than meters would, in view of the fact that the Waikanae River cannot always provide water to the Waikanae Treatment Plant. With peak demand a constraint, toxic algal bloom risk in Waikanae River and the borefield consent combine to constrain the ability of the system to meet demand peaks now and in future - and the 'best' water costs less to treat - affecting C (live within means).

> Sustained drought or 'dry' (as in 1978, 1989, 2001, 2003 and 2006) and/or increased toxic bloom in the river threatens the water security threshold - so Kapiti may live better within its means if it avoids CD'. In addition... Are the costs of meters and storage correct?

> So avoid CD' because....Water taste and undesirable effects on water fixtures and appliances are significant and costly concerns to Kapiti residents and businesses. KCDC say that meters rate poorly in terms of addressing these concerns, while they are only assumed to be capable of addressing the issue of peak demand (but in Tauranga, meters/education/regulation have led to $25 \%$ reduction - Beacon Pathway, 2008a. Compared to Kapiti, is there a higher proportion of commercial use of water in Tauranga? Did businesses become more water efficient when meters were introduced - or is the trend as much across domestic as industrial? Was better water use promoted when meters were introduced?). Should the Kapiti region continue to experience similar growth patterns to the previous decade, greater capacity will be likely be required to meet peak demand AND to address water taste and effect issues, whether meters reduce per person consumption or otherwise.

DD' Kapiti cannot D. Build Water Storage now and D'. Defer building water storage for 10 years.

D Can't do both: Because water storage costs $\$ 23$ million+ and the community cannot spend that and live within its means, without precluding storage options in 10 years.

BUT: Is water storage for $\$ 23$ million a correct assumption? Not necessarily, see SKM (2003 and 2008) for pond assessment.

DD'. Kapiti may be able to do both $\mathrm{D}$. Build storage and $\mathrm{D}^{\prime}$. defer building storage for 10 years...if the water storage built now can be cheaper than the $\$ 23$ million indicated by Council staff, and if staged storage now does not preclude adding more storage capacity later, and if (injection) behaviour 
change is accelerated through targeted education, incentives, and restrictions.

1. In six years peak demand has continued to be unreasonably high, so there is a need to manage the peaks with enough water storage.

Potentially, this could be met by a $600,000 \mathrm{~m}^{3}$ pond (at site 4 or 6 south of Waikanae River) with others (up to four) staged as required (indicative cost might be $\$ 14$ million judging by KCDC Review (2009) but not specifically estimated $-\$ 7-8$ million when estimated in 2003).

Some participants have suggested the Whakatiki stream (similar mean flow to Waikanae) and a reservoir (practicalities/costs?), and others believe the Paekakariki/Raumati aquifer and a reservoir is worth exploring to augment supply.

2. A further water storage solution could be visited in the next 10 years if growth and means warrant it. Signalling additional storage does need to be flagged in LTCCP.

3. Could go to the deferred storage once a predetermined condition is met.

Choose DD'. Build storage now and do not preclude introducing other supplementary sources in 10 years.

This gains the system flexibility and builds resilience in, more than demand management can achieve alone - based on discourse and data since 1999 and the TOC interpretation of the interviews.

However, it is useful to explore the consequences of action DD' with a causal loop diagram (CLD) that depicts archetypes. The archetype CLDs are a concept of system dynamics (Maani and Cavana (2000:59) and are a straightforward way to usefully capture unintended consequences, based on predictable patterns of behaviour and effects (Senge, 1994).

The CLD reveals DD' could backfire IF investment is not 'ramped up' for best water conservation initiatives and education. See Senge's $(1994,2008)$ Fix that Backfires Archetype CLD below...

\section{Causal Loop Diagrams (CLD) - Senge (1994 and 2008) System Archetypes}

Cox, Mabin and Davies (2005) discuss the contribution made by the CLD, used with the TOC EC-CRB process in a case of personal productivity. The authors argue that the CLD accommodates the annotation of both positive and negative relationships between variables, as an alternative to stating all 
influences and effects in sentences, with more complex diagrams likely in TOC.

Dettmer (2007) does not go as far as promoting using conventional CLDs in concert with TOC, though he does propose other complementary methodologies to aid 'brainstorming' (2007:218) for injections. Dettmer (2007) suggests that TOC deals with the likes of 'fixes that could backfire' with positive and negative reinforcing loops added when constructing the IO and CRT. The behaviour archetype models in Senge (1994 and 2008) appealed to the researcher, as providing a logical and intuitive way to reveal potential patterns and to locate leverage points where injections can be applied to change direction, and prevent fixes from failing. Note that 'the fix that backfires' or 'fixes that backfire' are also referred to in the literature as 'the fix that fails' or 'fixes that fail'.

Mabin, Davies and Cox (2006) present an illustrative classroom model of a common dilemma, combining TOC with other hard and soft operational research approaches to problem solving, focusing particularly on the contribution of causal loop diagramming. CLDs can provide a 'helicopter' perspective of the whole system that enhances the conceptualisation and understanding of complex relationships between entities, according to Mabin et al. (ibid. 2006:51). The authors conclude that the 'mutually informing nature' of multiple methods is an aid to purposefully developing a programme of action that seeks to bring about desired outcomes while avoiding pitfalls and unwanted side-effects (ibid. 2006:51).

The following two diagrams were constructed with feedback from participant Trevor Daniell and two KCDC Councillors following a KCDC workshop on 12 February 2009. B represents a balancing, or negative feedback loop and $R$ is a reinforcing, or positive loop. The first CLD shows the Fix, which is to invest in storage capacity, leading to a solution 'demand met'. The solution is short lived, as according to the pattern of water use and growth over the past decade, peak consumption will remain unacceptably high, and there is no guarantee that demand per capita will reduce. Therefore, over time, demand will approach environmental and infrastructural limits, and water security will again be a serious constraint to meeting the goal of a more sustainable urban water system. 


\title{
The 'Fixes that Backfire' Archetype
}

\author{
Adapted from Senge, 1994:126
}

The Causal Loop Diagram (CLD) shows what happens if $\mathbf{D}$ build storage BUT water conservation measures are not ramped up to manage demand. B represents the 'quick fix' balancing loop. $\mathrm{R}$ is the reinforcing loop a circle of variables propelling each other's growth or decline, also known as the 'snowball effect' (Senge, 1994: 116).

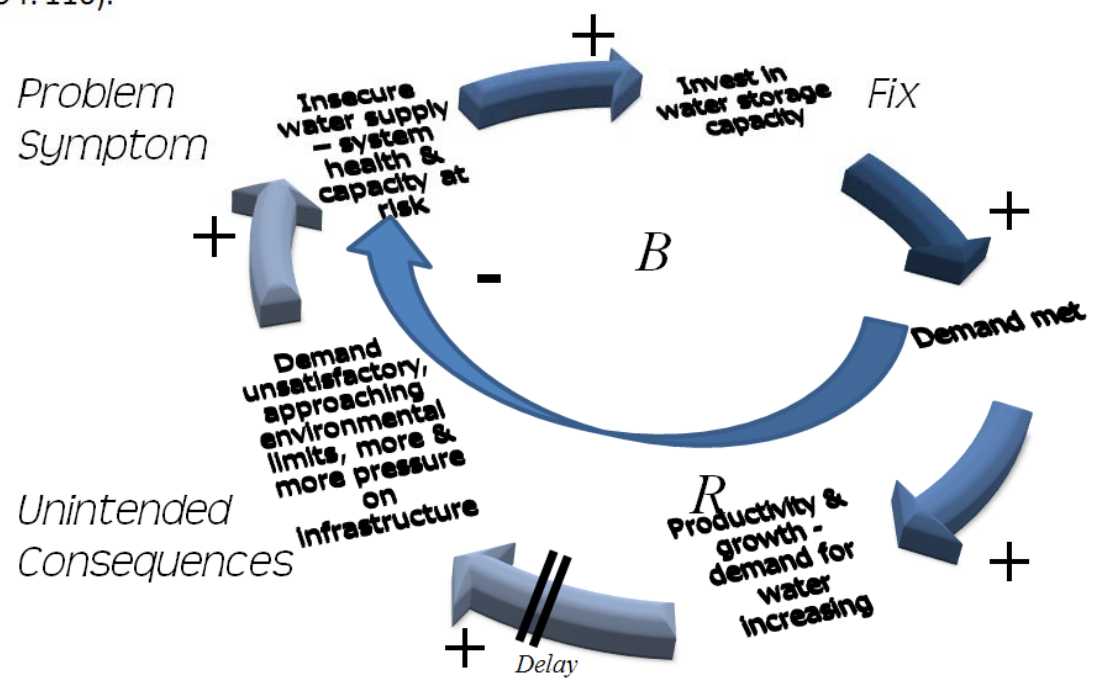

Figure 14: CLD

The CLD above captures the effects of choosing DD'. Kapiti may be able to do both $\mathrm{D}$. Build (staged) storage and $\mathrm{D}^{\prime}$. defer building storage for 10 years...if the water storage built now can be cheaper than the $\$ 23$ million indicated by Council staff, and if storage now does not preclude adding more storage capacity later. The CLD below captures the situation with the proposed injection implemented, accelerating behaviour change through targeted education, incentives, and restrictions.

It is important to state that the CLDs shown were the result of a group model building approach, and that the researcher had a fair understanding of the Fixes the Fail/Backfire Systems Archetype, but when constructing the first CLD, was less familiar with the conventions of Systems Dynamics that suggest positive noun phrases are used for variables. Consequently, the above CLD is poorly named, in terms of Systems Dynamic's conventions. As this CLD was the outcome of a workshop with participants that informed the later CLD (Figure 15), the Conflict Clouds, CRT and PRT, the researcher felt it was appropriate to show the original CLD, and disclose the error. For example, Invest in water storage capacity...is more correctly stated...Investment in water storage capacity. Likewise, Demand met...is more correctly stated...Level of demand met, while Insecure water 
supply...should read...Security of water supply (positive, rather than negative framing of the variable, following Sterman, 2000).

This Figure 14a is the Archetype of the Fix that Backfires/Fails with the variables more correctly named as noun phrases (according to Sterman, 2000), and other indicators ( + and - ) changed as appropriate.

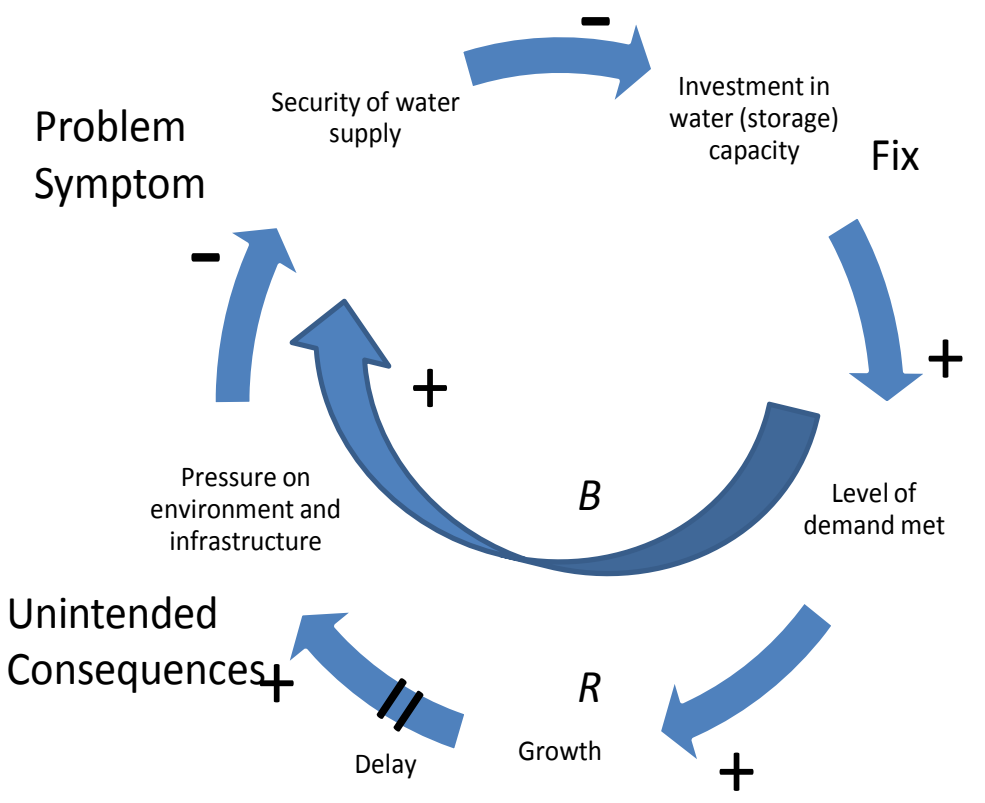

\section{The 'Fixes that Backfire' Archetype}

Adapted from Senge, 194: 126

The Causal Loop Diagram (CLD) shows what happens if $\mathbf{D}$ build storage BUT water conservation measures are not ramped up to manage demand. ' $B$ ' represents the 'quick fix' balancing loop. ' $R$ ' is the reinforcing loop - a circle of variables propelling each other's growth or decline, also known as the 'snowball effect' (Senge, 1994: 116). 


\section{Securing the Water Supply}

Injection for the 'fix that backfires'

Adapted from Senge, 1994: 126

If $\mathbf{D}$ invest in storage, then Kapiti must also fund and implement intensive and ongoing water conservation and WSUD initiatives in order to sustain a secure water supply and remain within the system limits as much as possible.

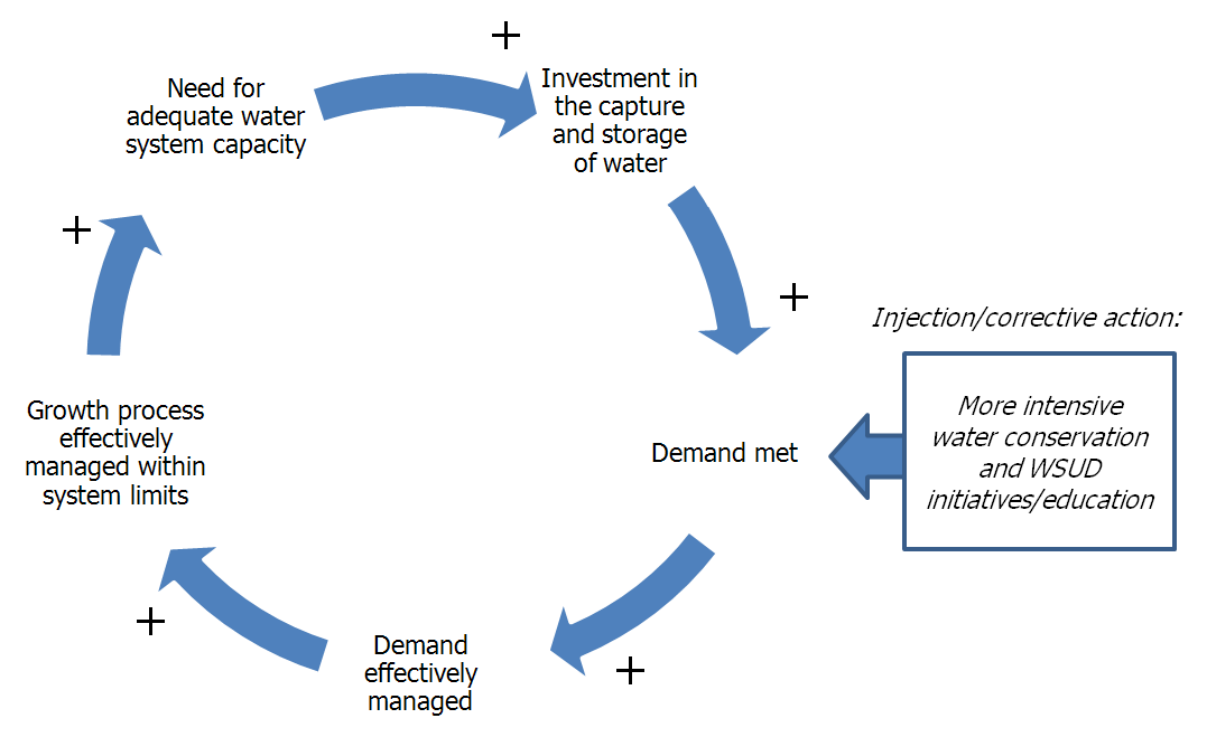

Figure 15: CLD Injection

The injection revealed by constructing the archetype 'fixes that backfire' is intended to change entrenched behaviour around water use in the community. The additional investment in water conservation initiatives and incentives is required to break the pattern of higher than acceptable peak time use, and to reduce average day to day water consumption to reasonable levels, and prevent the Storage 'Fix' failing. The 'corrective action' (Senge, 1994 uses this terminology, while TOC applies the term 'injection') has a direct relationship with sustaining the growth process.

KCDC predict that if the current target consumption of 400 lpppd (plus 75 for leakage) is reached (see Appendix 10), then even in the absence of the additional capacity offered by the 'fix', supply is likely to remain secure for 45 years, based on growth predictions.

If water demand is managed down and kept down using a variety of measures from the Prerequisite Tree (PRT), the growth process will be effectively managed with regard to the water resource (keeping the investment in staged storage to the minimum), with demand remaining within desirable limits that serve to ensure the security and sustainability of the water supply. 


\section{Reflections on the Methodologies}

(Stakeholder typology (Elias et al. 2002):

> Mapping the stakeholders surfaces 'new' information from decision makers and community, who may not have had their views and knowledge aired otherwise.

Stakeholder analysis and TOC are complementary:

> Using stakeholder typology and TOC together proved a practical way to explore a community problem at its core, and with a group of articulate participants who may otherwise have remained silent and kept their wisdom to themselves. The twin frameworks facilitated a process to realise opportunities and break constraints, with potential to increase the community's comfort about decisions being made on their behalf.

The EC:

$>$ Provides the analytical rigour with which assumptions are tested

Has the effect of articulating the core issues of conflict

$>$ Paints a picture of both sides

$>$ Shows potential for win/win through deeper thinking

$>$ Forces the important questions to be addressed

$>$ The answers create a more informed platform from which to make decisions and choices

CLD Archetype Modelling:

$>$ Provides a quick way to increase awareness of unintended consequences of the 'fix'

$>$ Reframes the problem to show the fixes that are only alleviating symptoms - rather than addressing the core problem

> Makes explicit the leverage point where an 'injection' is needed Where to next?

$>$ Other TOC methods - Use the modified TOC questions again and more specifically, to drill down to assess the stakeholder perceptions on desirability and effectiveness of the options.

$>$ Further validate or otherwise the arguments and assumptions using TOC tools. Develop a Future Reality Tree or apply the Prerequisite Tree (PRT) to test the proposed steps before implementing them (how to cause the change). 
The Conflict Cloud Presentation concludes with a reflection process that is presented in a summary of the value of the methodologies employed, in keeping with Basset's (1995) reflexivity principle. Bassett (1995) proposes that a reflective process of engagement with participants adds value to social research and thus should be an integral part of such endeavour. The researcher found that the Conflict Cloud diagrams and the systems archetypes were a valuable way to capture and simplify a great deal of rich and valid information and perceptions from the diverse stakeholders. Simplicity was essential to the success of this research process, due to the need to engage in reflective learning with people who had no prior experience with TOC or its diagrams. The Councillors reflected that articulating the goal, the needs and the wants of both sides of the dilemma in the Conflict Cloud Presentation (EC) was a useful exercise that expanded their thinking and gave clearer direction on how a win/win outcome might be achieved for Kapiti's water security issues.

A discussion document is in the process of being distributed to Kapiti ratepayers (April, 2009), with one of the options proposed being the staged storage option that is highlighted in the EC as a positive step towards meeting Kapiti's goals for its urban water system. However, it is not clear from the discussion document which option is which. This indicates a gap remains between what is required according to participants [superior communication with community] and the reality as stated above. An assumption might also be made that due to the [superior communication] condition not being met, the necessary condition [trust in $\mathrm{KCDC}$ ] will not be met. By comparing desired reality with the current one and focusing on the part of the system under discussion in the KCDC (2009) document (using IO maps and the CRB), the researcher reflects that a critical constraint has arisen that will reflect on the future reality, unless it is remedied. This constraint is the absence of [trusted leadership] at the point where it is most required - the point where stakeholder dialogue and knowledge exchange are set in motion to develop the next necessary condition [build a culture of trust/goodwill/leadership/knowledge]. The next section articulates the reflective learning that has resulted from ongoing dialogue with selected participants to disclose the final and most objective IO map.

\subsection{REACHI NG THE DESTINATION}

The value of the Thinking Processes is that they provide the tools to scrutinise the assumptions behind what people are saying. An updated IO map was prepared after the 12 February 2009 public workshop at KCDC, and in discussion with two Councillors on $3^{\text {rd }}$ March 09. In April 2009, a CRT was constructed, and following this, a PRT was used to test the findings. 


\section{THE I O: WHAT IS THE DESI RED STANDARD?}

The researcher has taken a liberty with Dettmer's (2007) IO mapping procedure. This adapted IO shows the system's goal, critical success factors, and the necessary conditions, as in Dettmer's model. In addition, it incorporates injections to identify the modified or new IOs identified through the process of interviewing participants and by preparing the CRT/CRB and the EC. These injections are subordinate to the chain of IOs. The FRT (or the 'road map' for how to make the changes) would normally begin with these injections. As this thesis does not include the FRT, the IO map and PRT combine to provide the steps required to reach the destination and overcome the key obstacles. Dettmer (2007) and Scheinkopf (1999) both argue that it can be sufficient to complete one or several of the steps from the suite of TOC Thinking Processes, depending on the problem and the connection the researcher has with the problem.

Dettmer describes the procedures for constructing an IO map, which are summarised by the researcher as follows:

\section{Define the System and its Boundary}

\section{Determine the System Goal by Consensus}

3. Determine the High-Level Terminal Conditions. These are up to Five Critical Success Factors (CSF) that must be Satisfied for the Goal to be Achieved

\section{Determine the Key Necessary Conditions (NC)}

\section{Arrange the IO Map Components with the Goal at the Top}

\section{Connect the Goal, CSF, and NCs using Single Arrows}

\section{Verify the Connections Using Necessity Logic}

\section{Enlist Outside Scrutiny of the Entire IO Map (Dettmer, 2007:86)}

IO mapping remains a somewhat contested procedure in TOC, and may be subject to minor modification in the same way that the other tools have evolved over time and through application. Scheinkopf (1999) agrees with Dettmer that mapping the system boundaries and purpose or destination is most useful at the outset of an investigation. Mabin et al. (2001) observe that mapping some sort of vision early on would have enhanced their plan for 'harnessing resistance', though they propose that a CRT may have been the place to do this. Some practitioners do not use the IO at all, while others, including Cox et al. (2003: 14-15), propose that an IO map be prepared, not at 
the outset, but in the final stages of a 'process of ongoing improvement'. Cox et al. (ibid.) provide a 'TOC road map to ongoing improvement' in their text. This is a tabulated list of Critical questions, Thinking Process steps and Techniques and sets the focus of the IO map as How to cause the change? The researcher contends that the IO is useful both at the outset and at the final stages of investigating a systems dilemma. 


\section{Below is the IO prepared with injections and setting out the vision for Kapiti's}

\section{Urban Water System:}

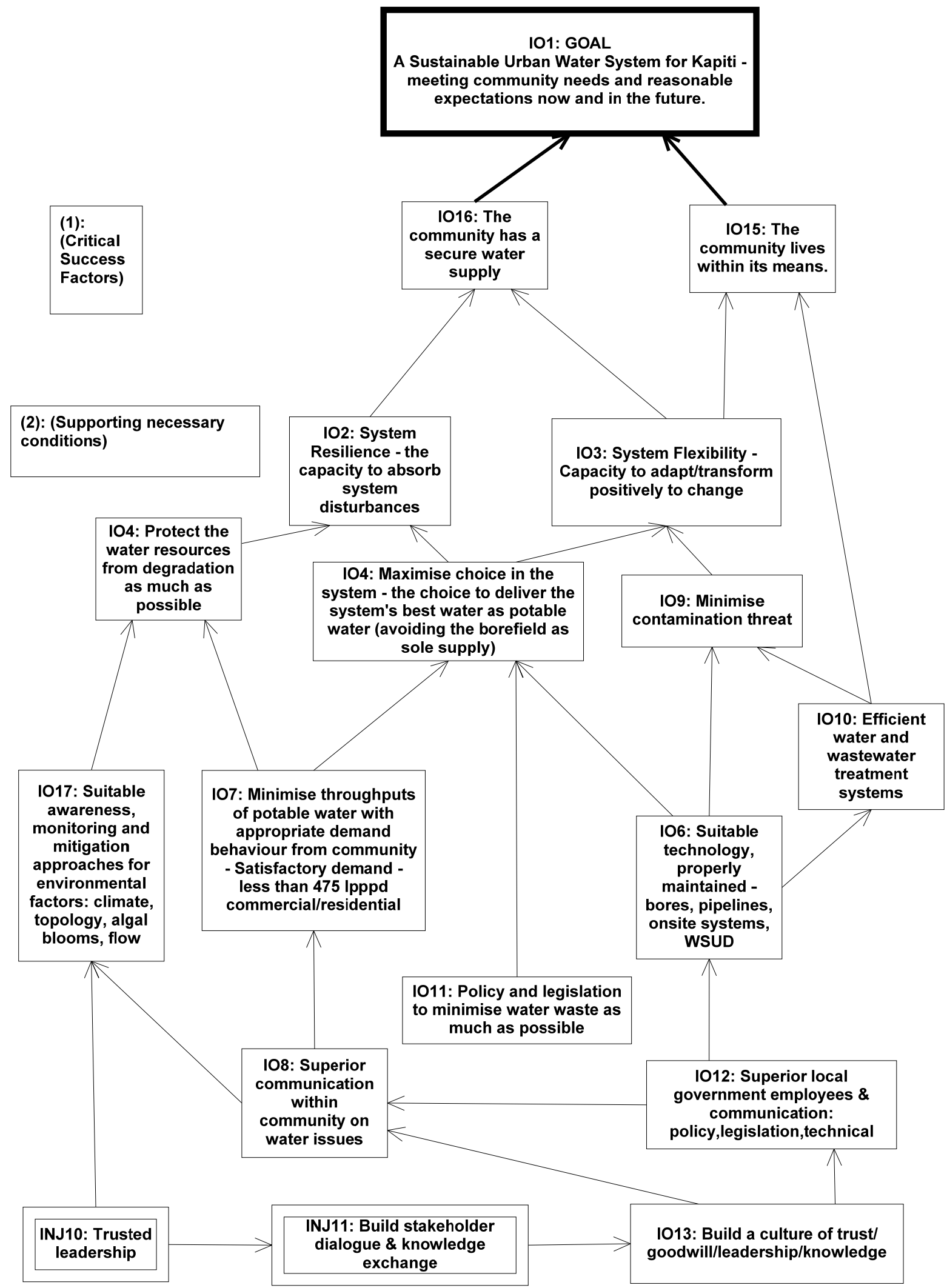

Figure 16: 10 Map Final 
The IO map 'fixes a firm baseline in space and time' (Dettmer, 2007: 68), which serves to explain the researcher refining the IO at various stages of the research. If this study had been carried out over a one or two month timeframe, one IO would likely have sufficed. IOs are connected in a logical hierarchy leading to the system goal. Applying knowledge of what is happening and what should be happening identifies gaps and determines the actions needed as part of systemic change.

The minimum injections necessary to change the current reality and influence the goal are [trusted leadership] and [build stakeholder dialogue and knowledge exchange]. Trusted leadership, according to one participant is leadership conferred by followers (the stakeholders) and is not necessarily defined by the perceived hierarchy of a system. As argued by Dettmer (2007), logic is not enough: emotional commitment is required as well, and a trusted leader can motivate this commitment, threading it through all parts of the system. Hence, in the context of the system under study, the 'trusted leader' is defined by their capability to understand and articulate the 'destination' or vision, and at the same time encourage the stakeholder dialogue and knowledge exchange necessary to achieving all the other IOs.

Read the IO thus:

\section{In order to...}

Achieve the goal of a more sustainable urban water system for Kapiti

\section{We must...}

Have a secure water supply

\section{We must...}

Live within our means

\section{In order to...}

Have secure supply and live within our means

\section{We must...}

Have a resilient system

\section{We must...}

Have a flexible system

\section{In order to...}


Have a resilient and flexible system

We must...

Maintain the choice to deliver the best water in the system as potable water ('start with the best water' - MOH/Gael F - avoiding the use of the borefield as sole supply)

We must...

Protect water resources from degradation as much as possible

We must...

Minimise contamination threats

\section{In order to...}

Minimise contamination threats and protect the water resources from degradation

We must...

Have suitable awareness, monitoring and mitigation approaches for environmental factors

We must...

Have efficient water and wastewater treatment systems

We must..

Have suitable technology

We must...

Minimise throughputs of water

In order to...

Achieve reduced throughputs of potable water (because people are more considerate of the water resource and its limits)

We must...

Have superior local government employees and communication

We must...

Have superior communication within the community on water issues 


\section{In order to...}

Have superior employees in Council and maintain superior communication with the community

\section{We must...}

Build a culture of trust/goodwill/knowledge and leadership

The Injections are read thus:

But we can't have a culture of trust etc. without building stakeholder dialogue and knowledge exchange AND this requires trusted leadership.

Two other injections could be added and tested:

\section{In order to...}

Build stakeholder dialogue and knowledge exchange

\section{And}

\section{In order to...}

Empower 'trusted leadership'

\section{We must also...}

Have a reliable and systematic means of targeting and communicating with relevant stakeholders

\section{We must..}

Have a reliable and systematic way to synthesise all the relevant perspectives, knowledge and data.

It is important to clarify that the last two objectives are indicative only. They are the subjective opinion of the researcher and require testing, whereas the final IO requires objective conditions (according to Dettmer, 2007). Given they appear to be connected to IOs that involve communications; an FRT would likely be the place to test these injections using sufficiency logic, with the PRT providing the means to explore how to achieve them. A future study could undertake this analysis. Inasmuch it would explore the application of stakeholder modelling and a systems framework (such as TOC) as injections for system improvement, the use of the FRT and PRT to test the validity of a multimethodology that was used in this thesis, is a variation on the researcher's approach to fulfilling the thesis purpose (stated in section 1.4). 


\section{THE CRT: WHAT TO CHANGE?}

The CRT and CRB are essentially gap-analysis tools (Dettmer, 2007). By comparing a map of the current reality (in April 2009) with an IO map created at the same time, the reasons behind the current reality differing from the preferred system state can be determined. The CRT and CRB tell us what to change - the one simplest change to make that will have the most positive effect on the system (Dettmer, 2007: 23). The EC showed that conflict has continued under the weight of some invalid assumptions, helping to identify the direction of the solution, by making key requirements and their prerequisites explicit, and by revealing some injections that might solve the most critical constraint on the system. The contribution the CRT makes is to point out deficiencies in some of the cause and effect thinking in regard to the system under consideration, particularly once the core dilemma was surfaced:

\section{whether to build storage now or to defer the cost of storage and install meters instead.}

\section{Are Water Meters in the Future Reality?}

\section{It's a question of equity and fairness [...] there's plenty of rain in the hills so we need to answer, where exactly is the problem? - Participant}

There is a perception, endorsed by five of the thesis participants, that installing domestic water meters are necessary (or what is missing) to meet the goal of a more sustainable urban water system. Seven other participants stated that water meters are necessary given certain conditions, such as strong legal protection mechanisms to prevent water being treated as a saleable commodity. Three other participants did not see that domestic meters were a necessary condition at this time, being undecided or having an open mind. Three participants (in one interview) believed water meters were undesirable, as they detracted resources and attention that would be better put to achieving other objectives, including education about water conservation, catchment protection, and understanding the water cycle and its connections with the community. The two pilot participants were not asked for their opinion on meters. Thus, domestic water meters have been proposed by the majority of participants as a high-level requirement, if not a CSF. Dettmer (2007) contends that IOs, being necessity logic trees, depict things that must be done if the goal is to be achieved, and cannot include things that simply have a chance of meeting the goal. This approach rules out including meters explicitly as a necessary condition. Instead, the suggestion of meters is reflected in IO6 
[suitable technology] and IO12 [suitable awareness, monitoring and mitigation approaches]. Water meters are a cost to the system, both fixed and operational, and they do not produce water. On the other hand, KCDC (data at KCDC workshops 2008; 2009), Watercare (2009) and Beacon Pathway (2008a) research suggests that where meters are installed, considerable savings are made.

Following is the CRT for the dilemma facing Kapiti in April 2009: 


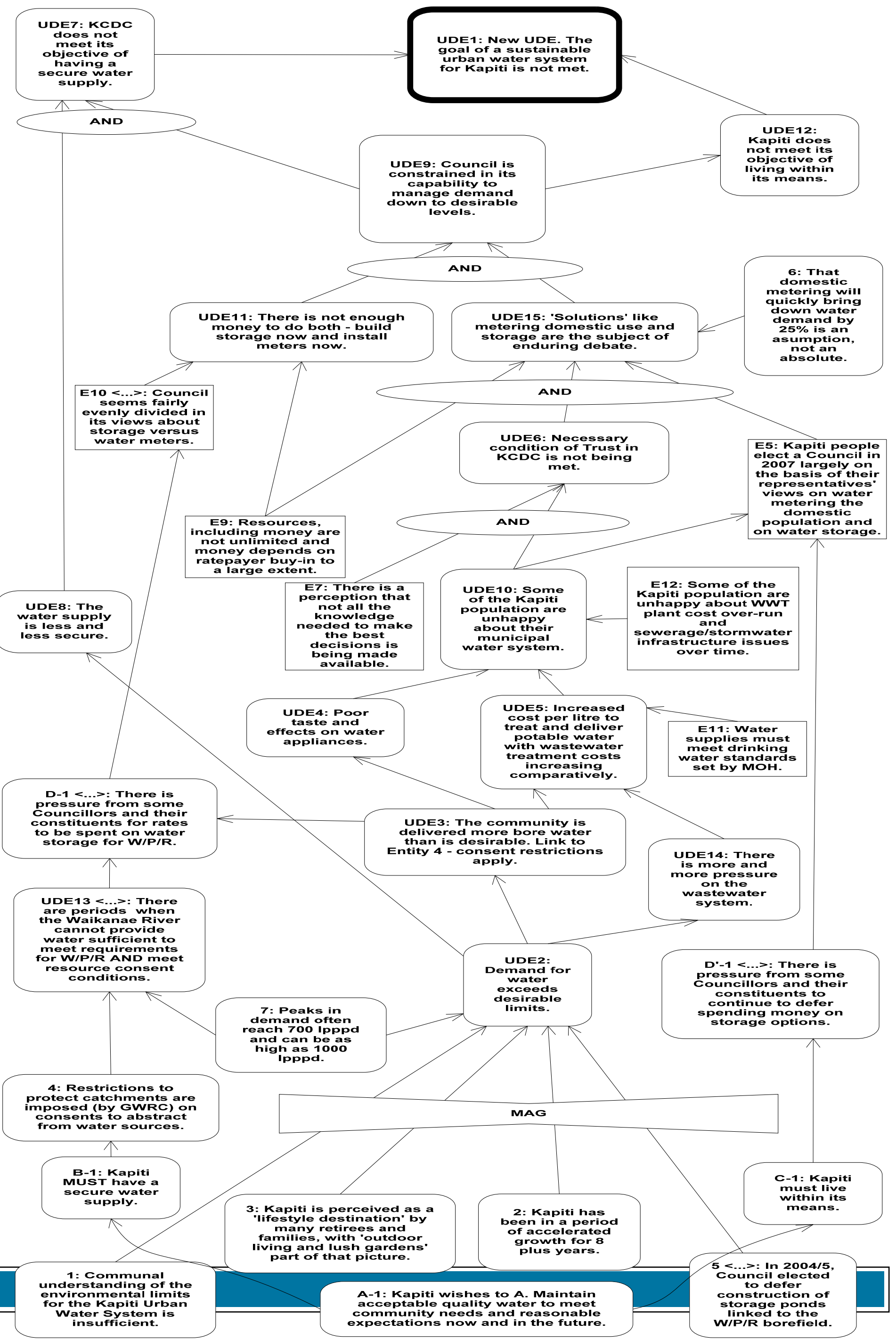


Figure 17 (previous page): Shows the CRT

The Current Reality Tree is a sufficiency tree. Note that MAG signifies magnitudinal 'AND'. In this condition, each cause contributes to the effect in an 'additive' way. In other words, each cause progressively contributes to the effect (Dettmer, 2007:47). 'AND' in an ellipse represents causes that cannot produce the effect without the help of the others. As a sufficiency tree (employing if...then logic), the builder of the CRT normally employs the Categories of Legitimate Reservation (CLR) to validate the logic (Scheinkopf, 1999), which would result in a much more dense tree. In the interests of simplicity for communicating easily on a reflective basis with the stakeholders, only the essential assumptions have been included in the tree presented here. Read the CRT thus:

\section{If...}

Kapiti wishes to maintain acceptable quality water to meet community needs and reasonable expectations now and in the future

\section{Then...}

Kapiti MUST have a secure water supply

And...

Kapiti MUST live within its means

$$
\text { If... }
$$

Communal understanding of the environmental limits is insufficient

\section{And...}

Kapiti is perceived as a lifestyle destination

\section{And...}

Kapiti has been in accelerated growth for 8 plus years

\section{And...}

In $2004 / 5$ Council elected to defer the construction of storage ponds

\section{Then...}

Demand for water exceeds desirable limits

\section{If...}


Demand for water exceeds desirable limits

\section{Then...}

The water supply is less and less secure

If...

The water supply is less and less secure

And...

Council is constrained in its capability to manage demand down to desirable levels, due to the effects of the entities below

\section{Then...}

Kapiti does not meet its objective of living within its means

\section{And...}

The goal of a sustainable urban water system is not met

The CRT shows the big picture. In the current reality, average water consumption is nearing manageable limits, while peak water use is nowhere near desirable levels, particularly in Waikanae/Paraparaumu/Raumati and in Otaki, being as high as 1000 litres per person per day (Ipppd) - see Appendix 10 for a table of figures. The desired maximum level of water use is $475 \mathrm{lpppd}$, allowing 75 Ipppd for leaks and miscellaneous losses (KCDC workshop data, 2008 and 2009).

The Waikanae River is the primary source of raw water for the Waikanae Treatment Plant when the flow rate in the river is more than $750 \mathrm{~L} / \mathrm{s}$ (litres per second). In 1978, there were twenty-eight days when flow was less than 750 L/s. In 1989, there were seventeen days. In 2003, there were 40 days (URS report, 2004), and to date, incidences of low flow continue to preclude the river from providing any raw water whatsoever. It is notable that extremes in flow, whether high or low, can be attributed to natural processes, and 'even though we have developed an understanding of the nature and frequencies of low flows and flood flows, we cannot prevent their occurrence' (Ibbitt, McKerchar and Woods, 2004:10.14).

On the above information, a fifteen to twenty-five per cent reduction in water use overall, as expected by promoters of the domestic meter option, may not be enough to prevent the system being stressed by peak demand at times when the river can least cope with it - during higher temperatures and dry conditions. Low flow is not the only constraint to consider. The incidence of 
toxic algal blooms in waterways throughout New Zealand appears on the rise and there is evidence that it is good practice to prevent blooms taking hold by maintaining a higher flow rate when a set of conditions occur together, including high temperatures (see Appendix 5). Hence, there are other days when the Waikanae River cannot meet the demand for water in the community and bore water either is mixed with river water, or is the sole supply through the treatment plant. Consent conditions dictate that bore water is used as sole supply for a maximum of ninety days per annum (indicated during 12 February 2009 KCDC workshop).

It must be concluded that although meters are one of a number of conditions that may be necessary to meet the goal of a more sustainable urban water system, they are not sufficient. They will not prevent the borefield being required as a sole source of supply through the Water Treatment Plant when the flow rate drops below desirable levels for the conditions and they will not contribute improvements to the taste and effects of water delivered from the Waikanae borefield. Indeed, there may be alternatives to meters that deserve closer attention - one or two changes that will be sufficient to shift the current reality to the one depicted in the IO map.

\subsection{Requi Red Changes}

The changes that came to light through this analysis are to build small scale storage capacity (in W/P/R) and to accompany any increase in capacity with strongly communicated and community-wide messages about conserving water, protecting catchments, respecting water restrictions, and taking up onsite technologies to provide alternative sources of non-potable water. There is a need for trusted leadership to build the stakeholder dialogue and knowledge exchange required to facilitate all the objectives anticipated by the participants as necessary for desired change that meets the system goal of a more sustainable water system. The Starborough case brought to light a number of effective alternative solutions to remedying the effects of water scarcity, finding ways to live, and to be even more productive with less water. Their case could inspire far-reaching change for Kapiti and other similarly challenged communities.

\subsection{Testing the Proposed Changes}

The PRT is a logic tree used to explicitly point out obstacles and test proposed injections to answer how to cause the change? It is an effective way to reveal flaws in logic, sometimes bringing to light new problems and injections that were missed in the CRT and the EC (Dettmer, 2007). The PRT was the final TOC logic tree used in this analysis. 
Intermediate objectives can be tested for their relevance and validity with the PRT. Alternatively, some direction and validation for IOs can be gained by constructing a future reality tree (FRT). The FRT is closely associated with answering the critical question what to change to? (Cox et al., 2003:115), for which the researcher applied the EC with assumptions and the CLDs. The apparent effectiveness of the selected TOC and Systems Dynamics tools in revealing what to change to? for this system issue, led to a decision that an FRT was not a necessity in this case.

\subsection{The PRT: How to Cause the Change?}

This is the Prerequisite Tree (PRT) for the dilemma facing Kapiti regarding securing the water supply and achieving a sustainable urban water system. The PRT is intended to answer the question: "What must we do to achieve...?" The PRT is a necessity structure, whereas a Current Reality Tree (CRT) is a sufficiency structure (as is the Future Reality Tree). The PRT aims to identify the minimum that must be done in order to move from one step to the next. 


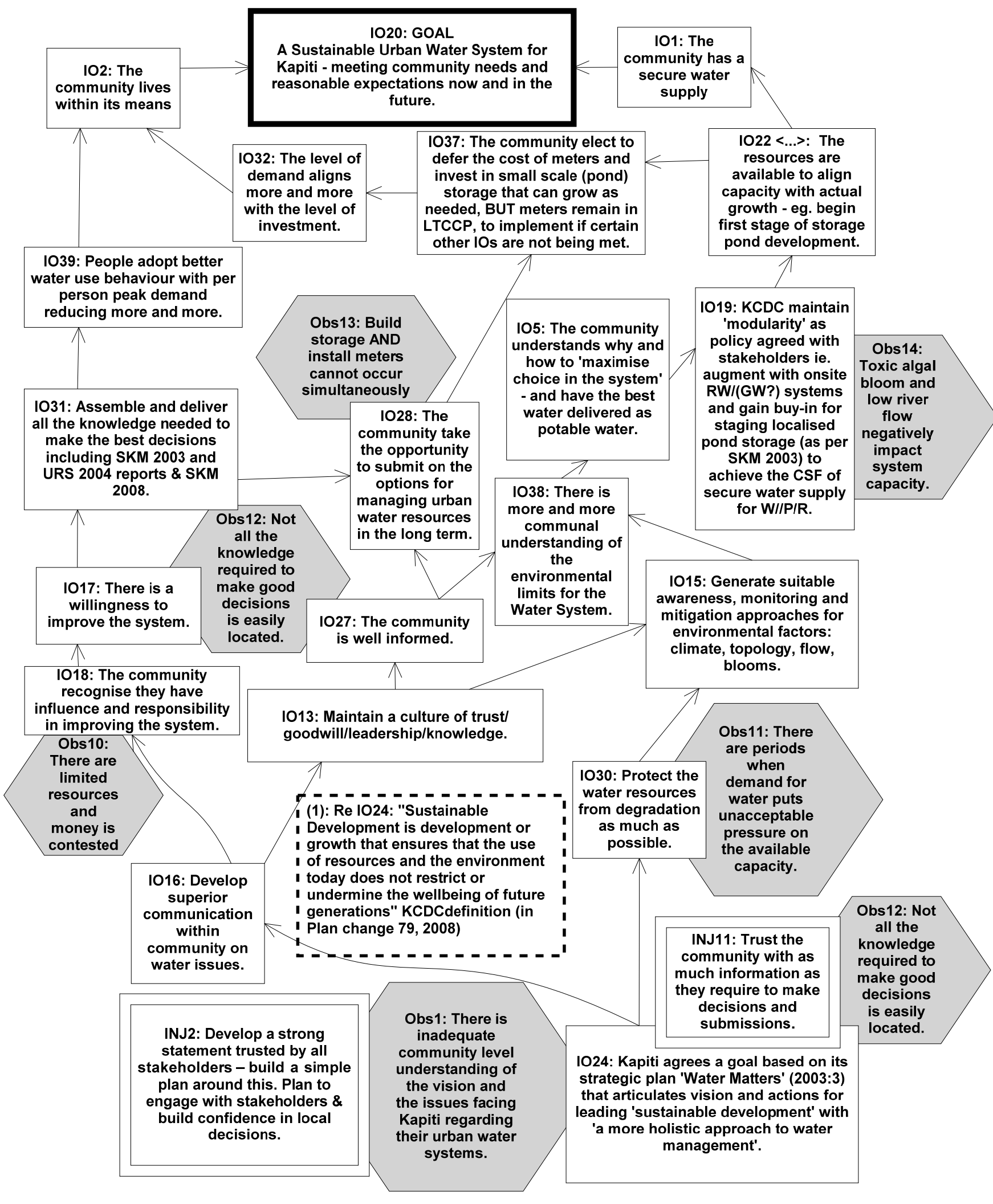

Figure 18: The Prerequisite Tree (PRT).

Read the PRT backwards from the goal, thus: 


\section{In order to...}

Achieve the goal of a sustainable urban water system for Kapiti

We must...

Live within our means

We must...

Have a secure water supply

\section{In order to...}

Have a secure water supply

We must...

Have the resources available to align capacity with actual growth

\section{In order to do that... We must...}

Ensure the community understands why and how to 'maximise choice' so KCDC can affordably deliver the best water in the system as potable water (in other words, protect the system's 'best water' - currently the river resource - as much as possible)

\section{And because of the obstacle...}

Toxic algal blooms and low flow impact on consents and on the capacity of the river to provide the system's best water

\section{We must..,}

Ensure KCDC maintains 'modularity' as policy...eg onsite systems and other small scale storage/recycling systems to augment capacity (onsite systems may also encourage closer connection with the water cycle to increase understanding)

Read other obstacles as follows:

\section{In order to...}

Adopt better water use behaviour, with per-person peak demand reducing more and more

We must...

Assemble and deliver all the knowledge needed to make the best decisions, including the SKM (2003 and 2008) reports 


\section{Because we must overcome the obstacle...}

Not all the knowledge required to make good decisions is easily located

\section{And, in order to...}

Cultivate a willingness to improve the system

\section{We must...}

Ensure the community recognise they have an influence and a responsibility in improving the system

\section{Because...}

There are limited resources and money is contested

ETC.

\subsection{SUMMARY}

This chapter has presented the outcomes of eighteen interviews with twenty participants identified using the stakeholder typology adapted from Rawlins (2006) and Elias et al. (2002). The use of the Stakeholder Typology to complement TOC provided a tactical element not routinely evident in systems studies, valuing the experiential and historical perspectives of those who might otherwise be treated as being outside the system, their perspectives potentially marginalised or ignored. The researcher applied the Theory of Constraints (TOC) Thinking Process (TP) tools to problems and undesirable effects revealed through the interviews, in order to find out what to change, what to change to and how to cause the change. As part of this process, the researcher constructed IO maps to show the destination, as envisaged by the stakeholder participants. A Current Reality Branch (CRB) and later a Current Reality Tree (CRT) were prepared to visualise the current situation and to suggest where the core tensions lie. Conflict was captured in the TOC Conflict (Evaporating) Cloud (EC), and explored with the participation of two Kapiti Coast District Councillors and selected participants, to reveal some weak assumptions and gaps between the current and desired reality, key to understanding how to resolve critical problems affecting the system goal to find what to change to. Causal loop diagrams (CLDs) in the form of a systems archetype from systems dynamics (SD) explored the potential negative effects of a suggested solution from the EC. Finally, a Prerequisite tree (PRT) was used as a means of finding out how to cause the desired change. 


\title{
ChAPTER Five - I nTERPRETATI ON OF Findings AND Di sCUSSION
}

\author{
The Conflict Resolution Cloud is a kind of creative engine \\ that allows us to invent breakthrough solutions to \\ nagging problems (Dettmer, 2007: 24)
}

\subsection{Introduction}

Chapter Five discloses the researcher's interpretation of the findings and discusses the relevance of the methodology to addressing the thesis purpose statement.

\subsection{Thesis Purpose Statement}

This qualitative study tests the use of the TOC (Theory of Constraints) systems framework and a stakeholder typology to examine ways that communities can gain better outcomes from their investment in urban water management initiatives. The thesis demonstrates the methodology by focusing on Kapiti, a coastal settlement north of Wellington, which has been actively debating and responding to serious water security issues for more than a decade.

\subsection{The Findings and their Significance}

The TOC thinking processes surfaced salient information and constructive arguments from the participants. These findings are significant, as the best information and careful arguments, located logically and coherently, are required by resource managers and other system stakeholders to make good decisions. These decisions have potentially far-reaching effects on the community and the ecology of which it is part.

\subsection{Using TOC to I dentify the Core Constraint}

The water from the wells is potable...but awful! [...] We need proper planning with due consultation (but) there's been no attempt to truly build trust - Participant

A characteristic of TOC, as used to understand the case of Kapiti's urban water system, has been its step-by-step approach to interpreting the bigger picture. This included identifying and agreeing with participants, the most important and undesirable effects of variation on the system goal, and the root cause of these - in this case a pattern of unreasonably high peak water consumption (see the Conflict Cloud analysis for the implications of identifying peak 
consumption as a critical constraint). Identifying the root cause of symptoms and problems that affect the system goal, before the system 'threshold' is breached has real significance to the management and conservation of natural resources.

Participants identified that the water system needed to become more resilient and develop more flexible design elements. These elements were identified by most participants as involving more uptake of onsite rainwater harvesting. A number of participants suggested that the Ministry of Health (MOH) and Department of Building and Housing (DBH) accept that recycling water to gardens and trees, and under certain conditions to toilets for flushing, must form part of a plan for change, if fresh water is 'to meet the (reasonable) range of values and uses for which it is intended' (participant comment). Generally, the participants who urged more flexible design were doing so with the expectation that homeowners and businesses would then take greater responsibility for one part of the water cycle. In this way, the system as a whole might benefit from a multitude of small changes that would allow it to more readily cope with or adapt to changing conditions, including peaks in demand.

The effects of variations of climate, earthquake or human activity can overwhelm an affected system that is ill prepared. The need for suitable awareness, monitoring and mitigation approaches were suggested in one form or other by the majority of participants and the two Councillors. This suggests that risks to the system, such as toxic blooms, low flows, discharges from rural activity and stormwater flow, must be made more transparent to the system stakeholders. It is apparent from the discourse I have come across in preparing this thesis (including letters to the Kapiti Observer) and from the interviews with consumer participants that there is a will to understand more about the water system. Councillors also, expressed a desire for timely and relevant information, so they can make informed judgements as to the issues they are considering. The actions and decisions required to achieve a new level of transparency and engagement are not easily identified or made. However, the study revealed that TOC can provide a useful, uncomplicated and unthreatening way to conduct meaningful conversations that capture the relevant information to assist the resource management process, and make progress towards the goal of a more sustainable system for all.

\subsection{THE POSITIVE ASPECTS OF APPLYING TOC}

Taking a systems approach to managing the community's resources, with the collaboration of community members and other interested stakeholders as 
participants, resulted in a number of positive effects, which were evident in the findings:

$>$ Key points became known and understood among more people so that necessary conditions and significant effects on the system could be agreed

> Communication was facilitated between stakeholders who otherwise would hardly ever exchange knowledge or perspectives, with the necessary condition 'building trust' a potential desirable outcome

$>$ Salient facts were uncovered that could assist with meeting the system goal

> Conflict logically described and interpreted in the Conflict Cloud (EC) (reproduced in the analysis) was allowed a meaningful conversation, with invalid assumptions able to be discounted from the argument. A key assumption that proved to be invalid is that people would use less and less water after the construction of the borefield, as the demand management strategy was implemented. Decisions were made in 2003/4 and onwards, based on a water consumption figure that was not achieved. This has led to unacceptable pressure on supplies at peak times, and a risk to water security.

$>$ The primarily one-on-one conversations between the interviewer and each participant, using the same range of questions for all, produced highly relevant data. This data (in the researcher's opinion) would have required greater effort and skill to amass, if using open-ended interviewing techniques or conducting focus group discussions, in the absence of the logical connections provided by the TOC Thinking Process Questions and complementary tools.

$>$ The TOC philosophy is that participants share their viewpoints and knowledge with others and each perspective is equally valid. By following this path and not requiring participants' comments to be confidential, interpretation of the information was somewhat collaborative, enhancing the range of understandings about the problems and opportunities facing the system, with a number of participants claiming this or that bit of information was new to them, and then offering a useful way to frame or apply it. This assisted the preparation of the IO Map (or Destination finder) and the EC (the Conflict Cloud), with all participants contributing to identifying the injections to break open the conflict and lead to a win/win pathway for achieving a more sustainable urban water system for Kapiti. 


\title{
5.6 Revealing What to Change and What to Change To with the TOC Tools
}

\author{
The search for a magic bullet goes on (when) really we \\ need a coherent package of options [...] we need good \\ advice and good science to support it [...] we need to be \\ properly informed [...] we need a connection to the wider \\ ecology - Participant.
}

The starting point for this study was the TOC IO map, prepared with the pilot participants and shared with participants before or at the time of their interview. The goal statement was discussed, as were the few critical success factors participants thought were required to realise it.

As the study progressed, the IO map was refined with the aid of the participants, until the final IO (or Destination) map was prepared. The addition of a set of injections that arose from interviews is a slight variation on Dettmer's IO map (see chapter three of Dettmer, 2007). The injections are essentially new IOs, uncovered in the course of the study, which are subordinate to other necessary conditions and may not be considered truly objective (as is required by Dettmer, 2007).

The new injections are part of the picture of what should be happening in the system, or what participants want to happen. The IO Map provides a benchmark to compare against the current reality, as illustrated in a Current Reality Tree or Branch. This study found that the EC and a Current Reality Branch was sufficient to provide a clear illustration of the core dilemma. This was derived by examination of the gaps between the state participants would prefer (the IO) and the actua/situation (CRB) in the part of the system most affected by the constraint.

Using the cause and effect logic to explain what is happening in the urban water system under scrutiny and then comparing that with the destination map, assisted the researcher to drill down and find the root cause of the undesirable effects participants talked about in the interviews. In the case of Kapiti, one of the root causes of its difficulty in maintaining water security is the assumption first made in 2002, and again in 2003 and 2004, that demand would reduce. This has not eventuated as envisaged, with peak water consumption actually increasing in the Waikanae, Raumati, Paraparaumu catchment. The peaks generally occur when rainfall is low, putting significant pressure on the system, because there are steps (or injections) required, but not yet in place to deal with the peak demand. For the assumptions and related 
injections, refer to section 4.9 that presents the Conflict Cloud (EC) analysis and the Causal Loop Diagrams (CLDs are also discussed below).

\subsection{The Causal Loop ArChetypes (Senge, 1994)}

By framing problems and solutions in a causal loop diagram, positive and negative feedbacks could be noted more easily than if they were articulated in a more complex (TOC) negative branch (Cox, Mabin and Davies, 2005:52). This agrees with the finding by Mabin, Davies and Cox (2006) that CLD's complement TOC.

On 3 March 2009, two Councillors reviewed and discussed the findings of the study with the researcher. The Councillors agreed that the Causal Loop Diagram showed the need for extra intervention if a certain pathway, indicated by the EC, was followed. By applying the 'fix that backfires' archetype (also known as the 'fix that fails'), it became evident that water storage was needed in the short term but that if water storage was provided, the community would use more and more water as growth was accommodated. Following patterns and trends of the past, people may become less conservative or protective about water when they perceive that the water supply is secure (Senge, 1994).

The injection provided through representing the situation in a CLD 'Fix that backfires' archetype, is that any investment in storage options for the community must be complemented by a substantial investment in water conservation education, catchment protection, and water sensitive design initiatives and incentives. Increasing access to information on recycling water for use on gardens, incentivising rainwater capture for toilet flushing (and washing clothes where practical and desirable), providing well-researched and credible safety messages for designing recycling systems, correcting misinformation; all of these activities require investment, according to the findings of this and other studies (Beacon Pathway, 2008a; White, 2007).

Thus, any investment in alternative water supplies for Kapiti must be accompanied by greatly enhanced water conservation practices if storage is not going to, in time, lead to overconsumption of the supply. The knock-on effects from increased water consumption are to produce more wastewater (with relative increased costs involved), and other discharges, such as stormwater runoff from outdoor water use (with relative increased risks and costs from carrying silt and pollutants into nearby waterways). These undesirable effects may contribute to degrading the system in a magnitudinal fashion, as has been the experience of the Goulburn-Broken catchment in Melbourne (see section 1.6). 


\subsection{STAKEHOLDER TYPOLOGY}

\section{Engagement is not as good as it should be - Participant}

The stakeholder map and stakeholder typology were a critical part of the research design. To the best of the researcher's knowledge, a Stakeholder Typology of the type described in Elias et al. (2002) and Rawlins (2006) has not previously been combined with TOC and tested with participants.

The first three steps to stakeholder analysis, according to Harrison and St. John (1994), are 'to identify stakeholders, classify them into meaningful groups, and prioritize them'. By combining stakeholder theory with the decision-making framework TOC, a comprehensive and systematic process for identifying and prioritising the stakeholder groups with contributions to make or be gained, has been identified.

Developing positive relationships with stakeholders 'is a necessity for organizations' (Rawlins, 2006). Traditionally, there is a tendency 'to respond to the squeaky whee/stakeholder' (Savage et al., 1991), to those with urgency, and to the obvious power holders (Rawlins, 2006). By properly prioritising a system's stakeholders and their relationships through the stakeholder typology adapted from Elias et al., (2002) and Rawlins (2006), so that situation and experience are explicitly considered, and legitimacy, power and urgency are measurably understood, the 'squeaky wheel stakeholder should only get the attention that is required to serve the system better' (Rawlins, 2006).

Mapping the participants using the stakeholder typology surfaced 'new' information from decision makers and community, who may not have had their views and knowledge aired otherwise. Stakeholder analysis and TOC appear to offer complementary strengths:

> Using stakeholder typology and TOC together proved a practical way to explore a community problem at its core, with a group of highly articulate participants who may otherwise have remained silent and kept their wisdom to themselves.

$>$ The twin frameworks facilitated a process that valued every participant's perceptions, to realise and implement opportunities, and break constraints. This has potential to elevate the community's comfort with the decisions being made on their behalf.

Through the typology, participants were identified who had useful and relevant knowledge to share. 
> Under the usual TOC framework conditions, the two Starborough Flaxbourne farmers, with their breadth of experience in managing water and soil in drought conditions, would likely have been excluded.

> Moreover, the members of Grey Power, with their interest and recollection of events, trends and problems experienced by Kapiti over time, may have been unlikely participants in a typical management study (though it is notable that KCDC staff recommended that Grey Power be included in the study).

The generic stakeholder map (Freeman, 1984 and Elias et al., 2002) assisted the researcher in deciding on stakeholders as they are linked to the system issue, while Rawlin's (2006) linkage model assisted in verifying that the perspective participants were indeed stakeholders. The stakeholder typology provided a valid means to identify the people and groups who had a measure of power, legitimacy, or urgency, or a combination of these, and who would, through sharing their viewpoints, offer relevant, partial, and impartial insights. When the insights were framed in a considered and logical way, such as using the TOC tools, new information appeared to surface.

\section{What's important is having a strong voice - Participant}

It is notable that in many management studies, the participants are chosen within or by the organisation under study, either randomly or purposively. Either way, there is potential for partiality when the participants are selected in this way and this may be the desired effect. The stakeholder typology appears to complement the systems view that perspectives from people with something to contribute to the system are required (Dettmer, 2007, Kim, 1993, Senge, 2008), whether that view is partial or impartial and whether the participants are internal or external (Elias et al., 2002) to the visible limits of the system. From the researcher's perspective, valuing external stakeholders more for their situational knowledge, than for their definitive characteristics, is a defining characteristic of the Stakeholder Typology as it was adapted for this project (see Rawlins, 2006 - linkage mode).

External stakeholders with low or no power or urgency included water engineer, Dave Alderton from Connell Wagner, and farmers Kevin Loe and Doug Avery from the Starborough Flaxbourne Group. The knowledge from these sources, delivered with minimal political, social or technological partiality, helped produce a key injection identified in the analysis. This was the proposal to build storage ponds in stages in line with growth and behavioural change outcomes, for a likely lesser cost than other 'enhanced supply' (KCDC, 2009) 
options. This option effectively connects with community prosperity - as the construction of more storage would be explicitly linked to growth and a comparative increase in rates dollars to Council. The spark of this idea came up during the interviews with Doug Avery and Kevin Loe, as they were at the time of the interviews dealing with consent issues around water allocation and water security, separate from their drought issues. Their problem shared similarities with that of Kapiti - population and business growth was putting undue pressure on the current water system, increasing risks to the system and the 'welfare' (Walker and Salt, 2006) it delivers, with costs to meet drinking water standards increasing, as the quality of raw water falls.

\subsection{INCREASI NG STAKEHOLDER AWARENESS OF THE SYSTEM AND ITS LI MITS}

Interestingly, applying the TOC Thinking Processes to the KCDC dilemma, regarding water meters and storage options, highlighted an unsatisfactory ambiguity of data around water consumption figures. It appears that statistical data presented as representing water consumption does not always reflect the true distribution of consumption by domestic versus commercial consumers. Data from the Ministry of Social Development's Quality of Life Report (2007) suggests Wellington City has among the lowest water consumption in the country (under 166 litres per person per day), while IPENZ (2008) suggests otherwise, with the figure closer to $350 \mathrm{lpppd}$. In reviewing a number of reports in similar periods, the researcher found there was a wide variation between figures. Accurate and timely information is required, as noted by the majority of participants in this study, because better decisions can be made when based on a sound understanding of where the weaknesses and opportunities in the system lie.

Finding solutions to the question of what can be done and who might pay for it requires that interested stakeholders gain a detailed understanding of how the water is distributed across the community. Public water supplies used $16 \%$ of New Zealand's allocated water in 2000 (Robb, 2000) and 20\% in 2006 (MfE, 2007). Irrigation use comprises around $77 \%$, but varies across the country between $1.4 \%$ and $249.8 \%$ (Robb, 2000). Business and industry use averages $11 \%$ of allocated water (MfE 2007) but ranges up to $42 \%$ of the public supply allocation (Robb, 2000). This indicates there may be more value to be gained from engaging with the business sector on the application of water sensitive design and conservation practices than broad opinion seems to reflect.

In response to the suggestion that a significant problem for the water system was caused through insufficient awareness of the system's limits, some participants proposed that a generous buffer was needed to mitigate the effects of breaching the limits. This buffer has been described by some 
participants as resilience (defined in the literature review) and describes the preparedness of the system to better absorb 'shocks' like climatic extremes or earthquake. In as much as they have been described as necessary conditions, resilience and flexibility deserve fuller discussion than is available within this paper, as the section on future research suggests.

Inevitably, increasing a community's awareness of the urban water system and its limits can serve to enhance system improvement, as community members are more willing to make necessary changes. In regard to SUWM, the triggers to system improvement and the levels of change have yet to be researched thoroughly in New Zealand. By comparison, Australian studies of triggers, barriers and responses are increasingly comprehensive. These may show extended drought as a common motivating factor for substantial (though not always sustained) reductions in water consumption. It is notable that in 1993/4 and 2006 respectively, when Auckland and Wellington experienced severe droughts (and at the same time Wellington suffered a significant loss of water through leakage), water consumption reduced markedly in affected areas. Both Auckland and parts of Wellington appear to have continued with water conservation practices, with Wellington City residents' per capita use 166 Ipppd as noted above (while nearby Porirua is higher, at around 350 lpppd), and Auckland City averages 190 Ipppd (figures from MSD's Quality of Life Survey, 2007; Watercare, 2008). In view of Wellington City's results, it appears that Wellington's Be the Difference campaign is emerging as a measurably successful tool to promote widespread uptake of the water conservation message (personal comment from BtD campaign organiser on World Water Day, 22 March 2009).

Opinion varies on the value of education and incentives to advancing positive behavioural change. New Zealand consortium Beacon Pathway (2008b) conducted research recently and concluded that a 5 per cent reduction in water consumption could be gained from education alone, while 10-15 per cent could be achieved during peak demand periods by combining education with regulation. Anecdotally at least, it appears that at household level, community members are prepared to take more responsibility for their water consumption by adopting greywater reuse options and by capturing and storing rainwater in household tanks for later use to fill pools, water plants, and flush toilets (White, 2007), with meaningful water savings made. Households and increasingly, businesses are adopting water saving technologies, such as low flow taps and toilet flush devices that save thousands of litres of water use each year, not to mention the energy savings from reduced hot water consumption. However, participants in this study pointed out that policies and legislation can sometimes impede progress being made in these areas. Ian White's (2007) 
case study of a water-sensitive urban design project in a house in Queensland, Australia, serves to reinforce this view, as does a Beacon Pathway study of water sensitive retrofitting (Birchfield, 2007).

It is notable that two participants were concerned with potential undesirable effects arising from household recycling of water. This appears to be a valid concern, judging from the poor record of some New Zealanders in maintaining their onsite sewage systems (the researcher undertook an informal study of systems in the Hawkes Bay in 2006, and was alarmed by the number of system failures and consequent environmental harm. Failures largely stemmed from systems being too small for the quantity of wastewater discharged.) Efforts to legislate or otherwise impose the use of onsite water recycling systems and rainwater harvesting systems must therefore be accompanied by encouraging users to develop a thorough understanding of their recycling or other onsite system and the implications of certain behaviours on the surrounding environment. It was suggested by some participants that 'alternative solutions' should be documented in various contexts so that users can be confident in their system design, with installers made aware that they must strictly adhere to all the design requisites. KCDC have organised 'Plumbers' breakfasts' accompanied by training and fairly detailed design descriptions of rainwater harvesting/recycling options, in an effort to 'get the right information into the right hands.' However, it remains for the plumber and the system retailer to communicate with the consumer on any health and safety issues that might arise from using certain detergents or bleaches, or simply from using too much water. High quality communication with the end user is a prerequisite for the success of WSUD initiatives (Thomas et al., 2007) so 'keeping in touch' should be encouraged. KCDC could use the Green Gardener or Green Plumber or Mayoral comment section in the media (Kapiti Observer) to voice potential concerns and solutions.

Within New Zealand, as in the rest of the world, there are increasing and competing demands for water resources (Birchfield, 2007). There are also differing perceptions about risk. Nevertheless, the opportunity exists for New Zealand communities to develop more resilient and sustainable urban water systems, but only if the most pressing issues can be addressed. Change requires deeper understanding of the possibilities, the risks, and the true constraints. It requires greater emphasis on how communities and other stakeholders can work together to facilitate more sustainable environmental, and sound business, agendas. The TOC tools can assist with identifying what is the destination, what to change, what to change to, and how to cause the change, and therefore appear to be fitting for this task. 


\subsection{THE NEGATIVE ASPECTS OF TOC}

The negative effects of applying TOC to complex problems stem from the not inconsiderable effort required to construct the diagrams. The greatest difficulty for the researcher was experienced when creating a comprehensive CRT from a diversity of data to depict the current reality. That this can be a timeconsuming and somewhat confusing task is not unique to TOC, 'and is the case for most systems dilemmas' (personal comment by systems expert John Friend, during a February 2009 seminar at Victoria University).

In this investigation, the constraint was duly overcome, when a decision was made to focus on the most problematic part of the system (as suggested in Dettmer, 2007). This had the effect of keeping the diagrams as simple as possible, while still capturing the essence of the situation. Following argument in Cox et al. (2005), the researcher expanded the methodology 'to illustrate the main relationships at play' (ibid. 2005:52). Using the TOC CRB and EC to describe the core dilemma, and combining this approach with the (Senge, 1994, 2008) archetype CLDs from systems dynamics, had the effect of furthering the researcher's and selected participants' understanding of the symptoms and their effects. The CLD was used to signal the most negative consequences of actions, policies, patterns and events, without the considerable effort apparent in preparing a CRT to describe the whole system.

\subsection{A SIMPLE PLAN}

\section{We're going to run out of water if we don't do something soon - that's why we have to be focused on simplicity - we need a simple plan and the right people - it's quality of communication that's missing - Participant}

A number of participants have asked for recommendations or 'a simple plan' arising from this thesis. The following interpretation of the findings was prepared in particular regard to the dilemma facing the Waikanae, Paraparaumu, Raumati catchment, and was distributed to participants at their request, in line with Bassett's (1995) suggestion for ongoing dialogue. See Appendix 10 for more background to the issues and an excerpt from the KCDC (2009) consultation document.

This investigation and exercise concluded in March 2009 that staged construction of one of a potential series of storage ponds is a favourable option that meets the community's requirements for better 'resilience' and 'flexibility', 'secure supply' and 'living within means'. It also does not contradict Kapiti's 
Water Matters (2003) strategy for urban water that is based on favouring an in-catchment approach to water supplies. An in-catchment approach appears to have the support of the wider community and is the preference of the iwi managing authority, according to the work carried out by the PCE in 2000/1, and based on my 2008 interview with Te Âti Awa's representative and other discourse. Some participants expressed concern that the idea of introducing an Otaki to Waikanae pipeline has been raised for a second time, with one making the following comment:

\section{The best thing the iwi could do is to make a very strong bid to protect the only river in the region that still has a natural flow - Participant}

The pipeline is not supported for the reasons above, and also for the following:

> Evidence suggests that the Otaki's underground water flow is directly affected by the river flow (see Young, Smart and Harding, 2004: 37.5), with river water streaming through the porous riverbed to the underground system below. Allocating water directly from the river (and from underground) for a distant catchment risks compromising the localised groundwater allocation that in this instance is already under pressure (see Painter, 2004:45.9).

> As noted by the participant above, Otaki is one of the least disturbed of all the river systems in the North Island. The science is not absolute in terms of determining the harm that may come from allocating Otaki's river water. However, in view of the less than acceptable quality of more than two thirds of New Zealand's surface freshwaters (EW, 2008), maintaining caution and preserving the qualities and characteristics of the Otaki river system, would seem the wisest approach.

Recommendation: Purchase of the land identified in the SKM (2003 and 2008) reports should be undertaken as soon as practically possible, with a commitment to connect the Waikanae borefield with the first pond (or reservoir). This has six overarching benefits:

$>$ The community water supply is secured for the conceivable future.

> The value of the borefield is preserved, as bore water can be mixed with stored water.

> The risk of toxic algal bloom is reduced through the bore water being introduced. 
> The taste of water supplied from storage ponds will be similar to the Waikanae River water, addressing ratepayers' quality concerns.

> Ill effects on water appliances from the effect of the bore water will be halted, also addressing quality concerns.

Costs to treat the stored water should track lower than costs to treat bore water.

The value of meters as a mechanism to manage demand down is not in question. However, household metering on its own will not reduce demand in the short term to what is required for a fully secure and sustainable water system for Kapiti. Therefore, defer retrofitting domestic meters and address the critical constraint - peak demand. There are unforeseen consequences to consider with the use of meters. These could be captured in a CLD (Senge, 1994) or negative branch Mabin et al. (2006) analysis. The priority must be to meet the objectives from the IO map and phase in 'enhanced supply' (KCDC, 2009 ), potentially with a $600,000 \mathrm{~m}^{3}$ pond just south of the Waikanae River. SKM (2003) had estimated the work to complete a pond of $1200,000 \mathrm{~m}^{3}$ would take two years, including time to purchase the land and gain consents. For the goal of a more sustainable urban water system to be met, the construction of one or more ponds must form part of a carefully managed plan to reduce water consumption. Peak consumption in particular must be addressed, by investing more than currently in education, incentives and engagement with the community and other stakeholders, and by ensuring the necessary people and processes are in place to direct this change.

If growth and demand do not require the construction of an additional pond within ten years, rates can positively reflect this. On the other hand, if the average per capita demand or peak demand does not reduce to target levels within a predetermined period and the recommended water sensitive design incentives, restrictions, education, and leak detection/maintenance programmes are adequate, then community-wide water meters must remain an option for Council. Policies and action to preserve the continuity and integrity of community water resources are vital to the wellbeing of current and future generations. 


\title{
Chapter Si X - Conclusions
}

\author{
Effectively, the community is likely to be in breach of \\ consent limits within the next five years. Breaching the \\ consent or running parts of the water supply system out \\ of water are not acceptable options (KCDC, 2009:5/19).
}

The motivation for this study was to consider how communities might take a more integrated and systematic approach to meeting the challenges of water management in New Zealand, and achieve more sustainable systems.

This thesis is essentially a conversation on the subject of how we might manage our fresh water better. The study engaged with a number of willing individuals, all stakeholders in a New Zealand urban water system, and asked them for their perspectives about the system destination, what to change, what to change to, and how to make the changes necessary for more sustainable urban water systems.

The overarching message from the participants in this study is that for the urban water system to serve our communities and businesses better, the range of stakeholders must develop a deeper understanding of the system's limits and opportunities. If limits are not understood and agreed, it is difficult to live within them. If opportunities are not revealed, it is hard to grasp them (planting drought-resistant lucerne instead of rye-grass and clover for example). The thesis findings suggest that better decision-making is required to develop more sustainable environmental, and sound business agendas, that address the widest possible range of stakeholder interests. This is no small task. The participants were almost unanimous in the view that resource managers must take responsibility for raising the depth of understanding and gaining agreement towards a defined goal for the system and its range of stakeholders - and they need the resources and mechanisms to do it.

Socrates would have us acknowledge, we know only that we know nothing (Socrates café, August 2005:5). Undertaking this thesis and using TOC and Stakeholder theory to consolidate thinking into vision and action leads the researcher to reflect that:

We know not nearly as much as we think.

To think out loud is to challenge the thinker to take an imaginative leap toward creative thinking. It follows that to foster the sort of innovative change 
required to create a shift in mindsets and patterns of behaviour, an environment must be built and sustained that stimulates the spirit of enquiry, and invites people to "think out loud". The Starborough Flaxbourne Project provides an illustrative example. TOC provides a constructive and nonthreatening way to encourage this kind of deeper level reflection. However, the TOC tools alone could not achieve the research objectives. There must be a way of opening up the field of enquiry, and to facilitate ongoing reflexivity (Basset, 1995), so that system improvement does not come to a halt. The use of a Stakeholder to complement the TOC Thinking Processes facilitated this reflexivity, developing a straightforward, systematic engagement process. Dettmer (2007) urges that simplifying approaches is the key to finding out what we know and that it is better to be approximately right than precisely wrong. This premise of simplicity was fundamental to the design of this research and to the process of ongoing engagement upon which this enquiry was constructed.

TOC was found in this study to have enabled enhanced decision-making by defining a shared goal for the system and valuing perceptions that actively enhance societal knowledge and insights about how to meet the conditions necessary to achieve a shared goal. The Parliamentary Commissioner for the Environment (2001) had predicted nearly a decade ago that reaching consensus between stakeholders on environmental, social and economic goals for urban water systems would become one of the greatest challenges facing communities New Zealand-wide. The veracity of this appears indisputable in 2009 and is reason to value a methodological approach that might recognise the perspectives of diverse stakeholders and at the same time provide the means to logically evaluate system issues and opportunities and reveal suitable leverage points for motivating change.

Currently, water managers access a variety of tools or frameworks to assist in modelling scenarios for decisions that attempt to represent many and varied interests and associated risks. The findings of this study suggest that TOC can offer a complementary perspective, differing from most frameworks because it applies rigorous criteria with 'soft' intuition to identify and importantly, to validate, the connections between the diverse elements of the system. Through TOC, the participants reached a common understanding and defined a goal that everyone aspired to, despite the fact that most of the participants never met one another.

Making better decisions about our fresh water is vitally important to our future. Armed with the right information, presented logically and coherently to as many representative stakeholders as practically possible, it is in the power of New Zealand communities to make better decisions - wise decisions that 
prevent or mitigate undesirable effects on their freshwater system today, preserving the integrity and health of the system for tomorrow.

\subsection{CONTRIBUTION}

This paper has sought to make two contributions. The first is to test a methodology that might facilitate more integrated and systematic approaches to meeting the challenge of achieving more sustainable urban water systems in New Zealand. The second is to present the insights of participants to reveal assumptions underlying the not uncommon dilemmas faced by urban communities regarding water, and present a TOC 'roadmap' of the minimum changes required to resolve these dilemmas.

This investigation has determined the effectiveness of methodological developments in the field of urban water management. The findings may contribute to theory and practice on Managing Sustainable Urban Water Systems (SUWSM) and the closely related Integrated Water Resource or Catchment Management.

It is possible that the combined theoretical framework can be applied to other resource management cases. The use of the Stakeholder Typology to complement TOC provided a tactical element not routinely evident in systems studies, valuing the experiential and historical perspectives of those who might otherwise be treated as being outside the system, their perspectives marginalised or ignored.

\subsection{FUTURE RESEARCH}

$>$ The Theory of Constraints, used with a Stakeholder Typology demonstrates the potential to assist our communities in decision making about the systems that sustain them. Applying the methodology to specific problems identified within village planning or other urban planning processes would test the methodology further, particularly how it deals with an even broader range of stakeholder interests. Research into windfarms and the communities affected by them is just one example. The rigour and 'testability' of TOC, with its linking of critical cause to effect may prove more valuable to Councils and communities attempting to make informed decisions around plan changes and consents, than would a more traditional case study approach.

- Another study might usefully apply TOC to identify the specific factors that build resilience and adaptive capacity within natural systems. This would assist resource managers to buffer for risk and uncertainty in a more structured and consensus-driven manner than some of the 
prevailing policies (on recycled water and rainwater harvesting for example) and the legislature permit.

$>$ A study to reveal the assumptions driving conflict around water meters and other water infrastructure such as dams would be timely, in the current context of Wellington's apparently declining water security and debate over water abstraction. Experience with the Kapiti stakeholders suggests there are win/win answers and that these might be revealed using a TOC approach.

> Finally, the value of TOC as an adjunct to SDI (Sustainable Development Indicator) theory (Palme, 2004) deserves exploration within the sphere of SUWM, due to the potential for TOC to address some of the perceived weaknesses (Palme, 2004) of SDI theory alone.

\subsection{SUMMARY}

This study set out to offer a different perspective and test a framework to work with that may make the constraints and the solutions inherent in managing urban water systems more transparent. The combined framework provided a source of deep insights into the challenges, dilemmas, potential solutions and side effects facing resource managers and other stakeholders in an urban water system under pressure from population growth and climatic/topographical conditions. The findings show that the methodologies applied to the case study revealed previously understated or hidden assumptions that were behind growing conflict, with system participants answering a series of questions that targeted critical constraints and ways to deal with them. The methodologies proved effective in enabling the researcher and participants to identify what to change? and what to change to? so that core constraints could be addressed and a more sustainable system solution revealed. 


\section{GLOSSARY}

\begin{tabular}{|c|c|}
\hline & DEFI NITION \\
\hline Abstraction & The removal of water from a water body. \\
\hline Bore & $\begin{array}{l}\text { Essentially, a bore is a hole of small diameter, sunk into the } \\
\text { ground to some depth. The bore taps into a water layer below } \\
\text { ground, pushing that water to the ground surface, generally } \\
\text { with the aid of a pump. }\end{array}$ \\
\hline $\begin{array}{l}\text { Demand } \\
\text { management }\end{array}$ & $\begin{array}{l}\text { Water demand is prone to increase at the same time as } \\
\text { source water flow decreases - during higher temperatures } \\
\text { and dry conditions. This necessitates that water demand be } \\
\text { monitored and managed, in order to control treatment costs } \\
\text { or to ensure that the water available is sufficient for the } \\
\text { community's needs. A demand management strategy might } \\
\text { require restrictions on garden sprinkler use to even numbered } \\
\text { days, } 2,4,6,8 \ldots \text { etc. for even numbered houses, to use a } \\
\text { Wellington example. }\end{array}$ \\
\hline Ecosystems & $\begin{array}{l}\text { Ecosystem means any system of interacting terrestrial or } \\
\text { aquatic organisms within their natural and physical } \\
\text { environment (GWRC). }\end{array}$ \\
\hline Greywater & $\begin{array}{l}\text { Greywater is wastewater from the sink, basin, laundry tub, } \\
\text { bath, shower, basin, and washing machine (but not including } \\
\text { toilet waste). In some areas, it can be collected and used for } \\
\text { irrigation or for flushing toilets, depending on the greywater } \\
\text { treatment system available. Note: waste from toilets, bidets } \\
\text { and in some cases, from sinks used for food preparation } \\
\text { and/or incorporating Insinkerator type waste disposal units, is } \\
\text { blackwater, normally discharged to sewerage systems. } \\
\text { Researcher comment: A premise for greywater recycling is } \\
\text { that it can help reduce the return of wastewater to sewerage } \\
\text { systems, and can take pressure off potable water supplies, as } \\
\text { part of the community's demand for water can be met with } \\
\text { non-potable sources including greywater, provided measures } \\
\text { to minimise risk are taken. }\end{array}$ \\
\hline Iwi & $\begin{array}{l}\text { Iwi are tribes, groups of Maori linked by common ancestry } \\
\text { and with common history (GWRC). }\end{array}$ \\
\hline Iwi authority & $\begin{array}{l}\text { Under the Resource Management Act, an iwi authority is: } \\
\text { The authority which represents an iwi and which is recognised }\end{array}$ \\
\hline
\end{tabular}




\begin{tabular}{|l|l|}
\hline & by that iwi as having the authority to do so. \\
\hline $\begin{array}{l}\text { Iwi } \\
\text { management } \\
\text { plan }\end{array}$ & $\begin{array}{l}\text { A planning document that is recognised by the iwi authority } \\
\text { (GWRC). }\end{array}$ \\
\hline Mana whenua & $\begin{array}{l}\text { Customary authority exercised by iwi or hapu in an identified } \\
\text { area (RMA, 1991). }\end{array}$ \\
\hline $\begin{array}{l}\text { Non-point } \\
\text { source } \\
\text { discharge }\end{array}$ & $\begin{array}{l}\text { Diffuse discharges of contaminants to air, water and land, } \\
\text { often from a range of sources and often not attributable to an } \\
\text { individual site or activity (GWRC). }\end{array}$ \\
\hline Non-potable & $\begin{array}{l}\text { Water not biologically and chemically safe or suitable for } \\
\text { drinking }\end{array}$ \\
\hline $\begin{array}{l}\text { Point } \\
\text { Source } \\
\text { discharge }\end{array}$ & $\begin{array}{l}\text { A discharge of contaminants where the point of discharge is } \\
\text { identified (GWRC). }\end{array}$ \\
\hline Potable & Water that is biologically and chemically safe for drinking. \\
\hline $\begin{array}{l}\text { Rainwater } \\
\text { harvesting } \\
\text { (roofwater } \\
\text { collection) }\end{array}$ & $\begin{array}{l}\text { Collecting water from water bodies and rainfall when the } \\
\text { amount of water is plentiful, and storing it. An onsite } \\
\text { rainwater/roofwater harvesting system consists of pipe-work } \\
\text { and connections, storage tank(s), pump(s) and valves, and } \\
\text { may include a point of use device that treats water to a } \\
\text { desired standard. }\end{array}$ \\
\hline Runoff & $\begin{array}{l}\text { Water flowing across the land surface, not soaking into the } \\
\text { ground. }\end{array}$ \\
\hline Swales & $\begin{array}{l}\text { Concave hollows designed to contain stormwater runoff that } \\
\text { will, over time, soak into the ground. }\end{array}$ \\
\hline
\end{tabular}

NB: Some definitions are from pages $175-180$ of the Draft Regional Policy Statement for the Wellington Region 2008: Quality for Life by the Greater Wellington Regional Council/Environment and are acknowledged as (GWRC). 


\section{REFERENCES}

Abbott, S. (2008). Rainwater harvesting in urban environments - why not? Conference Paper. Presented 25 September, 2008, at the NZ Water and Wastes Association's 50 ${ }^{\text {th }}$ Annual Conference, Christchurch Convention Centre. Source the paper by emailing: S.E.Abbott@massey.ac.nz Web site: http://roofwater.massey.ac.nz

Agle, B. R., Mitchell, R. K., and Sonnenfield, J. A. (1999). Who matters to CEOs? An investigation into stakeholder attributes and salience, corporate performance and CEO values. Academy of Management Journal, 42 (5), 507-525.

Askew, L.E and McGuirke, P. M. (2004). Watering the suburbs: Distinction, conformity and the suburban garden. Australian Geographer, 35 (1), 1737.

Atkins, H. (2007). Sustainability - the legal niceties. Whose water? NZWWA's 49th annual conference and expo Rotorua, 19-21 September 2007. Rotorua: New Zealand Water and Wastes Association Inc.

Balderstone, S. J. (1999b). Increasing user confidence in systems dynamics models through use of an established set of logic rules to enhance Forrester and Senge's validation tests, Systems Thinking for the Next Millennium, Proceedings of the $1 t^{\text {th }}$ International Systems Dynamics Conference and $5^{\text {th }}$ Australian and New Zealand Systems Conference, Wellington.

Bassett, K. (1995). On reflexivity: further comments on Barnes and the sociology of science, Environment and Planning, 27, 1527-38.

Beacon Pathway. (2008a). Slowing the flow: A comprehensive demand management framework for reticulated water supply, 2008. Integrated demand management. Retrieved May, 2009 from http://beaconpathway.co.nz/furtherresearch/article/integrated water management

Beacon Pathway. (2008b). Slowing the flow: A comprehensive demand management framework for reticulated water supply, 2008. Tauranga Case Study, Retrieved May, 2009 from: http://beaconpathway.co.nz/furtherresearch/article/case study tauranga city council

Birchfield, D. (2007). Demand Management through Water Retrofit Programmes. Report TE106/6 for Beacon Pathway Limited. April, 2007. In 
Beacon Pathway. (2008). Slowing the flow: A comprehensive demand management framework for reticulated water supply, 2008.

http://beaconpathway.co.nz/images/uploads/Public Report TE106(6) De mand Management through Water Retrofit Projects.pdf

Bishop, N. (1994). From the mountains to the sea: The secret life of New Zealand rivers and wetlands. Auckland: Reed.

Bloomberg, L.D. and Volpe, M. (2008). Completing your qualitative dissertation: a roadmap from beginning to end. Thousand Oaks, Cal: Sage Publications Ltd.

Brown, R. (1994/5). Write right first time, Literati Newsline, Special Issue, 1-8. Website: http://www.literaticlib.co.uk/writing/articles/write.html

Brown, R. and Farrelly, M. (2007). Barriers to advancing sustainable urban water management: a typology. Conference Paper. Presented at Rainwater and Urban Design 2007, (1-8). 21-23 August 2007, Sydney.

Brown, R. and Keath, N. (2007). Turning the Super-tanker: Drawing on Social Theory to Enable the Transition to Sustainable Urban Water Management. National Urban Water Governance Program, School of Geography and Environmental Science, Monash University, Rebekah.brown@arts.monash.edu.au and nina.keath@arts.monash.edu.au

Brugge, R., Rotmans, J., Loorbach, D. (2005). The transition in Dutch water management. Regional Environmental Change 5(4), 164-176.

Burgelman, R.A. (1991). Intra-organizational ecology of strategy-making and organizational adaptation: Theory and field research. Organization Science, 2: 239-262.

Cavana, Robert Y., Delahaye, Brian L., and Sekaran, Uma. (2001). Applied Business Research: qualitative and quantitative methods. Australia: Wiley.

Chapman, Dr. H. (2003). Programme 2F, Sustainable water sources. Retrieved 10 October 2007:

http://www.waterquality.crc.org.au/Programs/program2f.htm and see www.naiad.net.au or http://www.wqra.com.au

Clarke, J.M. and Brown, R. R. (2006). Understanding the factors that influence domestic water consumption within Melbourne. 7th International Conference on Urban Drainage Modelling and the 4th International 
Conference on Water Sensitive Urban Design. Victoria: Monash University, 143-150.

Clarke, T. and Clegg, S. (1998). Changing paradigms: the transformation of management knowledge for the 21st century. London: HarperCollins.

Cody, J. (2002). Conceptualising social capital - frameworks. In D. Robinson, G. Sullivan (eds.), Building social capital. Wellington: Institute of Policy Studies, Victoria University, 31-40.

Colorado Waterwise. (2009). Colorado WaterWise, Article. Retrieved 15 May 2009:

http://coloradowaterwise.org/images/stories/newsletters/waterwisespring 09.pdf

Covey, S. R. (1989). The seven habits of highly effective people: powerful lessons in personal change. NY: Simon and Schuster.

Cox, J. F., and Blackstone, J.H. and Schleier, J.G. (2003). Managing operations: A focus on excellence. Volume I. Great Barrington: The North River Press Publishing Corporation.

Cox, J. F., and Mabin, V. J. and Davies, J. (2005). A case of personal productivity: Illustrating methodological developments in TOC. Human Systems Management, 24, 39-65.

Davies, J., Mabin, V. J. and Balderstone, S. J. (2005). The theory of constraints: a methodology apart? - A comparison with selected OR/MS methodologies. Omega - The International Journal of Management Science, 506-524.

Davies-Colley, R., and Wilcock, B. (2004). Water quality and chemistry in running waters. In J, Harding, P. Mosley, C. Pearson and B. Sorrell (eds.), Freshwaters of New Zealand, (Ch. 11: 1-17). Christchurch, NZ: New Zealand Hydrological Society and New Zealand Limnological Society.

Denzin, N. and Lincoln, Y. (eds.) (2005). Handbook of qualitative research, $3^{\text {rd }}$ edn. Thousand Oaks, CA: Sage.

Department of the Prime Minister and Cabinet (2003). Key Government Goals to Guide the Public Sector in Achieving Sustainable Development, Retrieved 19 Feb 2008, Dept of the Prime Minister and Cabinet: http://www.dpmc.govt.nz/dpmc/publications/key goals.html

Dettmer, H. W. (2007). The logical thinking process: a systems approach to complex problem solving. Milwaukee WI: Quality Press. 
Dominion Post (2009). Article - Turbulence ahead on water take, Retrieved 18 March 2009 from: http://www.stuff.co.nz/dominionpost/communities/hutt-news/1756304/Turbulence-ahead-on-water-take

Elias, A. A., Cavana, R. Y. and Jackson, L. S. (2002). Stakeholder analysis for R\&D project management. $R \& D$ Management 32 (4), 301-310. Malden, Mass.: Blackwell Publishers Ltd.

Environment Waikato (2008). How healthy are our rivers, Retrieved 26 Jan 2008 from: http://www.ew.govt.nz/environmental-information/Riverslakes-and-wetlands/healthyrivers/

Freeman, R. E. (1984). Strategic management: a stakeholder approach. Boston MA: Pitman.

Friend, J. (26 February, 2009). Planning under pressure: an interactive approach. Seminar hosted by Victoria University of Wellington and ESR. (Reference relates to a personal comment quoted in this thesis).

Goldratt, E.M. (1990). What is this thing called Theory of Constraints? North River Press.

Goldratt, E. and Cox, J. (1992). The Goal 2nd revised edition. NY: North River Press.

Greater Wellington Regional Council. (2008). GWRC. Sourced from http://www.gw.govt.nz/section2377.cfm?, Greater Wellington Regional Council.

Greater Wellington Regional Council. (2009). GWRC. Are we doing the right things for the Wellington region? Proposed 10-year Plan 2009-19 (March 2009).

Grunig, J. E. \& Repper, F. C. (1992). Strategic Management, Publics, and Issues, In J. E. Grunig (ed.), Excellence in Public Relations and Communication Management. Hillsdale, NJ: Lawrence Erlbaum Associates: 117-157: 128.

Hart, C. (2005). Doing your Masters dissertation. London: Sage Publications Ltd.

Harrison, J.S., and St. John, C.H. (1994). Strategic Management of Organizations and Stakeholders. St. Paul, MN: West Publishing Co.

Heifetz, R.A. (1994). Leadership without easy answers. Cambridge: Harvard University Press. 
Huberman, A. M., and Miles, M. B. (1998). Data management and analysis methods. In N. K. Denzin and Y. S. Lincoln (eds.) Collecting and interpreting qualitative materials. Thousand Oaks, CA: Sage.

Hughes, H. R. (1993). New Zealand's clean, green, image - fact or fiction? Thomas Cawthorn Memorial Lecture No. 52. Nelson: Cawthorn Institute.

Ibitt, R., McKerchar, A. and Woods, R. (2004). Catchments, streamflow and the use of models. In J, Harding, P. Mosley, C. Pearson and B. Sorrell (eds.), Freshwaters of New Zealand, (Ch. 9). Christchurch, NZ: New Zealand Hydrological Society and New Zealand Limnological Society.

Institution of Professional Engineers Inc. IPENZ (2008). Submission. Water, New Zealand's valuable natural resource. Document can be requested from ipenz@ipenz.org.nz

Jackson, B. and Parry, K. (2008). A very short, fairly interesting and reasonably cheap book about studying leadership. London: Sage Publications Ltd.

Kandel, R. (2003). Water from Heaven: the Story of Water from the Big Bang to the Rise of Civilization and Beyond. New York: Columbia University Press.

Kapiti Coast District Council (2006). Kapiti Coast Choosing Futures Community Plan 2006, available from the Council website www.kapiticoast.govt.nz

Kapiti Coast District Council (2008). Kapiti Coast District Council Plan Change 75 - Water Demand Management- Section 32 Analysis Report, Retrieved 5 June 2008 from:

http://www.kapiticoast.govt.nz/NR/rdonlyres/2A34BCFE-674A-4434-8CF408B1C17B0FF4/52759/Section32NOTIFIED.pdf

Kapiti Coast District Council. (2009). Water - an important issue for the Kapiti Coast (23 April 2009). Advertisement placed by the Kapiti Coast District Council. In the Kapiti Observer. Issue published 23 April 2009: 8-9.

Kapiti Coast District Council. (2003). Water Matters, Kapiti Coast District Sustainable Water Use Strategy, January 2003.

Kapiti Coast District Council. (2008). Kapiti Water Supply

http://www.kapiticoast.govt.nz/HealthyServices/KapitiWaterSupply/Water Supply.htm

Kapiti Coast District Council. (2009). Kapiti Water Supply LTCCP review: water supply options for the Waikanae Paraparaumu Raumati area (2 April 2009), Retrieved 15 May 2009 from: 
http://www.kapiticoast.govt.nz/NR/rdonlyres/1F216626-D146-476C-9779F996DD3C74C7/65306/MAS09505LTCCPReviewWaterSupplyOptionsforWai kanaePa.pdf

Kapiti Observer. (2009). Newspaper comment. A moment with our Mayor. Issue published 11 May, 2009.

Kendall, G. I. (1998). Securing the future: strategies for exponential growth using the Theory of Constraints. New York: St. Lucie Press.

Kim, D. H. (1993). A framework and methodology for linking individual and organizational leaning: applications in TQM and product development. Thesis (PhD), Massachusetts Institute of Technology, Sloan School of Management. URI: http://hdl.handle.net/1721.1/12657

Landcare Trust. (2008). Article - Beyond reasonable drought: adapting dryland farming to climate change, August 2008. Published by the New Zealand Landcare Trust, as part of Sustainable Farming Fund Project No. 05/132; Changing attitudes and practice for farming dry land in Marlborough. Penny Wardle and Heather Collins (eds.), Retrieved 19 September 2008 from:

http://www.marlborough.govt.nz/content/docs/environmental/regulatory/ Beyond Reasonable Drought-Starborough Flaxbourne Aug 08BookletIntroductionandChapter1-PWa.pdf

Littlejohn, Stephen W. (1996). Communication theory and scholarship. Theories of human communication, 5th ed. California: Wadsworth, 2-21.

Maani, K. E., and Cavana, R. Y. (2000). Systems Thinking and Modelling. Auckland: Pearson Education New Zealand.

Mabin, V. J., Davies, J., and Cox, J. F. (2006). Using the theory of constraints thinking processes to complement system dynamics' causal loop diagrams in developing fundamental solutions. International Transactions in Operational Research, 13, 33-57.

Mabin, V. J., Forgeson, S. and Green, L. (2001). Harnessing resistance: using the theory of constraints to assist change management. Journal of European Industrial Training, 25 (2/3/4), 168-191.

Melbourne Water (2009). Melbourne Water Dam Water Storage Levels, Retrieved 11 February 2009 from:

http://www.melbournewater.com.au/content/publications/fact sheets/wat er/our precious drinking water.asp 
Miller, G.R., and Nicholson, H. (1976). Communication inquiry. Reading, Mass.: Addison-Wesley.

Mingers, J. The paucity of multimethod research: a review of the information systems literature. Information Systems Journal, 13 (3), 233-249.

Ministry for the Environment. (2009). Use of New Zealand's Allocated Freshwater, Use of allocated water in New Zealand, 2006. Retrieved 18 March 2009 from: http://www.mfe.govt.nz/environmentalreporting/freshwater/demand/pie-data.html

Mitchell, R. K., Agle, B. R. and Wood, D. J. (1997). Towards a theory of stakeholder identification and salience: defining the principle of who and what really counts. Academy of Management Review, 22 (4), 853-886.

Mitchell, V. G. (2006). Applying integrated urban water management concepts: a review of Australian experience. Environmental Management, 37 (5), 589-605.

Painter, D. (2004). Managing water related risks. In J, Harding, P. Mosley, C. Pearson and B. Sorrell (eds.), Freshwaters of New Zealand, (Ch. 45). Christchurch, NZ: New Zealand Hydrological Society and New Zealand Limnological Society.

Palme, U. A. (2004). Indicators for Sustainable Development of Urban Water Systems. Department of Environmental Systems Analysis. Sweden: Chalmers University of Technology.

Parliamentary Commissioner for the Environment. (2000). Aging pipes and murky waters. Urban water system issues for the $21^{\text {st }}$ century. Wellington: Parliamentary Commissioner for the Environment. June 2000.

Parliamentary Commissioner for the Environment. (2001). Whose water is it? The sustainability of urban water systems on the Kapiti Coast.

Wellington: Parliamentary Commissioner for the Environment. May 2001.

Rainwater and Urban Design. (2007). Program and Abstract Book with DVD of conference papers. Rainwater and Urban Design Sydney Conference, 2123 August 2007.

Rawlins, Brad L. (2006). Prioritizing Stakeholders for Public Relations. Sourced from

http://www.instituteforpr.org/research single/prioritizing stakeholders.

Published by the Institute for Public Relations, www.instituteforpr.org. 
Resource Management Act (RMA). (1991). Wellington: Ministry for the Environment, http://www.mfe.govt.nz/rma/

Richmond, C., Froude, V., Fenemor, A., and Zuur, B. (2004). Management and conservation of natural waters. In J, Harding, P. Mosley, C. Pearson and B. Sorrell (eds.), Freshwaters of New Zealand, (Ch. 44). Christchurch, NZ: New Zealand Hydrological Society and New Zealand Limnological Society.

Robb, C. A. (2000). Information on water allocation in New Zealand. Lincoln Environment Report 4375/1 to the Ministry for the Environment. Wellington: Ministry for the Environment.

http://www.maf.govt.nz/mafnet/publications/rmupdate/rm5/rm5001.html

Robb, C. A. and Bright, J. (2004). Values and uses of water. In J, Harding, P. Mosley, C. Pearson and B. Sorrell (eds.), Freshwaters of New Zealand, (Ch. 42). Christchurch, NZ: New Zealand Hydrological Society and New Zealand Limnological Society.

Robinson, B. and Robinson, D. Conceptualising social capital - frameworks. In D. Robinson, G. Sullivan (eds.), Building social capital. Wellington: Institute of Policy Studies, Victoria University, 41-66.

Ronen, B. and Pliskin, J. S. with S. Pass (2006). Focused Operations Management for Health Services Organizations. CA: Jossey-Bass.

Ryan, R. and Brown, R. R. (2000). The Value of Participation in Urban Watershed Management. Paper presented at Watershed 2000 Vancouver, British Columbia, Canada. Retrieved May 2009 from:

http://www.elton.com.au/pdfs/Storm2.PDF

Savage, G.T., Nix, T. H., Whitehead, C. J., and Blair, J. D. (1991). Strategies for Assessing and Managing Organizational Stakeholders. Academy of Management Executive, 19: 453-473.

Scheinkopf, L. (1999). Thinking for a change, putting the TOC thinking processes to use. Fl: St Lucie Press/CRC Press.

Schragenheim, E. (1998). Management dilemmas, the Theory of Constraints approach to problem identification and solutions. Florida: St Lucie Press/CRC Press.

Senge, P. M. (1994). The fifth discipline fieldbook: strategies and tools for building a learning organization. London: Nicholas Brealey Publishing Ltd.

Senge, P. M. with Smith, B., Kruschwitz, N., Laur, J. and Schley, S. (2008). The necessary revolution: how individuals and organizations are working 
together to create a sustainable world. London: Nicholas Brealey Publishing.

Shoemaker, T. E. and Reid, A. (2005). Applying the TOC Thinking Process: a case study in the government sector. Human Systems Management, 24, 21-37.

Slaney, D., and Weinstein, P. (2004). Water and human health. In J, Harding, P. Mosley, C. Pearson and B. Sorrell (eds.), Freshwaters of New Zealand, (Ch. 46: 1-14). Christchurch, NZ: New Zealand Hydrological Society and New Zealand Limnological Society.

Socrates Café. Josh Glenn (ed.) (2005). Retrieved 16 August 2005 from: http://www.philosopher.org/soccaf.html

Sterman, J. D. (2000). Business dynamics: Systems thinking and modelling for a complex world. Boston MA: Irwin McGraw Hill.

Suchman, M. C. (2005). Managing legitimacy: strategic and institutional approaches. Academy of Management Review, 20 (3), 571-610.

Suren, A., McMurtrie, S. and O'Brien, L. (2004). River restoration. In J, Harding, P. Mosley, C. Pearson and B. Sorrell (eds.), Freshwaters of New Zealand, (Ch. 38: 1-20). Christchurch, NZ: New Zealand Hydrological Society and New Zealand Limnological Society.

Thomas, F., Orton, J. and Brown, R. (2007). Sub-catchment planning in Marrickville: The urban stormwater integrated management (USWIM) project. Rainwater and Urban Design 2007, (1-8). Sydney.

Tolich, M. and Davidson, C. (1999). Starting fieldwork: an introduction to qualitative research in New Zealand. Auckland: Oxford University Press.

Walker, B. and Salt, D. (2006) Resilience thinking: sustaining ecosystems and people in a changing world. Washington: Island Press.

Watercare (2009). Feb 29, 2009 Three Waters Strategic Plan December 2008, Retrieved March 2009 from:

http://watercare.co.nz/default,publications.sm

White, I. (2007). Everything but the kitchen sink: My waterwisehome.com - $A$ case study in water sensitive urban design. Paper presented at Rainwater and Urban Design 2007, (Sydney Conference 21-23 August 2007):

http://www.Mywaterwisehome.com 
World Commission on Environment and Development (1987). Our common future. Oxford University Press.

Young, R., Smart, G. and Harding, J. (2004). Impacts of hydro-dams, irrigation schemes and river control works. In J, Harding, P. Mosley, C. Pearson and B. Sorrell (eds.), Freshwaters of New Zealand, (Ch. 37: 1-16).

Christchurch, NZ: New Zealand Hydrological Society and New Zealand Limnological Society.

REPORTS - COMMISSIONED BY KCDC AND CONSULTED FOR THE KAPITI CASE STUDY

Opus International Consultants Ltd. (2004). Waikanae River Water Supply: Assessment of Environmental Effects. Opus International Consultants Ltd. July 2004.

Sinclair Knight Merz (SKM). (2003). Kapiti Coast District Council: Waikanae Storage Pond Development Stage 1 - Prefeasibility Site Selection Report. September, 2003.

Sinclair Knight Merz (SKM). (2008). Kapiti Coast District Council: Water Storage/Supply Options Study. December, 2008.

URS. (2003). Waikanae/Otaihanga Borefield Drilling Strategy. URS New Zealand Limited. May 2003.

URS New Zealand Ltd. (2004). Assessment of Environmental Effects Waikanae Borefield. URS New Zealand Limited. July 2004. 


\section{APPENDICES}

\section{Appendix One - Reflection}

The reflection conveys the researcher's thoughts on carrying out this research. This reflection was provided to examiners and was completed immediately after the interviews (based on Brown's Eight Questions, Brown 1994/5).

\section{Appendix Two - Three waters strategy}

Water demand management will be a critical requirement for the successful delivery of efficient three waters services... (Watercare, 2008)

The Introduction has excerpts from the Three Waters Strategic Plan December 2008. The strategy was retrieved 29 February 2009 from: http://watercare.co.nz/default,publications.sm

Appendix Three - Where does our water come from and where is it used?

\section{Where Does Our Water Come From?}

The following shows where our water comes from and is the source for the water allocation statistics quoted in this thesis, retrieved 18 March 2009 from: http://www.nzbcsd.org.nz/water/nzbcsd water.pdf with information provided by Ministry for the Environment 2007:

New Zealand's freshwater bodies are mainly made up of relatively small catchments including rivers and streams with a total length of $425,000 \mathrm{~km}$. Half of this lies in catchments with natural land cover - bush, alpine rock and tussock. Some $43 \%$ of this river length is in catchments that have been modified by agriculture, $5 \%$ by plantation forestry and just $1 \%$ by urban settlement.

Of New Zealand's 50,000 lakes: 4,000 are larger than one hectare more than 200 have an area greater than 50 hectares about $40 \%$ are in catchments where agriculture is the major water use.

There are about 200 groundwater bodies or aquifers. 
Each year 500,000 million cubic meters of water fall onto New Zealand as rain or snow, enough to fill Lake Taupo from empty eight times over. Most freshwater from rain and snow each year eventually flows to the sea.

Only about $5 \%$ of the annual inflow is extracted for commercial use, mainly for farming: the so-called 'abstractive' uses (MfE, 2009)

\section{Where is Our Water Used?}

In 2006, 77 per cent of New Zealand's allocated water was used for irrigation. The remainder was shared among public water supply, manufacturing and industry, and stock watering (MfE, 2009).

MfE (http://www.mfe.govt.nz retrieved 18 March 2009) provides the following statistics on where New Zealand's fresh water is used:

Stock watering $3 \%$

Public water supply $9 \%$

Manufacturing Processes 11\%

Irrigation $77 \%$

This and more information about the use of allocated water in New Zealand can be found in the state of the environment report, Environment New Zealand 2007. 


\title{
Appendix Four - News article turbulence ahead on water take
}

\author{
The following article is illustrative of the issues and conflicts that require \\ management attention and might benefit from a decision-making framework \\ like TOC, retrieved 18 March 2009 from http://www.stuff.co.nz/dominion- \\ post/communities/hutt-news/1756304/Turbulence-ahead-on-water-take
}

\section{Turbulence ahead on water take}

\section{NICHOLAS BOYACK - Hutt News}

The regional and city councils remain on a collision course over the taking of more water out of the Hutt River.

The issue caused tension between the two councils late in 2008. Greater Wellington Regional Council wants to increase the abstraction rate at Kaitoke weir for the next few years to meet a projected shortfall in bulk water.

In December, GWRC sent a delegation to assure Hutt councillors there wouldn't be a problem. But city councillors have repeatedly expressed concern that even the regional council acknowledges that toxic algal blooms in the river are on the increase.

GWRC says the cause of the blooms is unknown and there is no evidence that reducing the flow of the river will result in them worsening. City councillors want scientific evidence to back that up.

Now a report to a GWRC committee earlier this month has caused more angst amongst Hutt councillors. The report appeared to gloss over the concerns raised by the city council.

$\mathrm{Cr}$ Margaret Cousins wrote to the chair of the Utilities Committee tersely criticising the report.

"I am concerned at the tenor of the report going to your committee tomorrow and, in particular, the way it is quite dismissive about our council's view of the proposals on which you were consulting in regard to future water supply options.

"I draw your attention to (Hutt's) resolution (28 November) that 'council will not support any initiative that contributes to the further degradation of the Hutt River environment and/or potentially threatens the future water supply potential for Lower Hutt City'."

Cr Cousins goes on to say that "any future take of water from the Hutt River must not be at the expense to the overall health of the river." Last week Cr Cousins told the Hutt News she was very surprised by the tone of the report and she is concerned that the regional council continues to ignore the city's view.

Cr Max Shierlaw, who has taken a close interest in the issue, says that it needs to be sorted out. If the GWRC applies for resource consent it seems inevitable that the city council will oppose it. That has the potential to cost both councils hundred of thousands and seriously damage inter-council relationships.

Much of the blame, he contends, lies with the three Hutt councillors on the regional council. They should have been advocating for the Hutt Valley and made sure the report that went to the utilities committee was rejected.

GWRC deputy chair Peter Glensor says he fully understands such views and agrees a solution needs to be found. He has told GWRC CEO Dave Benham that Hutt City's concerns must be taken seriously.

"We (Hutt regional councillors) are really pressing our officers to listen and respect the questions raised by Hutt politicians." 
He agrees more scientific research is needed on algal blooms. Without such data, $\mathrm{Cr}$ Glensor says it is likely that resource consent to take more water will be rejected. He also agrees with Cr Shierlaw that a legal dispute between the two councils over the issue would be futile and a waste of money.

The two councils will again discuss the issue at a meeting this Thursday at 5.30pm.

\section{Appendix Five - Information on toxic algal bloom}

\section{GWRC Information Sheet on Toxic blue-green algae}

\begin{abstract}
What are blue-green algae?
Blue-green algae (cyanobacteria) are an ancient group of organisms with characteristics in common with both bacteria and algae. Cyanobacteria are widespread in many lakes and rivers in New Zealand, and are found in a wide range of water quality conditions, including relatively 'clean' waters.
\end{abstract}

\section{What is the problem with blue-green} algae?

\section{Under favourable conditions,}

cyanobacteria cells can multiply and form blooms in lakes or thick mats attached to river and stream beds. Some species produce natural toxins called cyanotoxins which are a potential threat to people and animals if present in drinking water or if people and animals come into contact with the water during recreational activities.

In the summer of 2005/06, thick mats of cyanobacteria were found in some reaches of the Hutt, Mangaroa, Wainuiomata, Otaki, Waikanae and Waipoua rivers. The Hutt River was affected for much of the summer, with extensive thick, dark-brown/ black mats of Phormidium sp. present on the river margins in the Boulcott-Avalon area during a period of extended low river flows in November 2005. At least five dogs died around this time, after coming into contact with the algae at the water's edge. Analytical tests confirmed the presence of toxins, leading Regional Public Health and local councils to erect health warning signs restricting access to affected rivers in the region over the summer.

The above page was retrieved February 9, 2009 from the GWRC website: http://www.gw.govt.nz/section2377.cfm?

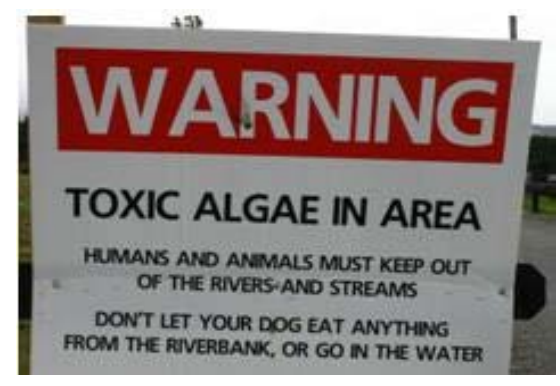

Supporting the commentary in this thesis on the effects of toxic algal blooms, the following is an excerpt from the SmartWater Fund newsletter 5 February 2007 retrieved from:

http://www.smartwater.com.au/downloadDocs/Newsletter Final.pdf 
"Treatment plants must reduce the amount of phosphates in the wastewater they produce because high levels can result in the formation of toxic algae blooms in the bodies of water into which the waste is released.

"These blooms are a global concern. They're not just unsightly, they produce carcinogenic toxins that can kill fish and plant life and cause serious health problems for those who live near inland wastewater treatment plants, "says Professor Robert Seviour, Director at La Trobe University's Biotechnology Research Centre.

\section{Appendix Six - Be the difference campaign}

\section{Be the Difference}

\section{Help the Wellington region's environment for generations to come}

Greater Wellington Regional Council has set up the Be the Difference programme to encourage everyone to take personal responsibility for the environment of the region.

When you join the programme we'll show you small changes that you can make to your daily life that will make a difference to the environment. Over 7000 people have joined so far!

\section{Community outreach}

Greater Wellington is also working with community groups, such as church groups, interest groups and service clubs to help them make a difference to the region's environment. Groups can get involved in a number of ways, from learning more about environmental issues to ways of being more environmentally friendly. Groups can also take part in environmental projects around the region.

This community outreach project was set up in July 2004 and has partial funding from Ministry for Environment's Sustainable Management Fund. In this first year of the project, work is focusing on Wellington City and Kapiti Coast.

The above page was sourced March 25, 2009 from GWRC website:

http://www.gw.govt.nz/section1352.cfm? 
Appendix Seven - Consent and information forms with indicative questions

NOTE: THE VICTORI A UNI VERSI TY OF WELLI NGTON HUMAN ETHI CS COMMITTEE HAS APPROVED THIS RESEARCH.

Date

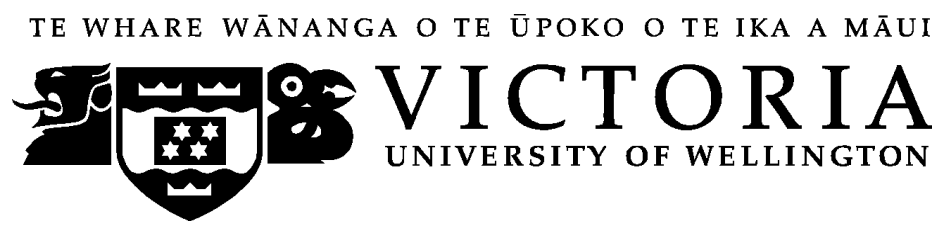

CONSENT TO PARTICIPATE IN RESEARCH

\section{Research Project:}

\section{Shaping More Sustainable Communities: A Case Study in Urban Water Management}

$\square \quad$ I have been given and have understood an explanation of this research project. I have had the opportunity to ask questions and have them answered to my satisfaction.

$\square \quad$ I understand that I may withdraw myself (or any information I have provided) from this project before September $4^{\text {th }} 2008$, without having to give reasons and without penalty of any sort.

- I understand that with my consent the results may include my name and my opinions may be attributed to my organisation or agency.

$\square \quad$ I agree to be interviewed and have given my voluntary consent to participate in this project. I understand that the study will be carried out as described in the information sheet, a copy of which I have retained.

$\square \quad$ I consent/do not consent to views being attributed to my name.

I consent/do not consent to views being attributed to my organisation/agency.

I would/would not like to receive a summary of the results of this study.

I agree to participate in this research.

Participant:

Signature:

Name:

Date: 


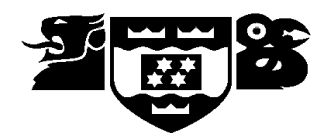

\section{INFORMATION SHEET}

\section{Shaping More Sustainable Communities: A Case Study in Urban Water MANAGEMENT}

\section{WHO IS CONDUCTING THIS RESEARCH?}

Hello, my name is Robyn Moore. I'm a student at Victoria University of Wellington, New Zealand, working towards a Master of Management Studies. I'm very interested in understanding more about New Zealand's Urban Water Systems and their management. With this in mind I have identified a case study (The Kapiti Coast) to look at in depth. You have been selected to take part in this study because you have an interest in the success of the Water System under study. I hope to work with you to identify frustrations; to identify gaps in our understanding; and to find answers to conflicts and problems in managing our Urban Water Systems. It is envisaged that this research will eventually lead to better outcomes for everyone.

The Victoria University of Wellington Human Ethics Committee has approved this research. My supervisor is Dr. Vicky Mabin, who is an associate professor in the Management School at Victoria University of Wellington. Advising on the scientific aspects of this study is Stan Abbott, Senior Lecturer in Microbiology and Communicable Diseases and Director of the Roof Water Research Centre, Institute of Food Nutrition and Human Health at Massey University.

\section{THE PURPOSE OF THIS RESEARCH}

This research explores the application of a systems framework called the Theory of Constraints (TOC) in Urban Water Management to identify the constraints in managing the urban water resource sustainably. TOC is a valuable and widely acknowledged framework for thinking about and understanding complex systems (see Davies, Mabin and Balderstone, 2005 for more). The goal of the research is to examine ways that the TOC framework can be usefully applied to surface problems, solve conflicts and provide practical and testable solutions, to shape more sustainable, dependable water systems in our communities.

\section{WHAT DO YOU NEED TO DO?}

I would like you to complete an interview with me where we can talk about the frustrations and successes you see in managing our community water resources, with particular reference to Kapiti. We will discuss the level of these frustrations and successes, what causes them, and what conflicts or undesirable events have resulted from unsolved 
problems. The interview will last for about one hour or longer if you care to go into more detail with me.

\section{PROTECTING YOUR CONFIDENTIALITY}

With your permission, your name, affiliation and/or position will be used.

I hope to record our conversation so I can analyse and review the material we'll be discussing. However, if you prefer not to be tape recorded, I am happy to take notes instead. The record and aggregated data will be accessible to my supervisor Vicky Mabin as well. I expect some data to require scientific review, so Stan Abbott, an expert in water quality from Massey University, has kindly offered to examine limited quantities of data and provide advice where appropriate.

You can choose not to be referred to by name, and your affiliation and position can also be kept confidential if you choose. However, the nature of the research means that opinions of everyone interviewed are equally valued and valid. Each individual viewpoint is a vital part of building up a picture of what needs to change in the system, what to change to, and how to make the required changes. Therefore, it would be useful to attribute names and/or affiliations as appropriate. The tape and data will be securely stored and will be destroyed five years after the completion of the research (May, 2014). A summary of the findings of the research can be emailed or posted to you when the research is completed if you choose.

\section{YOUR RIGHTS AS A PARTICIPANT IN THIS RESEARCH}

You are welcome to:

Refuse to answer any question, discuss any issue

Withdraw from the research by September $4^{\text {th }} 2008$

Ask any questions about this research at any time

Ask for the voice recorder to be turned off at any time, or request that certain information isn't written down in my notes

Have a summary of the findings when completed

\section{CONTACT INFORMATION}

Please feel free to contact me at any time during this research. My email address is robyn@j.co.nz

My phone number: 04-2399008. You are also welcome to contact my supervisor:

Dr. Vicky Mabin, Management School, Victoria University of Wellington, PO Box 600, Wellington, New Zealand. Ph +64-4-4635140 (DDI), Fax +64-4-4635253, e-mail address: Vicky.Mabin@vuw.ac.nz

Thank you very much.

Robyn Moore 


\section{Interview Questions*}

1. What is the overall system goal/the most desirable outcome from your perspective?

2. What are the Critical Success Factors (CSFs) or the two or three things that must be delivered on to meet the system goal (the necessary requirements)?

3. What key activities (or necessary conditions) are required to realise the CSFs?

4. Which necessary requirements (CSFs) aren't being met properly?

5. What are two or three obstacles that get in the way of meeting the overall system goal?

6. Which do you see as the most serious obstacle or deficiency in meeting the system requirements?

7. What is the effect (UDE) of this obstacle on the system goal?

8. Regarding the UDE you describe, why do you put up with it?

9. Is there a specific action that results from the UDE?

10. Is there a specific action causing the UDE?

11. Does the UDE create a conflict? What is the UDE in conflict with? Describe the conflict?

12. Can you identify a root cause for the obstacles or conflicts remaining?

* These questions, adapted from Cox et al. (2003:90) and Dettmer (2007: Chapter 3), are designed to be both necessary and sufficient enable the researcher to perform a TOC analysis: to build a cause-effect map of the problem issues, causes and consequences, and to develop a solution.

The following questions were asked if time allowed and depending on context:

\section{A few other things...}

Water meters - do you support their introduction? Why? Why not?

Would you support them as a measuring device? What are the conditions under which you would support their introduction to households?

The Government has recently released a draft National Policy on Fresh Water; any thoughts on what effect it might have on meeting our goals for more sustainable communities?

Processes: How do you feel about current processes, legislative or otherwise that underpin the management of our fresh water systems? 
Appendix Eight - Presenting the research summary to prospective participants identified with the stakeholder typology Slide 1

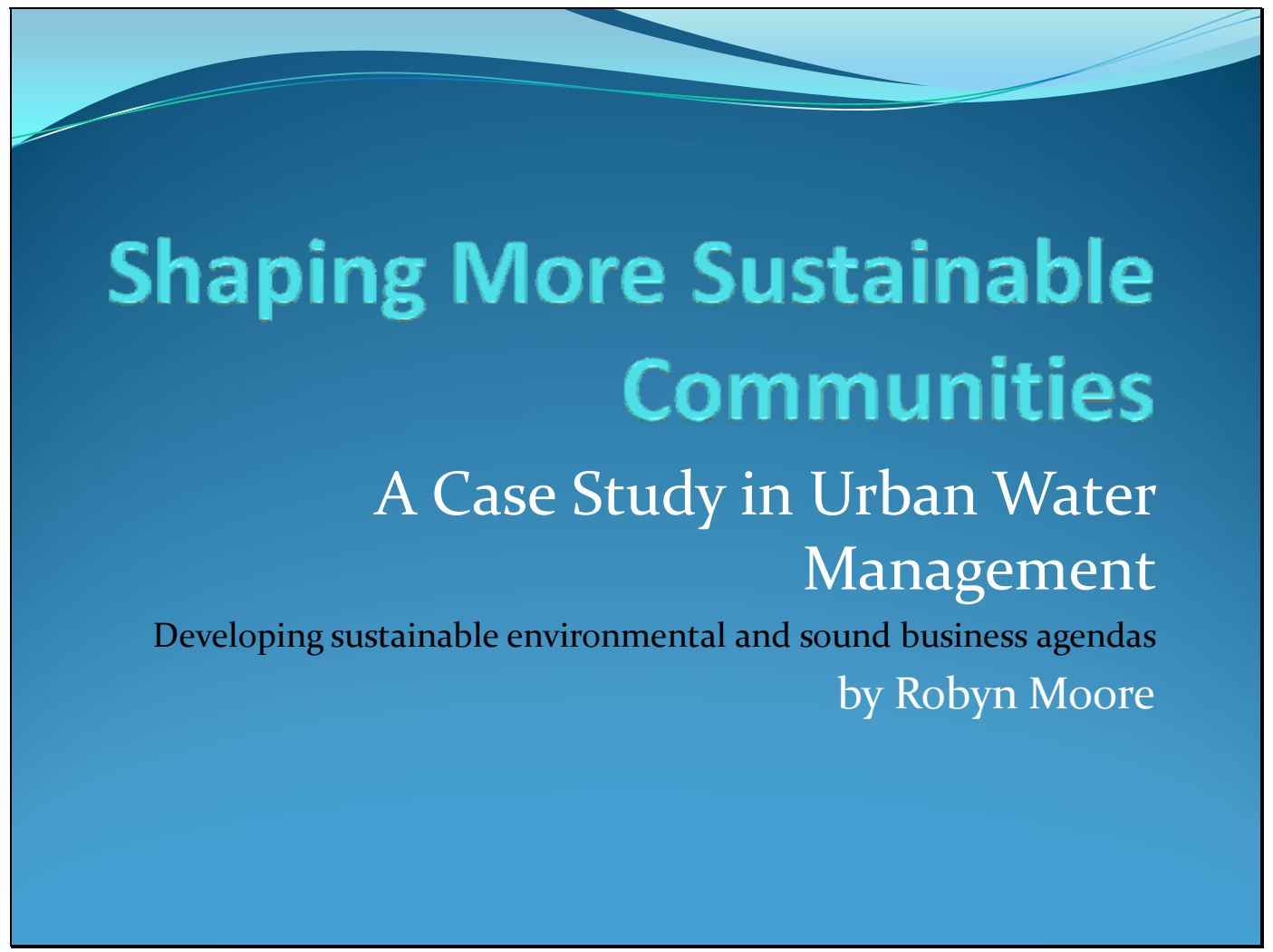


Slide 2

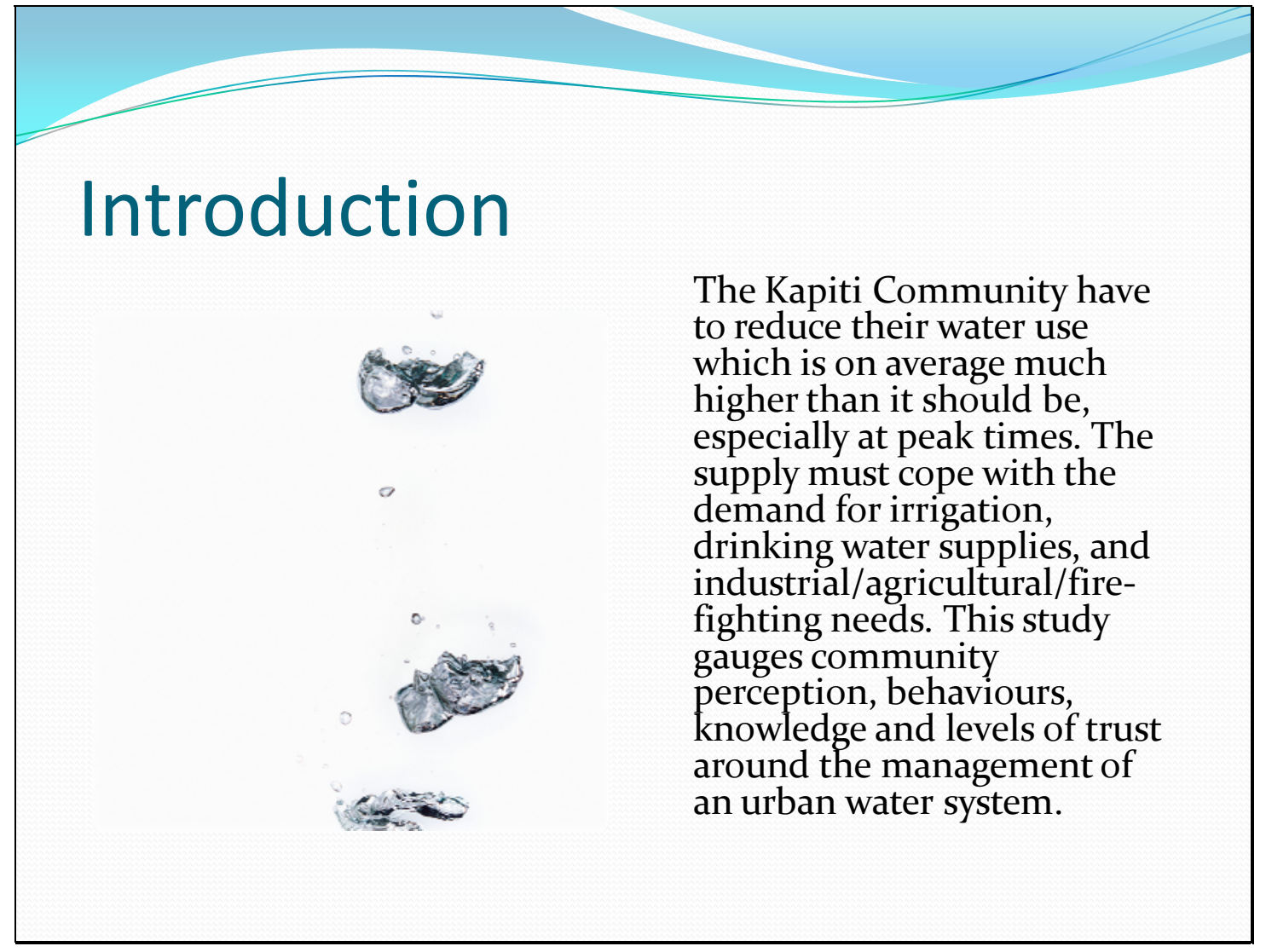

Slide 3

\section{Objectives}

Determine and record the level of understanding about urban water systems. Discover the knowledge gaps at community and at legislative level.

Conduct action research with relevant Ministries, local Councils and the Greater Wellington Regional Council and include expert opinion from other stakeholders.

Focus on KCDC as the participant case study. 


\section{Slide 4}

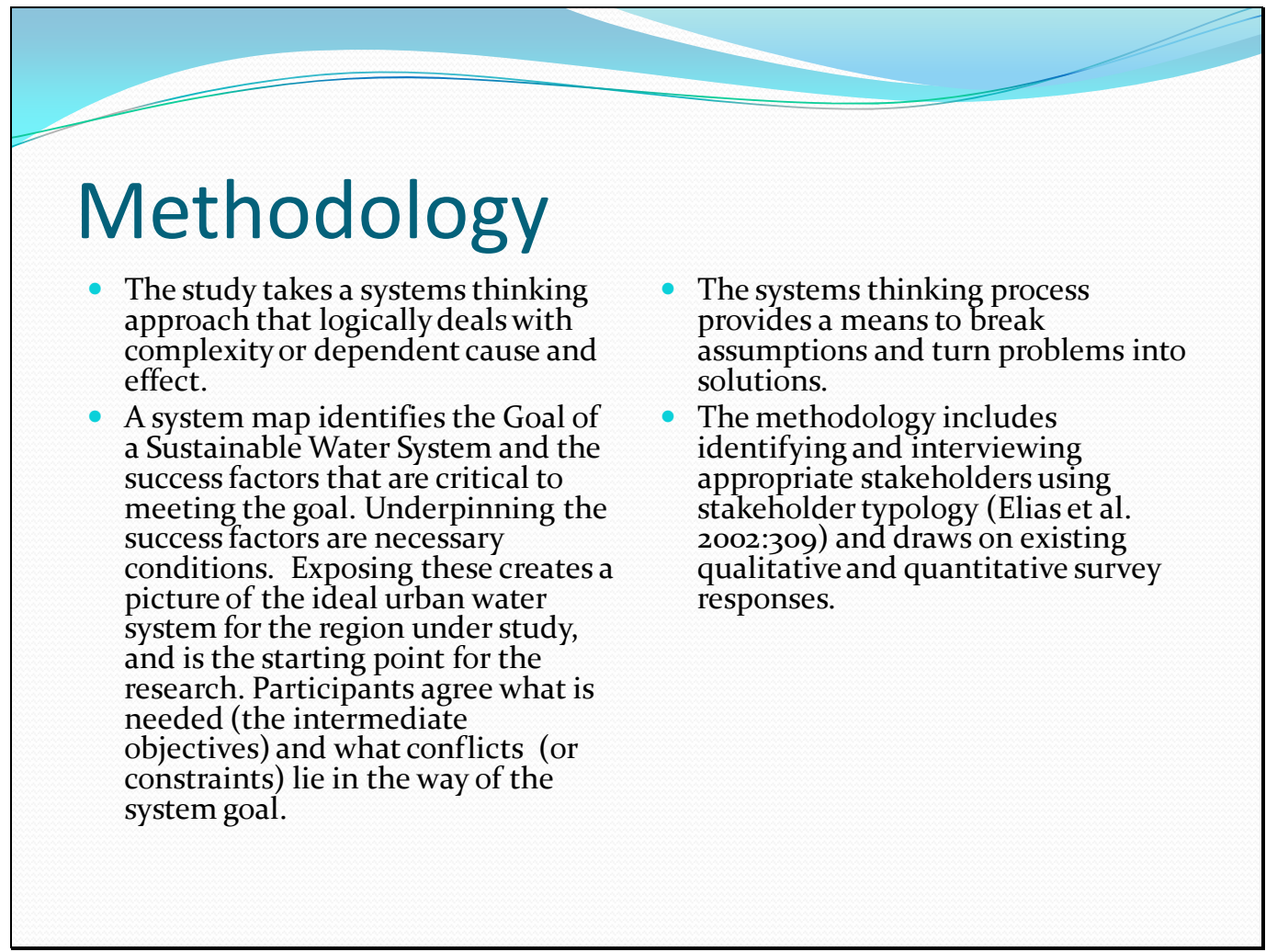

\section{Slide 5}

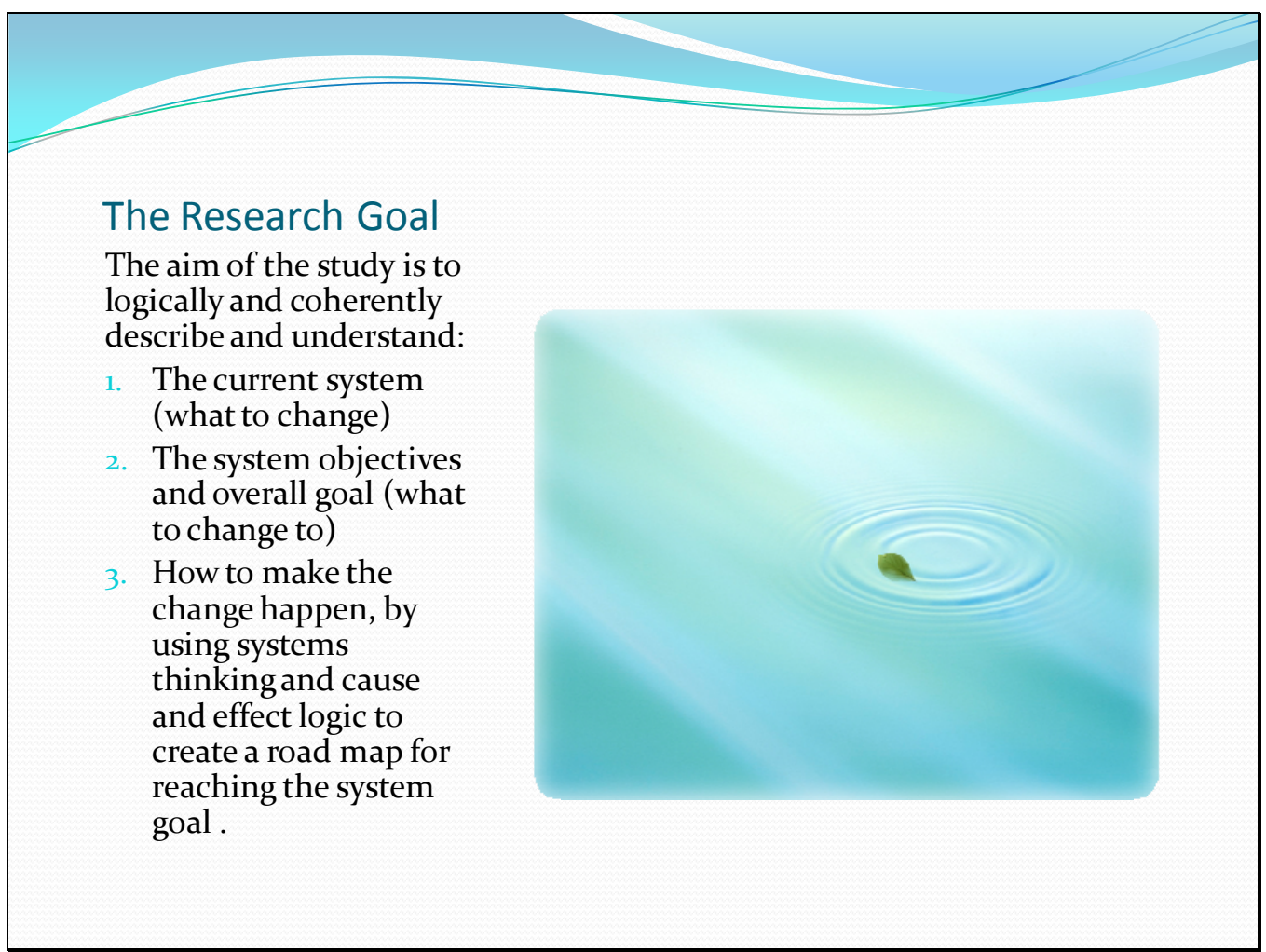


Slide 6

\section{Timeframe}

- The Masters Thesis will be completed by February 2009.

- Participants will be interviewed/surveyed in July/August 2008

- A report of findings and conclusions will be available to participants in March/April 2009

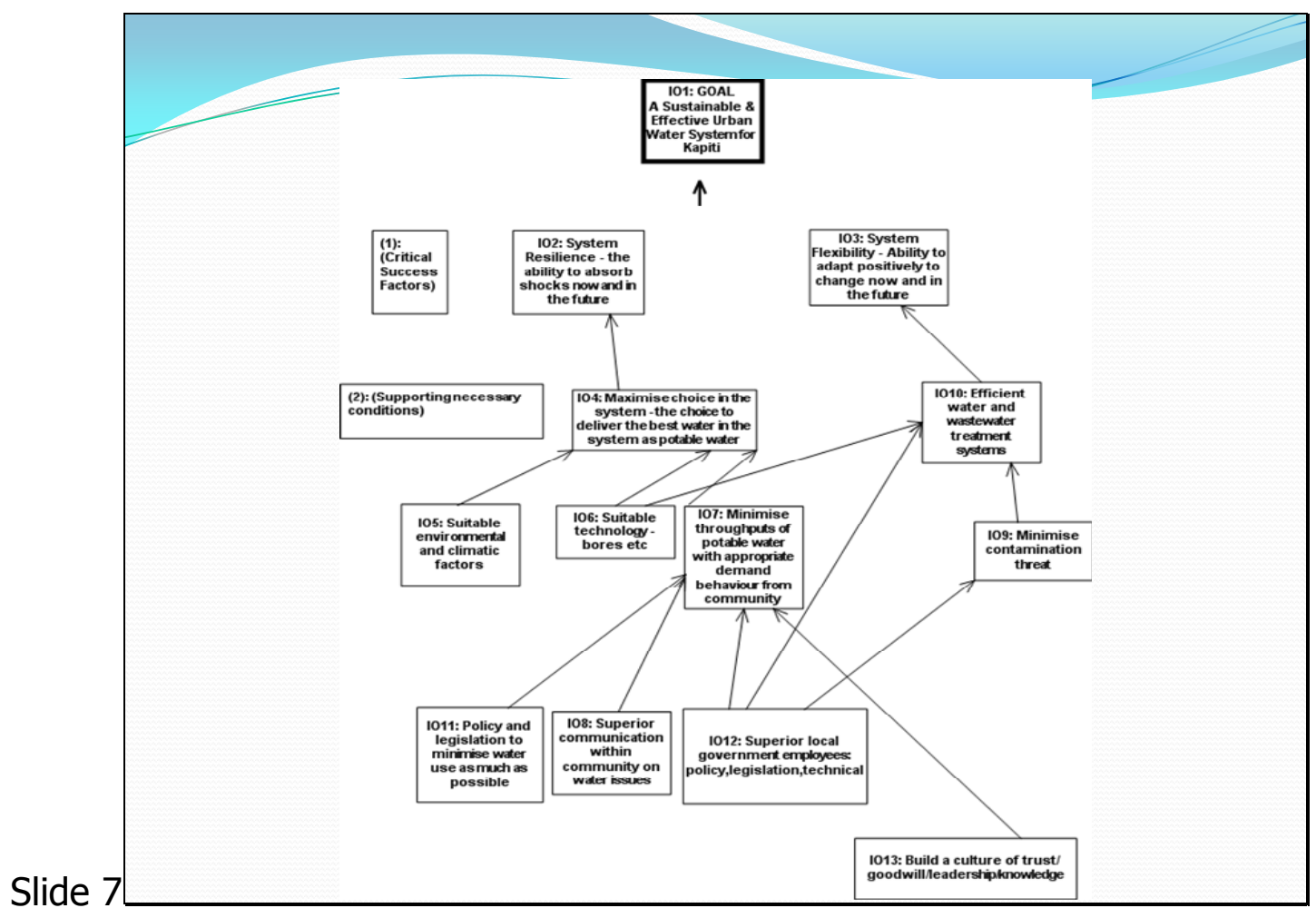


Slide 8

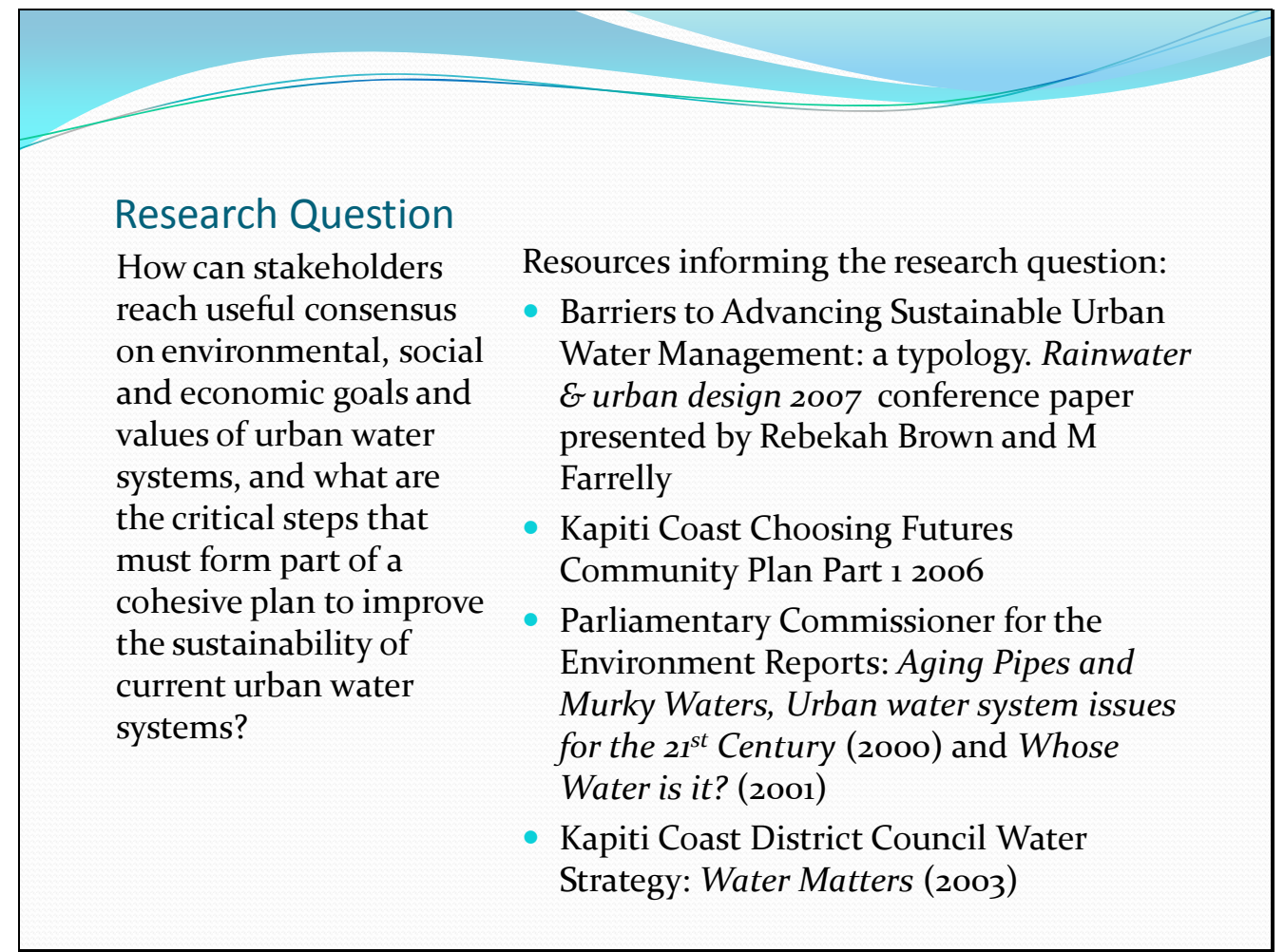

\section{Appendix Nine - Presenting the Dilemma and the Conflict Resolution Diagram to Participants (powerpoint)}

Available on request - and see Section 4.9 


\section{Appendix Ten - The Issues and a Recommendation}

Much of the information presented here has been used to inform the approach to the research and to prepare a summary of recommendations, with contributions from participants and two KCDC Councillors.

\section{Issues}

In 2003, the Council adopted a target of reducing per capita peak water consumption to 400 litres per person per day and this figure was reconfirmed as part of the draft 2009 LTCCP (KCDC, 2009). Kapiti has experienced an $8.8 \%$ increase in population (3753 new residents) since the last census (Mayoral comment, Observer, 11 May 2009). Water and wastewater infrastructure and management account for a significant proportion of rates spending. In a typical urban example, for every one dollar of rates, urban water and wastewater management costs 43 cents (KCDC, 2006). Wastewater management comprises the greater proportion at 20 cents, water management 17 cents, with stormwater costing 6 cents in every dollar. Water consumption has a direct impact on rates on more than one level, affecting both wastewater costs and water management costs, as the more water used, the more goes down the drain as wastewater (or stormwater when used outdoors). Engaging with stakeholders to achieve reduced water consumption targets has multiple benefits. While there are economic and social benefits from reducing the need for more infrastructure and having better tasting water, environmental benefit is gained from reduced $\mathrm{CO} 2$ emissions, as the energy required to treat and process water and wastewater is reduced, while benefits can also be gained by consumers from lower water heating costs. In addition, according to participant comment, KCDC water-treatment energy costs are currently among the highest in New Zealand, so aside from emission reduction, significant treatment cost savings stand to be gained from higher quality source water and 'better' water use, with rainwater harvesting/greywater initiatives potentially contributing.

The following table shows the desired state for water usage in Kapiti:

\section{Consumption Targets Per Household (KCDC Consultation Paper, 2009)}

\begin{tabular}{|l|c|c|c|}
\hline Household Size & $\begin{array}{c}\text { Number of } \\
\text { households }\end{array}$ & Usage (litres/ day) & Annual usage $\mathbf{( m}^{\mathbf{3}}$ ) \\
\hline Single person & 6565 & 400 & 146 \\
\hline Two person & 9211 & 600 & 219 \\
\hline
\end{tabular}




\begin{tabular}{|l|c|c|c|}
\hline Three person & 2924 & 750 & 274 \\
\hline Four person & 2620 & 900 & 329 \\
\hline Five person & 1122 & 1050 & 383 \\
\hline Six person & 361 & 1200 & 438 \\
\hline Seven person & 191 & 1350 & 493 \\
\hline
\end{tabular}

The next table shows the current reality:

Average Annual Water Consumption per Person (KCDC, 2009) in litres per person per day (Ippd):

\begin{tabular}{|l|c|c|c|}
\hline Supply Area & 2006/ 07 Ipppd & 2007/ 08 Ipppd & 2008/ 09 Ipppd \\
\hline Otaki & 742 & 798 & 780 \\
\hline Waikanae & 477 & 570 & 602 \\
\hline $\begin{array}{l}\text { Paraparaumu and } \\
\text { Raumati }\end{array}$ & 361 & 369 & 356 \\
\hline Paekakariki & 480 & 421 & 399 \\
\hline
\end{tabular}

Comparing the single person usage figure in the upper table with the lower average water use figures, suggests a continuing and significant difference between the desired state and the current reality. Of the urban water supply areas in Kapiti; Paekakariki and Paraparaumu/Raumati have achieved the average single person average target water consumption figure of fewer than 400 lpppd. However, none of the supply areas meet the target amounts for households with two or more people living in them. Nor do they meet the requirement to reduce peaks to 400 Ipppd. Otaki's average three year usage is 774 Ipppd, while Waikanae has a 550 Ipppd three year average. Based on the pattern of the past decade, the issue of risk to supply is likely to remain or worsen, unless targeted changes are made, both behavioural and structural (and see KCDC, 2009: 5/19 comment below). While current levels of average consumption may put pressure on the water supply, it is peak demand that poses the greatest risk to supply security. Below is a table that shows the peaks in water consumption throughout the district.

Peak Demand per Capita 2000/ 01-2008/ 09 (KCDC, 2009)

\begin{tabular}{|l|c|c|c|c|c|c|c|c|}
\hline $\begin{array}{l}\text { Reticulated Supply } \\
\text { System (Ippd) }\end{array}$ & $\begin{array}{c}\text { 01/ 02 } \\
\text { peak }\end{array}$ & $\begin{array}{c}\text { 02/03 } \\
\text { peak }\end{array}$ & $\begin{array}{c}\text { 03/04 } \\
\text { peak }\end{array}$ & $\begin{array}{c}\text { 04/ 05 } \\
\text { peak }\end{array}$ & $\begin{array}{c}\text { 05/ 06 } \\
\text { Peak }\end{array}$ & $\begin{array}{c}\text { 06/ 07 } \\
\text { peak }\end{array}$ & $\begin{array}{c}\text { 07/ 08 } \\
\text { peak }\end{array}$ & $\begin{array}{c}\text { 08/ 09 } \\
\text { peak }\end{array}$ \\
\hline Otaki & 1,070 & 1478 & 1144 & 1106 & 1300 & 1012 & 1019 & 1075 \\
\hline
\end{tabular}




\begin{tabular}{|l|c|c|c|c|c|c|c|c|}
\hline Waikanae & 808 & 803 & 736 & 762 & 745 & 811 & 767 & 757 \\
\hline $\begin{array}{l}\text { Paraparaumu and } \\
\text { Raumati }\end{array}$ & 621 & 565 & 540 & 613 & 606 & 506 & 662 & 524 \\
\hline Total WPR (average) & 677 & 635 & 598 & 657 & 647 & 595 & 693 & 592 \\
\hline Paekakariki & 603 & 580 & 564 & 593 & 640 & 643 & 669 & 606 \\
\hline
\end{tabular}

According to KCDC, these peak figures vary depending on the weather over the summer period, with peak demand for the 2008/09 year tracking down from the previous year in most areas, which is likely to be due to the relatively wet summer. Nevertheless, despite tracking down, these figures are a critical constraint on the system. Councils invariably use an average figure to communicate water consumption (Wellington City Council, for example). This practice fails to take account of the fact that any resource system must be designed to accommodate peaks, or it risks failure. KCDC note that peak demand is the figure that must be used to design and plan for infrastructure investment and drive compliance with resource consent conditions (KCDC, 2009). The table below indicates the present risk to supply security.

\section{Number of Days Total Daily Consumption Enters the Risk Zone for Waikanae, Paraparaumu and Raumati (KCDC, 2009), as highlighted}

\begin{tabular}{|l|c|c|c|}
\hline Year & $\mathbf{2 0 , 0 0 0 \mathbf { m } ^ { \mathbf { 3 } }}$ & $\mathbf{2 1 , 0 0 0 \mathbf { m } ^ { \mathbf { 3 } }}$ & $\mathbf{2 2 , 0 0 0 \mathbf { m } ^ { \mathbf { 3 } }}$ \\
\hline $2002 / 2003$ & 4 & 0 & 0 \\
\hline $2003 / 2004$ & 0 & 0 & 0 \\
\hline $2004 / 2005$ & 3 & 0 & 0 \\
\hline $2005 / 2006$ & 3 & 0 & 0 \\
\hline $2006 / 2007$ & 4 & 0 & 0 \\
\hline $2007 / 2008$ & 20 & 6 & 2 \\
\hline $2008 / 2009$ & 17 & 7 & 2 \\
\hline
\end{tabular}

The consented limit is $23,000 \mathrm{~m}^{3}$ per day.

'Effectively, the community is likely to be in breach of consent limits within the next five years. Breaching the consent or running parts of the water supply system out of water are not acceptable options' (KCDC, 2009:5/19).

The source of the first two of the above tables is a two page KCDC consultation document on water supply options for the Waikanae, Paraparaumu and Raumati area carried in the local Observer newspaper (23 April 2009). A \$14 million 'enhanced supply' (KCDC, Observer 23 April 2009) option was included 
(this may be the SKM estimate for staging the construction of storage ponds, but it is not entirely clear). A $\$ 23$ million 'enhanced supply' option is also up for consideration. No information was provided in the advertisement as to what either of these options entail, or indeed what the higher cost option would provide in comparison with the lower. Although the public can refer to the KCDC website to 'find out more about the options, costs and comparative benefits' (MAS-09-505 LTCCP Review: Water supply options, 2009), the nature of the 'enhanced supply options' remains unclear to the reader. Excerpts below are from this review:

There are a number of supply options available, with the final preferred location and design yet to be established. These range from a storage dam, storage ponds, extended borefield and the Otaki Pipeline. There are a number of site options which remain to be assessed in detail.

The currently estimated range of capital costs is between $\$ 14 \mathrm{~m}$ (Option 1A) and $\$ 23 \mathrm{~m}$ (Option 1B) with annual operating costs ranging from $\$ 700,000$ (Option 1B) to $\$ 800,000$ (Option 1A). At this stage, the Council has chosen the higher capital cost estimate for inclusion in the draft LTCCP, along with an annual operating cost of $\$ 700,000$ (i.e. Option 1B). The range of capital and operating costs will be included when comparing the augmented supply and water meters options.

The final design parameters for an augmented water supply are dependent on decisions made about four main variables: the return period of the drought to be withstood, the design life of the project, the population growth during that time and the rate of water consumption. Decisions on these parameters and the exploration of detailed solutions are just starting but it is assumed here that any augmented supply solution will at least: provide a secure water supply through to 2065 (i.e. 50 year design horizon from the construction date); supply water at 400 litres per person per day; allow for predicted low flow conditions associated with a 1 in 50 
year drought. Under this option, water services would be initially funded via the current user pays flat charge. [...]

At current tracking of water consumption levels, an augmented supply system would need to be completed by $2015 / 16$. While intensive education could help flatten peak summer consumption levels, past experience shows that this has a temporary impact and an increasing regulation and enforcement is required over time. This includes night patrols and a 'neighbourhood watch' type approach. General education will generally assist in reducing peak consumption by about $1-5 \%$, insufficient to delay the need for augmented supply within the next five years. [...]

The construction of an augmented water supply could also completely remove the need for the supplementary bores but again this needs to be considered in conjunction with the significant investment already made on these bores. It is more likely that the supplementary bores would still be used but that the adverse effects experienced by the community would be avoided by diluting the bore water with water from the augmented supply. Both the augmented supply options would therefore address the water quality issues. (KCDC LTCCP Review: Water supply options, 2009:7/19)

\section{Researcher Comment}

In their overall assessment of options, $\mathrm{KCDC}$ propose that the $\$ 14$ million storage option is excellent as a long term capacity solution, excellent as a water quality solution, and moderate in terms of affordability. However, their nineteen page review document does not elaborate on the nature of the different supply options to the extent that readers could confidently choose a preferred storage option, based on understanding the costs and implications. Meters attract a 'poor' rating in terms of addressing water quality issues, while they are 'good' as a long term capacity solution, and 'good' for affordability, according to the review. 
Grey Power contends that the information provided to the public by KCDC has not met their expectations, publically stating their concerns in the local Observer paper (7 May, 2009). Grey Power has requested that Council should more 'carefully put the issues to the community' before any decisions are made, and asked that their members direct submissions to the LTCCP through them, so they can gauge community feeling about the various options, before making a Grey Power submission.

At the Kapiti water workshops in 2008 and 2009, the type of water storage under discussion has until March 2009 been generally perceived as a dam (this is the researcher's view, based on the comments of all Councillors and the study participants who have attended the workshops). Neither the SKM (2008) report, nor this exercise supports the construction of a dam to answer Kapiti's water security issues.

\section{Melbourne's Experience - Dams}

Although there are undoubted differences between the hydrology and typology of Kapiti and Melbourne, the following comments on dams from Melbourne Water appear to endorse the SKM (2003 and 2008) conclusion that the expense and other impacts of a dam point to it being a high risk option for a community of Kapiti's population and characteristics:

Melbourne Water (retrieved February 2009):

Melbourne's water supply system is based on the principle that it is better to start with the highest quality source water than having to treat it to reach required standards.

Some facts about the creation of new dams:

New dams do not create any new water. They simply take it from somewhere else - either from farmers who currently rely on it or from the environment. However, upgrading and improving dam and pipeline infrastructure is an important way to increase water security.

If a new dam were built for Melbourne, it would need to be filled with water that is currently used by rural and regional communities and the environment. Such a dam 
would take water from rivers that are already stressed.

This would not only harm the habitat of our native plants,

fish and animals, but also threaten our waterways, tourism and recreation industry. (Melbourne Water, 2009).

\section{Recommendation}

This investigation and exercise concluded in February 2009, that staged construction of a series of storage ponds is a favourable option for the Waikanae, Paraparaumu, Raumati catchment that meets the community's requirements for 'flexibility', 'secure supply' and 'living within means'. It also does not contradict Kapiti's Water Matters strategy for urban water that is based on favouring an in-catchment approach to water supplies. An incatchment approach appears to have the support of the wider community and is the preference of the iwi managing authority, according to the work carried out by the PCE in 2000/1, and based on my 2008 interview with Te Äti Awa's Daniel Mullen. Staged construction must form part of a carefully managed plan to reduce water consumption, by investing more than currently in education, incentives and engagement with the community and other stakeholders.

The value of meters as a tool to manage demand down is not in question. However, meters alone will not reduce demand to what is required for a fully secure and sustainable water system. Therefore, the priority must be to meet the objectives from the IO map and phase in enhanced supply, potentially with a $600,000 \mathrm{~m}^{3}$ pond just south of the Waikanae River. If growth and demand do not require that an additional pond be constructed within ten years, rates can positively reflect this. On the other hand, if water storage is provided and the recommended water sensitive design incentives/restrictions/education and leak detection/maintenance are adequate, but average per person or peak demand does not reduce to desirable levels within a predetermined period, water meters must remain an option for Council. The overarching objective must be to preserve the continuity and integrity of community water resources for current and future generations.

\section{Addendum (November 2009)}

\section{Research limitations/ implications}

The present study provides a starting-point for further research combining TOC with a stakeholder engagement methodology in the resource management sector. One perceived limitation is that once the TOC practitioner disengages from the research, this leaves stakeholder insights to be shared with other 
stakeholders in a potentially ad hoc manner, if indeed they are shared at all limiting ongoing improvement. Training an in-house TOC practitioner would help to resolve this. To a limited extent, this has occurred in this instance, with a Kapiti Coast District Council (KCDC) Water Project Manager receiving guidance in IO mapping from the researcher and having access to the full thesis. Following the Kapiti case as it progresses will reveal further study limitations.

\section{Originality/ value}

The combined TOC, CLD, and Stakeholder Typology framework has proven of value in seeking and testing a number of solutions to the long-standing problem of water insecurity on the Kapiti Coast. In particular, the Kapiti Coast District Council has adopted a Water Communications Strategy to inform and sustain an engagement process with the aim of representing and ultimately satisfying as many stakeholder interests or needs as practically possible. Investing more in effective and targeted communication was identified as a necessary condition for a more sustainable urban water system, according to the IO maps and CLDs prepared with Councillors and other participant stakeholders. That the thesis played some part in informing actions - with the researcher consulted to review KCDC's Water Communications Strategy (in September 2009) - is a notable and promising outcome of the study, from a resource management - and also a personal - perspective. 


\section{Appendix Eleven - Presenting the Data}

The participants' comments were grouped according to the themes identified as necessary to build destination (IO) maps and current reality trees (CRT). The data was reduced for the TOC analysis by grouping similar responses together. Each statement (or a generic version of a set of similar statements) was written on a post-it note and the responses were grouped against each of the twelve questions. Different coloured post-its were used to keep track of each of the entities required for the TOC analysis, with themes such as 'secure water supply' or 'living within limits (means)' emerging through this process as CSFs (critical success factors) in the IO map. Each set of statements was checked as to whether they were in fact necessary conditions, undesirable effects, problems, a statement of conflict or a goal statement.

\section{Participants}

$>\mathrm{MOH}$ - Paul Prendergast Public Health Note: Personal views unless stated

> Bob Zuur- Resident and Contributor to PCE 2001 (for MfE)

$>$ Te Āti Awa - Danny Mullen Iwi environmental manager

$>$ DBH - Bruce Klein (work on Building Act) Note: Personal views only unless stated

$>$ Stan Abbott - Scientist/Roofwater expert, Massey University senior lecturer

> Water supply management GWRC - Tony Shaw

$>$ Resource management GWRC - Murray McLae

$>$ Connell Wagner Non-resident water-engineering specialist -Dave Alderton

$>$ Non-resident Doug Avery - Starborough Flaxbourne Resident/Farmer, Flaxbourne District - comparative case with near lowest rainfall in NZ

> Non-resident Kevin Loe Starborough Resident/Farmer Flaxbourne District

$>$ Stu Farrant - Residents Association (Environmental Engineer with Tonkin Taylor)

$>$ T Daniell - Kapiti resident

$>$ Grey Power executive member: Views not necessarily of Grey Power

$>$ KWAG members - Stacey/Chris/Tina (interviewed together - collaborated to answer most questions)

$>$ Resident - Karen

$>$ Resident - Murray Williams (Scientist and tertiary teacher)

$>$ Betty Van Gaalen - Kapiti resident with local body experience, long held strong interest in water issues, active voice in Kapiti Grey Power but not necessarily representing all their views

$>$ Ben Thompson - KCDC Kapiti water coordinator (3+ years) Note: personal views only unless stated

$>$ Gael Ferguson - KCDC: personal views only unless stated

Data and more about the analysis is available on request and with participants' consent 